\title{
Fabrication of NiTi through Additive Manufacturing: A Review
}

\author{
M. Elahinia a ${ }^{\text {a, }}$, N. Shayesteh Moghaddam ${ }^{\text {a }}$, M. Taheri Andani ${ }^{\text {a,b }}$, A. Amerinatanzi ${ }^{\text {a }}$, B.A. Bimber ${ }^{\text {, }}$, and \\ R.F. Hamilton ${ }^{\mathrm{c}}$ \\ ${ }^{a}$ Dynamic and Smart Systems Laboratory, Mechanical Industrial and Manufacturing Engineering \\ Department, The University of Toledo, OH, 43606 \\ b S.M. Wu Manufacturing Research Center, College of Engineering, Department of Mechanical \\ Engineering, University of Michigan, Ann Arbor, MI, USA, 48109 \\ ${ }^{c}$ Multifunctional and Adaptive Material Laboratory, Engineering Science and Mechanics Department, \\ Pennsylvania State University, University Park, PA 16802
}

\begin{abstract}
Nickel-titanium (NiTi) is an attractive alloy due to its unique functional properties (i.e., shape memory effect and superelasticity behaviors), low stiffness, biocompatibility, damping characteristics, and corrosion behavior. It is however a hard task to fabricate NiTi parts because of the high reactivity and high ductility of the alloy which results in difficulties in the processing and machining. These challenges altogether have limited the starting form of NiTi devices to simple geometries including rod, wire, bar, tube, sheet, and strip. In recent years, additive manufacturing (AM) techniques have been implemented for the direct production of complex NiTi such as latticebased and hollow structures with the potential use in aerospace and medical applications. It worth noting that due to the relatively higher cost, $\mathrm{AM}$ is considered a supplement technique for the existing. This paper provides a comprehensive review of the publications related to the AM techniques of NiTi while highlighting current challenges and methods of solving them. To this end, the properties of conventionally fabricated NiTi are compared with those of AM fabricated alloys. The critical steps toward a successful manufacturing such as powder preparation, optimum laser parameters, and fabrication chamber conditions are explained. The microstructural characteristics and structural defects, the influencing factors on the transformation temperatures, and functional properties of NiTi are highlighted to provide and overview of the influencing factors and possible controlling methods. The mechanical properties such as hardness and wear resistance, compressive behaviors, fatigue characteristics, damping and shock absorption properties are also reported. A case study in the form of using AM as a promising technique to fabricate engineered porous NiTi for the purpose of creating a building block for medical applications is introduced. The paper concludes with a section that summarizes the main findings from the literature and outlines the trend for future research in the AM processing of NiTi.
\end{abstract}

* Corresponding author at: 2801 West Bancroft St. Toledo, OH 43606, USA. Tel.: +1 4195308224 . fax: +1 4195308206 . Email address: mohammad.elahinia@utoleod.edu (M. Elahinia).

(C) 2016. This manuscript version is made available under the Elsevier user license

http://www.elsevier.com/open-access/userlicense/1.0/ 
Keywords: Shape Memory Alloy, NiTi, Additive Manufacturing, Powder preparation, Microstructure, Transformation temperature, Stiffness-tailored, Patient-specific.

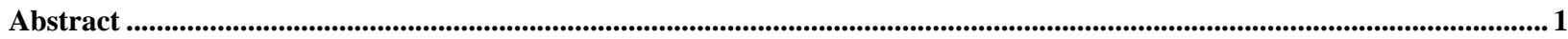

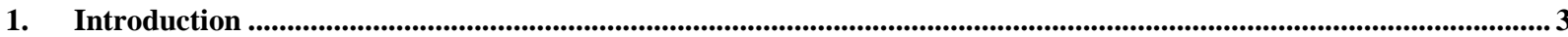

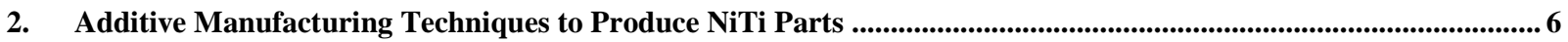

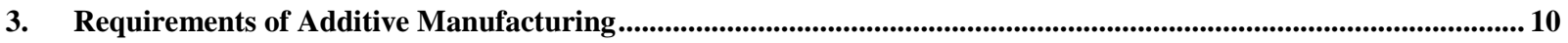

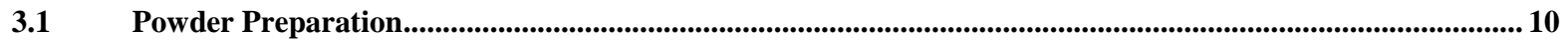

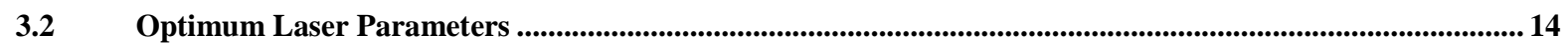

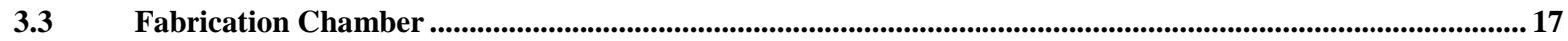

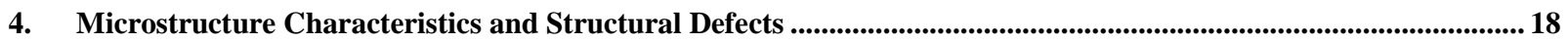

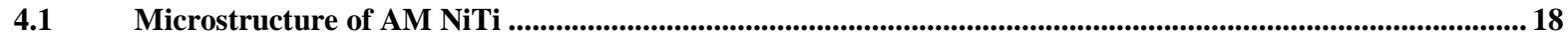

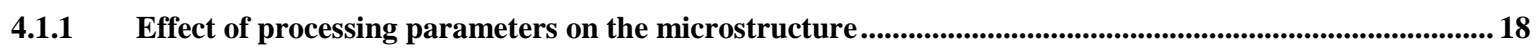

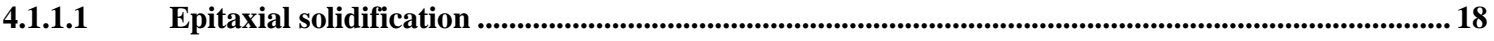

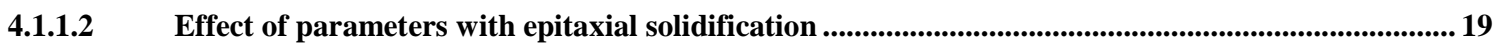

4.1.1.3 Effect of parameters in absence of epitaxial solidification ...................................................................22

4.1.2 Effect of powder properties on the microstructure ...........................................................................................23

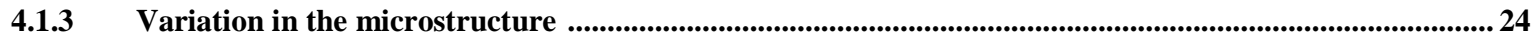

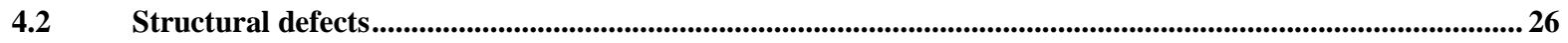

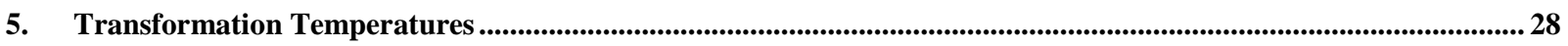

5.1 The effect of material composition and processing parameters on the transformation temperatures .......... 29

5.2 The effect of post-heat treatment on the transformation temperatures and behavior ...................................... 31

5.3 The effect of thermal cycling on the transformation temperatures and behavior ...........................................35

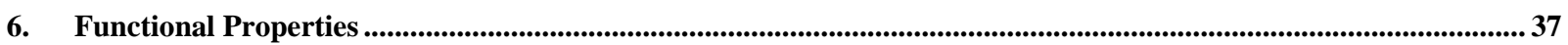

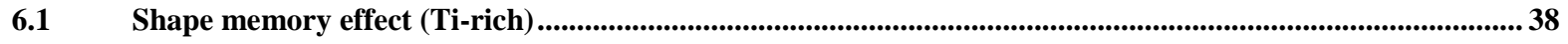

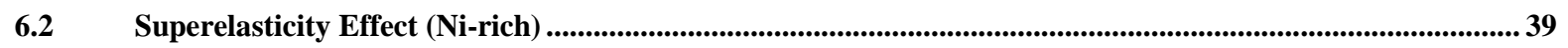

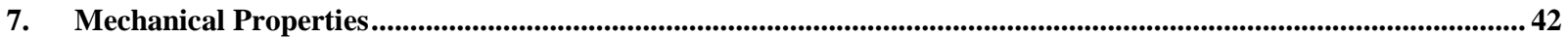

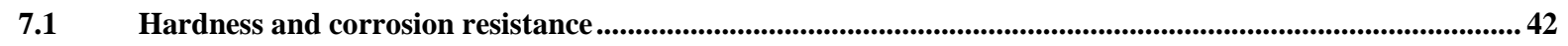

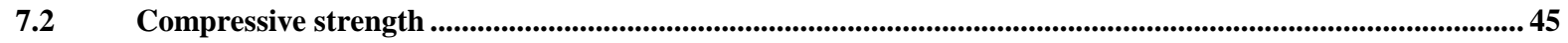

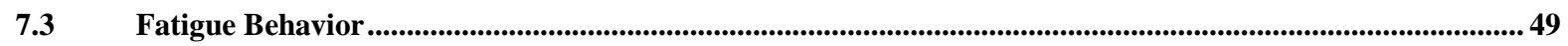

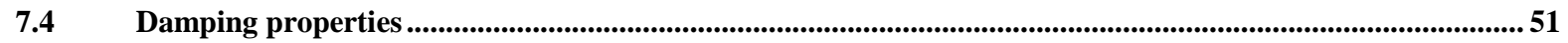

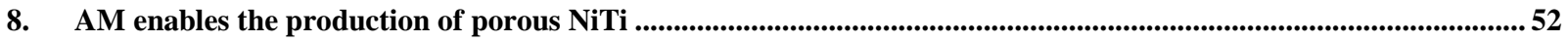

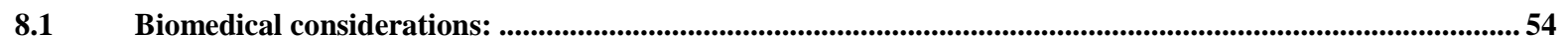

8.2 Optimum laser parameters to produce engineered porous AM NiTi: .........................................................55

8.3 Mechanical properties of engineered porous NiTi ..................................................................................58

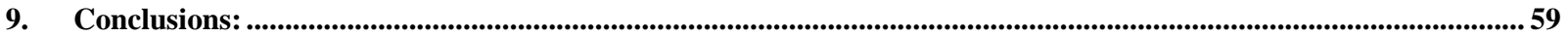

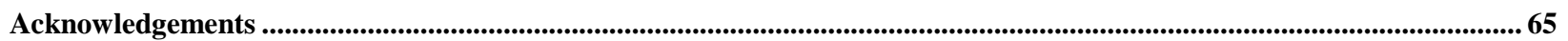

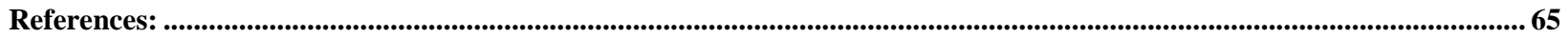




\section{Introduction}

In recent years, shape memory alloys (SMAs) have entered a wide range of engineering applications in fields such as aerospace and medical devices. Nickel-titanium (NiTi) is the most commonly used SMA due to its excellent functional features including shape memory (SM) and superelasticity (SE) effect. SE and SM behaviors consist of restoring large strains up to $8 \%$ by unloading and heating, respectively. These properties are based on a solid-solid phase transformation between martensite and austenite. Besides these two characteristics, low stiffness, biocompatibility, damping characteristics, and corrosion behavior of NiTi make this alloy an attractive candidate for biomedical applications (e.g., bone plates, bone screws, and stents) [1-5].

Unlike many of the conventional materials, there is no single fabrication recipe for realizing NiTi devices. Over the years, several common processing steps for manufacturing shape memory and superelastic NiTi devices are developed including casting and powder metallurgy processes. Figure 1 summarizes various manufacturing methods for producing NiTi devices $[1,6]$.

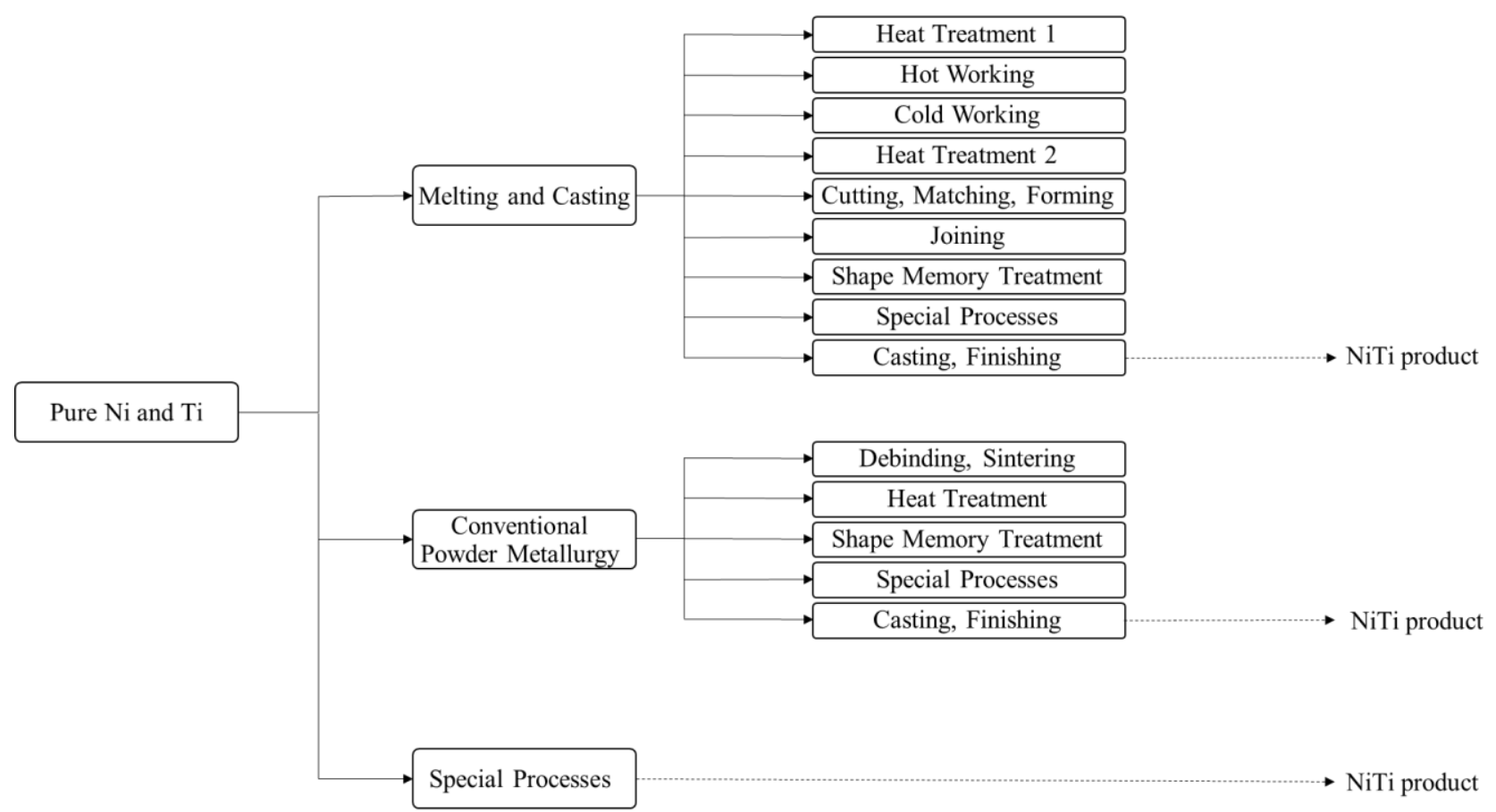

Fig.1. Various routes are used to fabricate NiTi products [1]. 
Casting technique is one of the common conventional methods for producing NiTi. This technique is associated with high temperature melting procedures that result in an increase in the impurity level (e.g., carbon, oxygen), and, therefore, the formation of Ti-rich phases including $\mathrm{TiC}$ and $\mathrm{Ti}_{4} \mathrm{Ni}_{2} \mathrm{O}_{\mathrm{X}}$. The functional properties of NiTi, are degraded as the result of these secondary phases formation. Since machining is used to form the final shapes from this alloys, another challenge associated with this technique is the difficulty of machining procedures for these super-ductile alloys which results in excessive tool wear [1].

Powder metallurgy (PM) is another conventional technique that is used for producing near-netshape devices. Powder preparation is a required step prior to PM processing. One of the major disadvantages of this method is the high impurity pick-up that is resulted from the large surface area of the powder particles. Additionally, these techniques are limited in the complexity of the resulting parts and in controlling the size and shape of porosity, when desired [6].

In the past decade, Additive Manufacturing (AM) has gained significant attention for processing NiTi because they have circumvented many of the challenges associated with the conventional methods. These processes rely on the CAD data and entails adding material in consecutive layers made of powders and melted, in most cases by a laser [4]. The AM techniques for NiTi are either powder-bed based technologies such as Selective Laser Melting (SLM), or flow-based methods such as Laser Engineered Net Shaping (LENS). The powder-bed based techniques deal with deposition of the powder through a roller, blade, or knife, while the flow-based technologies deposit the powder through one or more nozzles that directly feed the powder into the laser focus. Powder-bed based technologies are more common for creating complex parts $[1,6,7]$.

The first step in AM processing is preparing the NiTi powder. The ratio of Ni and Ti elements are important factors to guarantee the desired functional properties (i.e., shape memory or superelasticity) of the final part. Parts that are fabricated from a Ti-rich powder exhibit the shape memory effect $[8,9]$. On the other hand, those fabricated from a Ni-rich powder demonstrate superelasticity behavior after 
subsequent solution annealing and aging $[8,9]$. In addition to the $\mathrm{Ni} / \mathrm{Ti}$ ratio, the procedure of preparing powder plays an important role in the features of the final products. The powders can be created either by pre-alloying or by elementally blending the $\mathrm{Ni}$ and $\mathrm{Ti}$ particles. It is notable that processing from elementally blended powders results in other intermetallic phases, pure nickel, and pure titanium in the fabricated parts [10]. Finally, the procedure of powder preparation (e.g., hydriding, mechanical attrition, water atomization, and gas atomization) is critical because it affects the final particle size, particle distribution, and the impurity of the resultant powders. EIGA (Electrode Inert Gas Atomization) procedure is shown to be more favorable due to producing more accurate particles as well as the acceptable level of impurity contents $[11,12]$.

The second important requirement for the AM processing is the processing parameters. Optimal parameters are methodically developed to make sure that the final product is not only fully dense, but also shows a low level of impurity contents. These two requirements are important as they affect the mechanical performance (e.g., high strength) and the success of the potential applications (e.g., medical applications) [13].

The third important requirement is to provide an inert atmosphere (e.g., argon) throughout the processing to minimize the oxidation and impurity pick-up (e.g., oxygen and carbon), increase the surface quality, enhance the density and, achieve similar functional behavior to the conventionally processed NiTi [14-16]. The level of impurity content is suggested to be less than $500 \mathrm{ppm}$ in the produced parts based on ASTM F2063-05 [8]. In addition to providing inert atmosphere, it is suggested to preheat the build platform (i.e., substrate) prior to the fabrication in order to reduce the warping effect (i.e., separation of the sample from the substrate) (more details in section 3.3) [17-20].

One of the main potential areas of application of AM NiTi is in stiffness-tailored patient-specific implants. This method of processing allows for introducing interconnected porosity to match the stiffness of the host tissues as well as tailoring the shape to match the anatomical shape of the host tissues. The fabrication process is initiated based on the CT scan data of the patient [6]. It has been successfully 
demonstrated that AM NiTi has very low impurity contents for medical devices that satisfies the ASTM F2063-05 standard for medical devices $[8,15,16]$. Initial biocompatibility studies of AM NiTi have also shown promising results $[3,21,22]$.

This paper is the second part of a recent review paper [6] on the methods of manufacturing of NiTi devices. To this end, the current paper highlights the main technologies and approaches that have been used to additively fabricate these alloys. In this context, the main advantages, as well as challenges of the additive manufacturing methods are studied. This review while summarizing the main lessons learned, also identifies the critical studies that should be conducted toward achieving repeatable functionality in additively manufactured NiTi shape memory and superelastic devices.

\section{Additive Manufacturing Techniques to Produce NiTi Parts}

The more commonly used AM techniques for producing NiTi products are powder-bed based technologies, such as selective laser sintering (SLS), direct metal sintering (DMLS), selective laser melting (SLM), and LaserCUSING [6]. For the powder-bed based techniques, the desired CAD model (The CAD file includes the geometry of the part and the supports) first is sliced into layers with predefined thicknesses which contain the processing parameters (e.g., laser energy, scan trajectories). Subsequently, a roller or blade deposits a powder layer with the thickness similar to that of sliced CAD layer, typically range from 20 to $100 \mu \mathrm{m}$ [23]. Then, the laser beam melts selectively the powder layer based on the geometrical information of the sliced CAD. After solidification, the building piston drops down by the thickness of one powder layer to allow the deposition of the next layer. The procedure is repeated until it produces the desired 3D shape completely. The final step is to remove the loose powder and the supports (See figure 2) [24]. It should be noted that the oxygen level has to be controlled for the production of NiTi parts through filling the chamber with argon to minimize the possibility of oxidation [4]. 


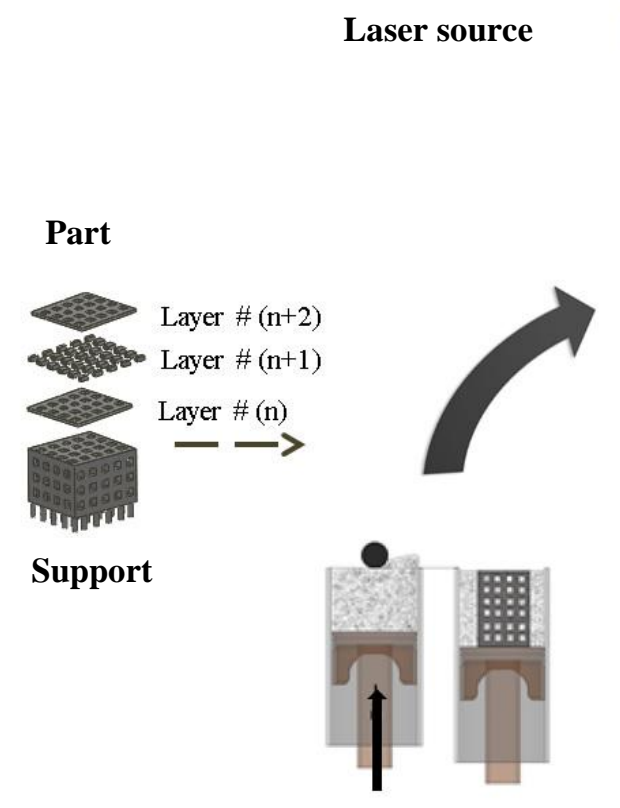

1. Powder deposition

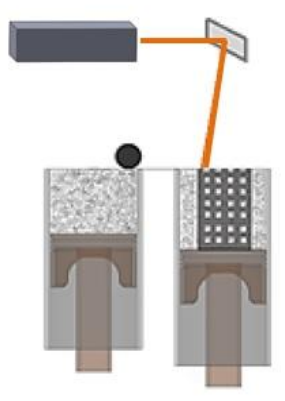

2. Layer printing
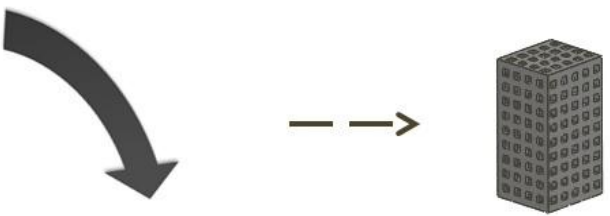

Final product
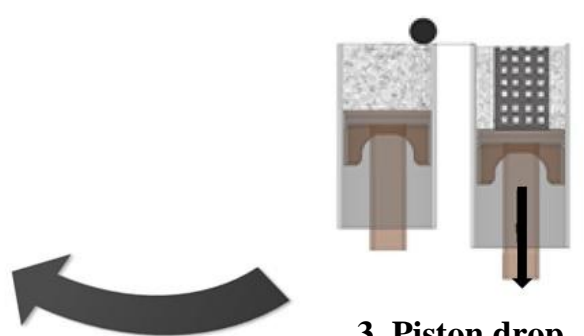

3. Piston drop

Fig.2. The sequence of operation of powder-bed based machines. This procedure starts with slicing the CAD model, and continues with a repeatable three-step procedure. After the supports and loose powders are removed, the final product is ready to use[1].

Another less common AM methods that have been used to fabricate NiTi devises are flow-based techniques. Directed energy deposition (DED) is another common term for the flow-based methods [25]. Based on their application, DED techniques are named by different terms including Laser Engineered Net Shaping (LENS), Direct Light Fabrication (DLF), Laser Consolidation (LC), Laser Cladding, and Shape Deposition Manufacturing (SDM). In the flow-based processes, the CAD file is first sliced into several layers containing pre-defined processing parameters as well as thickness. Then, a controllable stream of powder is injected through a feedstock into the molten pool, while the laser is scanning the injected powder simultaneously. Generally, there are two methods to provide the powder over the platform. In the first method, the focusing lens and nozzle are stationary during the process while the XY table moves according to the sliced CAD data [24]. In the second method, the table is stationary while the focusing lens and nozzle move based on the CAD data information [26]. In both methods, the nozzle and focusing 
lens move up by a thickness layer according to the sliced CAD after the fabrication of the previous layer is completed. This procedure is continued until the final product is fabricated (See figure 3).

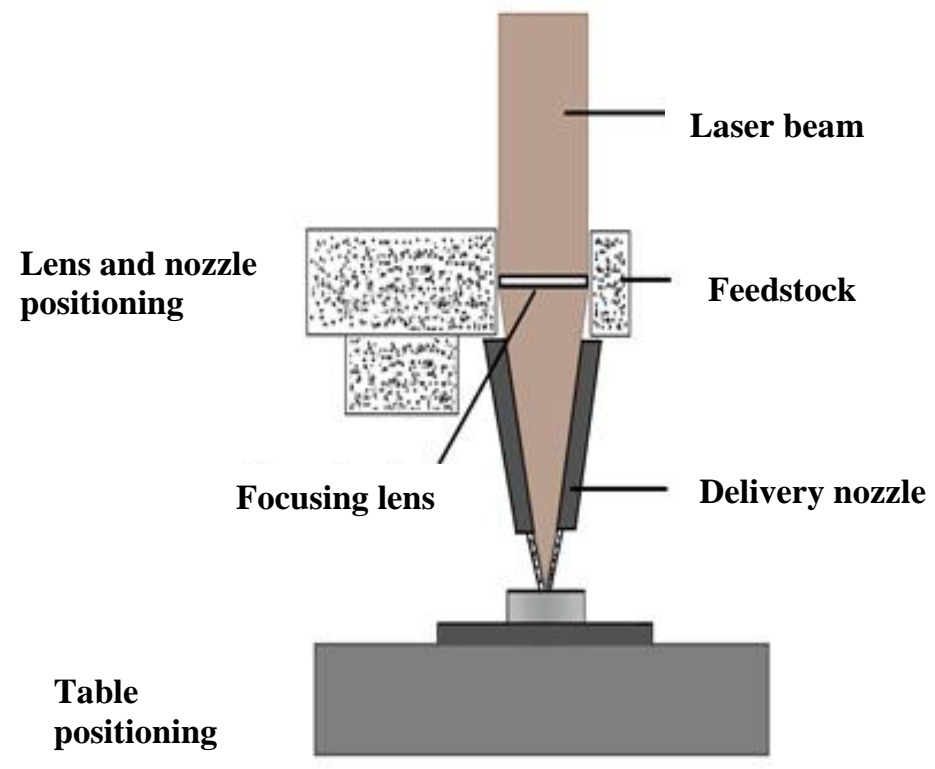

Fig.3. Schematic representation of flow-based methods. This procedure initiates with slicing the CAD model and continues with depositing and laser scanning the powder simultaneously. After the completion of each layer, the nozzle and lens move up by a thickness layer to allow the fabrication of the next layer.

Several groups have implemented AM to produce and evaluate NiTi parts. Table 1 shows a list of current publications on the powder-bed based and flow-based technologies that have been used for processing NiTi. The type of the machines, the laser power, the powder composition as well as the substrate composition are summarized in Table 1.

Table. 1. List of current publication on laser-based AM techniques of NiTi.

\begin{tabular}{|c|c|c|c|c|c|}
\hline $\begin{array}{l}\text { Laser-based } \\
\text { AM } \\
\text { Technology }\end{array}$ & Machine Type & Laser Power & $\begin{array}{c}\text { Powder } \\
\text { Composition } \\
(\text { at. } \%)\end{array}$ & Substrate & Author(s) \\
\hline \multicolumn{6}{|c|}{ Powder-bed fusion } \\
\hline SLM & $\begin{array}{c}\text { Phenix/3D Systems } \\
\text { of type PXM }\end{array}$ & $\begin{array}{l}300 \mathrm{~W} \text { Ytterbium } \\
\text { fiber laser }\end{array}$ & Ni55Ti & $\begin{array}{l}\text { Stainless } \\
\text { Steel }\end{array}$ & $\begin{array}{c}\text { Shishkovsky et } \\
\text { al. }[10]\end{array}$ \\
\hline SLM & Realizer 100 SLM & $\begin{array}{l}100 \mathrm{~W} \text { Ytterbium } \\
\text { fiber laser. }\end{array}$ & $\begin{array}{l}\mathrm{Ni49.7Ti} \\
\mathrm{Ni50.2Ti}\end{array}$ & $\mathrm{NiTi}$ & $\begin{array}{l}\text { Meier et al. }[9, \\
14,27-29]\end{array}$ \\
\hline SLM & Realizer SLM 100 & $\begin{array}{l}100 \mathrm{~W} \text { Ytterbium } \\
\text { fiber laser }\end{array}$ & $\begin{array}{l}\mathrm{Ni} 49.7 \mathrm{Ti} \\
\mathrm{Ni} 50.2 \mathrm{Ti}\end{array}$ & $\mathrm{NiTi}$ & $\begin{array}{l}\text { Haberland } e t \\
\text { al. }[8,9,13,\end{array}$ \\
\hline
\end{tabular}




\begin{tabular}{|c|c|c|c|c|c|}
\hline & & & 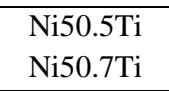 & & $15,16,29]$ \\
\hline SLM & Realizer SLM 100 & $\begin{array}{l}100 \mathrm{~W} \text { Ytterbium } \\
\text { fiber laser }\end{array}$ & $\mathrm{Ni50.2Ti}$ & NiTi & $\begin{array}{l}\text { Habijan et al. } \\
\text { [21] }\end{array}$ \\
\hline SLM & Realizer SLM 100 & $\begin{array}{l}100 \mathrm{~W} \text { Ytterbium } \\
\text { fiber laser }\end{array}$ & $\mathrm{Ni50.2Ti}$ & NiTi & Wild et al. [30] \\
\hline SLM & Realizer SLM 100 & $\begin{array}{l}100 \mathrm{~W} \text { Ytterbium } \\
\text { fiber laser }\end{array}$ & Ni50.82Ti & - & $\begin{array}{l}\text { Bormann et } \\
\text { al.[31-33] }\end{array}$ \\
\hline SLM & Realizer SLM 100 & $\begin{array}{c}100 \mathrm{~W} \text { Ytterbium } \\
\text { fiber laser }\end{array}$ & Ni50.82Ti & - & $\begin{array}{c}\text { Hoffmann et el } \\
{[34]}\end{array}$ \\
\hline SLM & Phenix Systems PXM & $\begin{array}{l}300 \mathrm{~W} \text { Ytterbium } \\
\text { fiber laser }\end{array}$ & $\begin{array}{l}\text { Ni50.09Ti } \\
\text { Ni50.81Ti }\end{array}$ & NiTi & $\begin{array}{c}\text { Saedi } \text { et al. } \\
\text { [35\{Saedi, } \\
2016 \# 2036]\}\end{array}$ \\
\hline SLM & Phenix Systems PXM & $\begin{array}{c}300 \mathrm{~W} \text { Ytterbium } \\
\text { fiber laser }\end{array}$ & $\begin{array}{l}\text { Ni50.09Ti } \\
\text { Ni50.81Ti }\end{array}$ & $\mathrm{NiTi}$ & $\begin{array}{c}\text { Walker et al. } \\
{[36-38]}\end{array}$ \\
\hline SLM & Phenix Systems PXM & $\begin{array}{c}300 \mathrm{~W} \text { Ytterbium } \\
\text { fiber laser }\end{array}$ & $\begin{array}{l}\text { Ni50.09Ti } \\
\text { Ni50.81Ti }\end{array}$ & NiTi & $\begin{array}{l}\text { Taheri Andani } \\
\text { et al. }[39,40]\end{array}$ \\
\hline SLM & An in-house built & $\begin{array}{c}300 \mathrm{~W} \text { Yb:YAG } \\
\text { fiber laser }\end{array}$ & Ni 55.2Ti & - & $\begin{array}{l}\text { Dadbaksh et } \\
\text { al. }[41,42]\end{array}$ \\
\hline SLM & In-house developed & $\begin{array}{c}300 \mathrm{~W} \text { Yb:YAG } \\
\text { fiber laser }\end{array}$ & $\mathrm{Ni55.2Ti}$ & - & $\begin{array}{c}\text { Speirs et al. } \\
{[43]}\end{array}$ \\
\hline SLM & DiMetal-240 & $\begin{array}{c}100 \mathrm{~W} \text { Yb: YAG } \\
\text { fiber laser }\end{array}$ & Ni50Ti & - & $\begin{array}{l}\text { Yang et al. } \\
\text { [44] }\end{array}$ \\
\hline SLM & MCP Realizer & $\begin{array}{c}100 \mathrm{~W} \text { Ytterbium } \\
\text { fiber laser }\end{array}$ & Ni54.4Ti. & - & Clare et al.[45] \\
\hline \multicolumn{6}{|c|}{ Flow-based deposition } \\
\hline DED & Custom built & $\begin{array}{c}1 \mathrm{~kW} \\
\text { Yb-fiber laser }\end{array}$ & $\begin{array}{c}\text { Elementally } \\
\text { blended } \\
\text { Ni47.9Ti } \\
\text { Ni53Ti } \\
\end{array}$ & $\begin{array}{l}\text { heated } \\
\mathrm{Ti}\end{array}$ & $\begin{array}{l}\text { Hamilton et al. } \\
\text { [20] }\end{array}$ \\
\hline LENS & LENS-750 & $\begin{array}{c}2 \mathrm{~kW} \\
\text { Nd-YAG laser }\end{array}$ & $\begin{array}{c}\text { Pre-alloyed } \\
\text { Ni50Ti } \\
\text { Ni50.1Ti }\end{array}$ & $\mathrm{Ti}$ & $\begin{array}{l}\text { Krishna et al. } \\
\quad[46-48]\end{array}$ \\
\hline LENS & Optomec LENS 750 & $\begin{array}{c}0.5 \mathrm{~kW} \\
\text { fiber laser }\end{array}$ & $\begin{array}{c}\text { Elementally } \\
\text { blended } \\
\text { Ni57Ti } \\
\text { Ni55Ti }\end{array}$ & $\mathrm{Ti}$ & $\begin{array}{l}\text { Halani et al. } \\
{[49,50]}\end{array}$ \\
\hline LRM & Custom built & $\begin{array}{c}2 \mathrm{~kW} \\
\text { fiber laser }\end{array}$ & $\begin{array}{c}\text { Elementally } \\
\text { blended } \\
\text { Ni45Ti } \\
\text { Ni50Ti } \\
\text { Ni55Ti } \\
\end{array}$ & $\mathrm{Ti}$ & Shiva et al.[51] \\
\hline DMD & - & $\begin{array}{c}0.25-0.6 \mathrm{~kW} \\
\mathrm{Nd}: Y A G \text { laser }\end{array}$ & $\begin{array}{c}\text { Pre-alloyed } \\
\text { Ni50.4Ti }\end{array}$ & $\mathrm{Ti}$ & $\begin{array}{l}\text { Malukhin et } \\
\text { al.[52] }\end{array}$ \\
\hline LENS & LENSTM $^{\text {TM }}$ MR & Ytterbium-doped fiber & $\begin{array}{c}\text { Pre-alloyed } \\
\text { Ni50.05Ti }\end{array}$ & - & $\begin{array}{c}\text { Marattukalam } \\
\text { [53] }\end{array}$ \\
\hline & & Laser & & & \\
\hline
\end{tabular}




\begin{tabular}{lccccc}
\cline { 2 - 5 } LSF & Custom built & $\begin{array}{c}5 \mathrm{~kW} \\
\mathrm{CO}_{2} \text { laser }\end{array}$ & $\begin{array}{c}\text { Elementally } \\
\text { blended } \\
\text { Ni45.3Ti }\end{array}$ & $\mathrm{Ti}$ & Xu et al.[54] \\
\cline { 2 - 5 } LENS & LENS $_{\mathrm{TM}^{-7}}$ & $\begin{array}{c}\text { Elementally } \\
\text { blended } \\
\text { Ni50Ti }\end{array}$ & $\mathrm{Ti}$ & $\begin{array}{c}\text { Bernard } \text { et al. } \\
{[55,56]}\end{array}$ \\
\hline
\end{tabular}

- These values were not reported.

- SLM (Selective laser melting), DED (Directed energy deposition), LENS (Laser engineered net shaping), LRM (Laser rapid manufacturing), DMD (Direct metal deposition), LSF (Laser solid forming).

\section{Requirements of Additive Manufacturing}

\subsection{Powder Preparation}

The first step in the additive manufacturing of NiTi is to prepare the powder. Based on the desired functional properties (i.e., shape memory or superelasticity) of the final product, the Ni/Ti ratio needs to be selected. An ingot with a higher level of Ti (i.e., Ti-rich) results in higher transformation temperatures and shape memory properties in the final product. On the other hand, higher Ni contents (Ni-rich) produces parts with the superelastic behavior (more details in section 5) [9, 21]. The next procedure is to prepare powder either from pre-alloyed NiTi or elemental nickel and elemental titanium. Blending the powders elementally results in the formation of intermetallic phases, pure nickel, and pure titanium in the resulting parts [10]. The use of pre-alloyed NiTi powder, therefore, is preferred. Several groups [20, 4951, 54-56] have fabricated parts using elementally blended powders and flow-based techniques. On the other hand, the pre-alloyed powders have been used for almost all of the powder-bed based processing [8$10,13-16,21,22,27-34,36-41,43,44,57]$ as well as a few number of the flow-based methods [46-48, $52,53]$.

There are different techniques for making powder including hydriding, mechanical attrition, water atomization, and gas atomization. Regardless of the method, it is expected that the impurity content of the final powders will be more than that of the starting material which at the end affects the functional properties of the produced NiTi products. Except gas atomization, the other techniques deal with different challenges that make them less suitable for powder preparation. For example, the resultant powders from 
hydriding method have high levels of hydrogen content which directly affect the functionality of the final products; Mechanical attrition technique is a tough task due to the poor workability of NiTi, and the resulting powders have irregular shape due to high solidification rate. Water atomization also increases the hydrogen content and creates powders with irregular shapes. On the other hand, gas atomization is a more promising technique because the inert atmosphere in the processing chamber, as well as the lower solidification rate of the particles, leads to less impurity pick-up and more regular shape for the final powders $[1,21,58]$.

The gas atomization is categorized into two major types: NANOVAL and EIGA processes. In NANOVAL (Berlin Germany) process, the ingot is melted in a graphite crucible in an autoclave under an inert atmosphere (typically argon), and the melt flow is subsequently led through the nozzle. This process also utilizes a laminar gas flow in order to stabilize the melt flow while passing through the nozzle. In the narrowest region of the nozzle (neck), the gas flow speeds up dramatically and cause the melt to be unstable and broken up into powder droplets because its tension pressure exceeds the external pressure. Finally, the powders are solidified in the atomization tower, and they can be collected in a vacuum chamber located under the tower [11, 12, 59]. (See figure 4) 


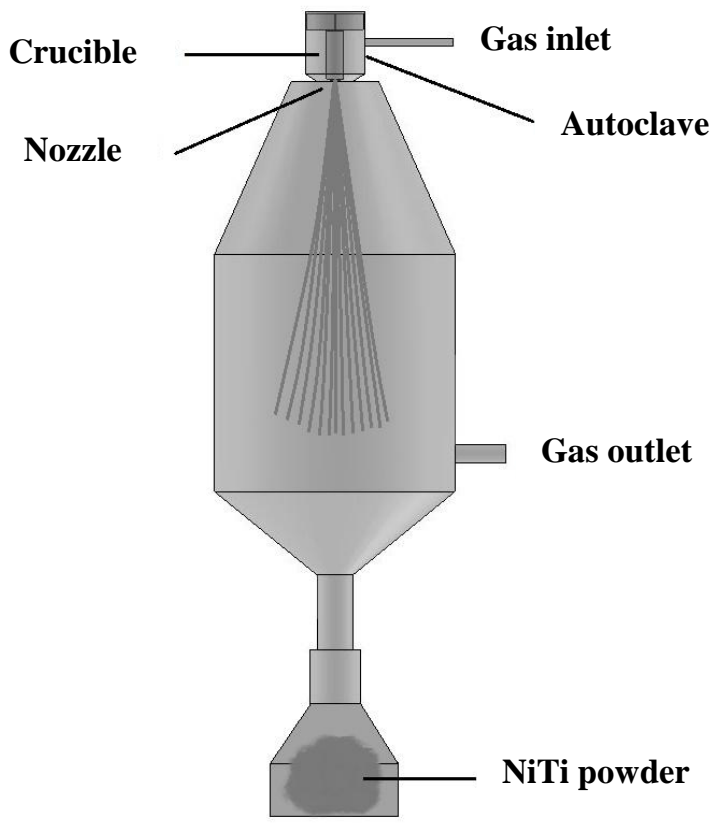

Fig.4. Schematic of NiTi powder preparation using the NANOVAL technique. The NiTi ingot is first melted in a crucible in an autoclave and it subsequently converts into the powder droplets as passing through the nozzle [60].

As shown by Bram et al. [61], most of the resulting particles are smaller than $45 \mu \mathrm{m}$ (See figure 5A). The main disadvantages of NANOVAL method are the formation of distinct numbers of hollow particles, the adhesion of small particles to the larger ones, and the existence of high impurity contents (Carbon 0.03-0.1 wt.\%; Oxygen 0.05-0.18 wt.\%). The high impurity content, in particular, carbon, is most probably the result of the exposure of the melt to the graphite crucible [62]. Fine powder particles are also responsible for the increased level of impurity due to having a higher surface to volume ratios [61]. 

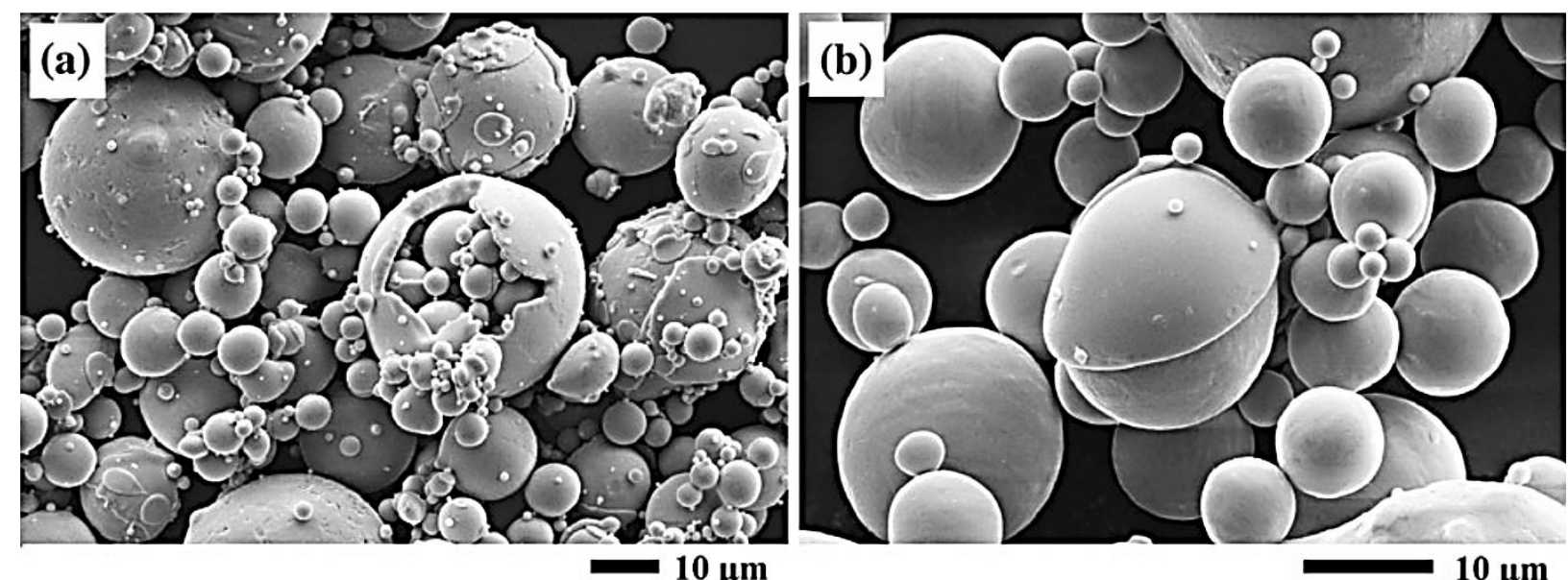

Fig.5. The morphology of pre-alloyed NiTi powders prepared by a) NANOVAL, and b) EIGA process. NANOVAL technique is associated with the formation of a high number of hollow particles, the adhesion of smaller particles to large ones, and high impurity content while EIGA technique show a few number of imperfect particles [61].

EIGA process can overcome the problems associated with NANOVAL by replacing the crucible with an induction coil $[29,61,63]$. In this method, the induction coil melts the ingot without any physical contact. The molten NiTi then flows downward toward a gas nozzle system, where the melted NiTi is burst and converted to droplets. Then, the droplets are solidified as they are falling in the atomization tower, and the powders can finally be collected in a powder container [1] (See figure 6). As depicted in figure 5B, Bram et al. [61] demonstrated that the final powders as the result of EIGA technique show a considerable reduction in the numbers of imperfect particles and impurity contents (Carbon 0.01-0.03 wt.\%; Oxygen 0.04-0.1 wt.\%). The limitation of this method is, however, the broad range of particle sizes as well as the existence of non-spherical particles in the resulting powders [63]. Therefore, sieving and fractioning procedure are required after atomization to collect the desired particle shape and size range in different containers (See also section 4.1.2) [13, 29]. 


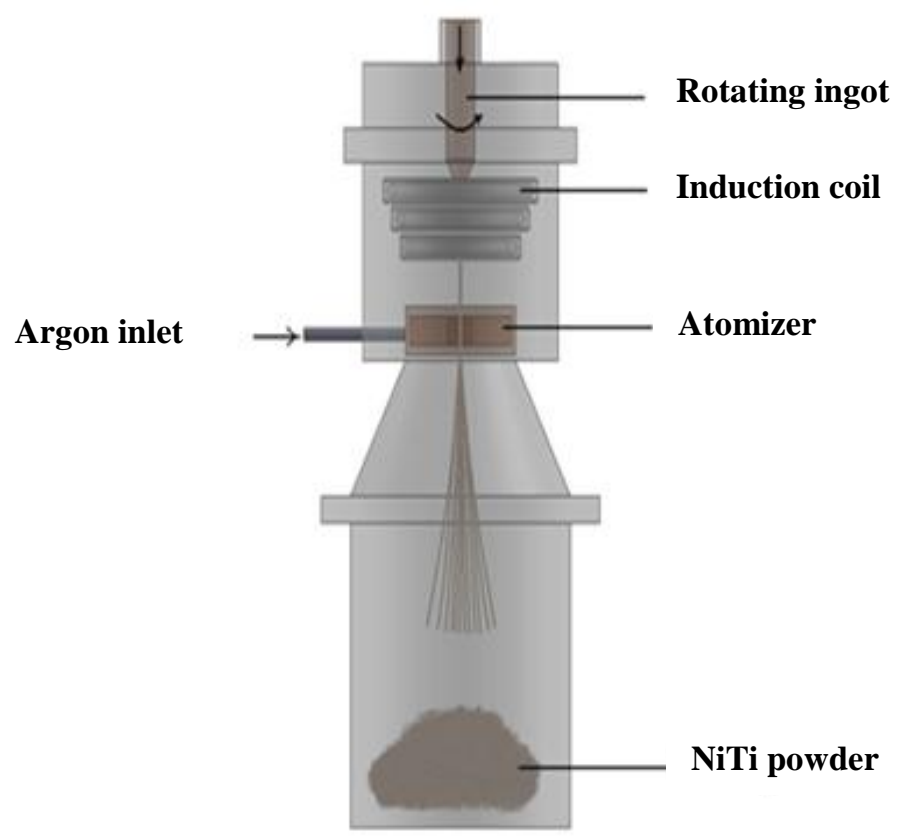

Fig.6. Schematic of NiTi powder preparation using the EIGA method. The NiTi ingot is first melted via an induction coil without any physical contact and it subsequently converts into the powder droplets as passing through the nozzle [1].

\subsection{Optimum Laser Parameters}

Another step in fabricating NiTi is to define optimum laser parameters such that the achieved parts possess two critical features of the high level of density, as well as the low level of impurity contents $[8,64]$. Low impurity pick-up is especially important for medical applications, which is the largest market for NiTi devices $[65,66]$. The maximum level of impurity content is prescribed to be $500 \mathrm{ppm}$ based on ASTM F2063-05 [8]. A common practice to find such parameters is to fabricate single tracks of NiTi and to change the parameters until the produced tracks meet the requirements [64]. According to Haberland et al. [8], a higher level of energy density enhances the density in the resulting SLM NiTi products, while increasing the impurity pick-up during the processing (See figure 7). It is worth noting that the fabrication chamber of the machine was filled with Argon during the fabrication. Based on these results, the energy density of approximately $200 \mathrm{~J} / \mathrm{mm}^{3}$ (or energy input of approximately $54.7 \mathrm{~J} / \mathrm{mm}^{3}$ ) produces a fully 
dense NiTi with the allowable level of impurity contents (Oxygen 0.03-0.04 wt.-\%; Nitrogen 0.01-0.02 wt.-\%; Carbon 0.028-0.03 wt.-\%).

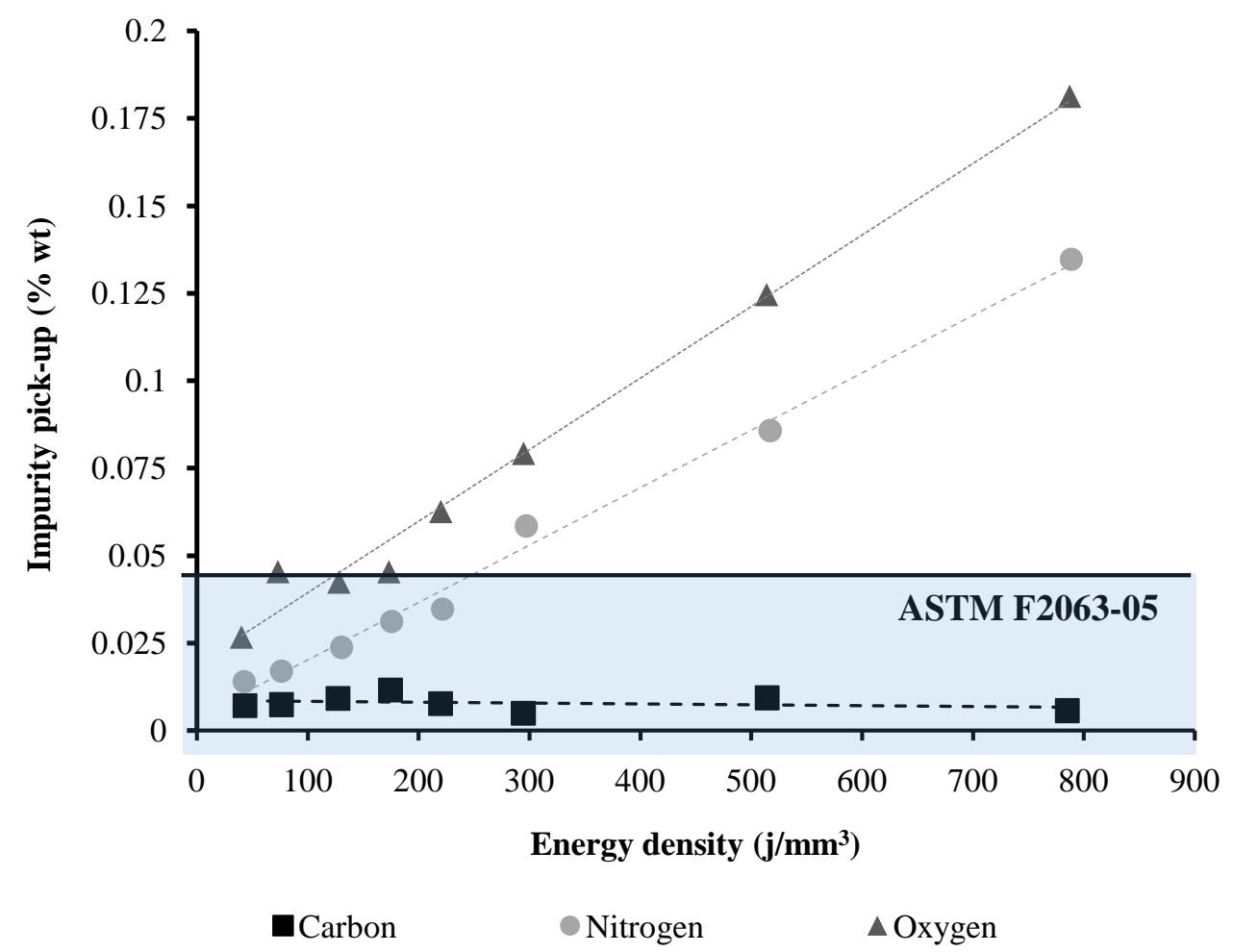

Fig.7. The effect of energy input on the impurity pick up through AM processing. This figure indicated that the energy density should not exceed $200 \mathrm{~J} / \mathrm{mm}^{3}$ to assure the allowable level of impurity contents based on ASTM F2063-05 within the final product [8].

Considering these two important factors, different groups tried to optimize the process parameters using powder-bed as well as flow-based techniques. Table 2 summarizes these optimum parameters achieved by different groups using AM technologies. The term "P-energy input" in the table is defined as the energy that delivers to the powder. Energy input $\left(\mathrm{J} / \mathrm{mm}^{3}\right)$ is the combination of several processing parameters including P-laser power (W); v-scanning velocity $(\mathrm{mm} / \mathrm{s})$; h-hatch spacing $(\mathrm{mm})$; and t-layer thickness (mm).

According to Meier et al. [27], energy input is described by the following equation:

$$
E=\frac{P}{v \cdot h \cdot t}
$$


Haberland et al. [8] presented a modified function to describe the energy input named " $\mathrm{w}_{\mathrm{v}}$ energy density $\left(\mathrm{J} / \mathrm{mm}^{3}\right)$ ". The purpose is to incorporate other parameters including $\mathrm{d}_{\mathrm{b}}$-beam diameter (mm); $d_{t}$-track width (mm); and $\rho_{\mathrm{r}}$-the relative density of the powder-bed/a.u.

$$
\begin{array}{lr}
\mathrm{w}_{\mathrm{v}}=\frac{\mathrm{P}}{\rho_{\mathrm{r}} \cdot \mathrm{d}_{\mathrm{b}} \cdot \mathrm{t} \cdot \mathrm{v}} & \mathrm{d}_{\mathrm{t}} \leq \mathrm{h} \\
\mathrm{w}_{\mathrm{v}}=\frac{\mathrm{P}}{\rho_{\mathrm{r}} \cdot \mathrm{d}_{\mathrm{b}} \cdot \mathrm{t} \cdot \mathrm{v}} \cdot\left(2-\frac{\mathrm{h}}{\mathrm{d}_{\mathrm{t}}}\right) & 0<h<\mathrm{d}_{\mathrm{t}}
\end{array}
$$

It is reported that the achieved optimum parameters are suitable for limited features (e.g., geometries and dimension.) and, therefore, future works might be needed to obtain universal laser parameters $[27,28]$.

\begin{tabular}{|c|c|c|c|c|c|c|c|}
\hline AM technique & $\begin{array}{c}\text { Effective } \\
\text { Laser } \\
\text { power }(W) \\
\end{array}$ & $\begin{array}{c}\text { Scanning } \\
\text { velocity } \\
(\mathbf{m m} / \mathbf{s}) \\
\end{array}$ & $\begin{array}{c}\text { Hatch } \\
\text { distance } \\
(\mu \mathrm{m})\end{array}$ & $\begin{array}{c}\text { Powder } \\
\text { rate } \\
(\mathrm{g} / \mathrm{min}) \\
\end{array}$ & $\begin{array}{c}\text { Layer } \\
\text { thickness } \\
(\mu \mathrm{m}) \\
\end{array}$ & $\begin{array}{c}\text { Energy } \\
\text { Input } \\
\left(\mathrm{J} / \mathbf{m m}^{3}\right) \\
\end{array}$ & Author(s) \\
\hline \multicolumn{8}{|c|}{ Powder-bed fusion } \\
\hline SLM & 77 & 200 & 120 & - & 50 & $\begin{array}{c}64.1 \\
\left(234^{+}\right)\end{array}$ & $\begin{array}{c}\text { Meier et al. }[14, \\
27,28]\end{array}$ \\
\hline SLM & 77 & 200 & 120 & - & 50 & $\begin{array}{c}64.1 \\
\left(234^{+}\right)\end{array}$ & $\begin{array}{l}\text { Haberland et } \\
\text { al. }[8,9,13,15 \text {, } \\
16,29,67]\end{array}$ \\
\hline SLM & 250 & 1250 & 120 & - & 30 & 55.5 & $\begin{array}{c}\text { Walker et al. }[36- \\
38]\end{array}$ \\
\hline SLM & 250 & 1250 & 120 & - & 30 & 55.5 & $\begin{array}{c}\text { Taheri Andani et } \\
\text { al. }[68]\end{array}$ \\
\hline SLM & 250 & 1250 & 120 & - & 30 & 55.5 & $\begin{array}{l}\text { Saedi et al. [35, } \\
\text { 69] }\end{array}$ \\
\hline SLM & 40,250 & 160,110 & 75,60 & - & 30 & 111,126 & $\begin{array}{c}\text { Dadbaksh et al. } \\
{[41,42]}\end{array}$ \\
\hline SLM & 56 & 133 & 120 & - & 50 & 70 & $\begin{array}{l}\text { Bormann et } \\
\text { al.[31-33] }\end{array}$ \\
\hline SLM & 56 & 133 & 120 & - & 50 & 70 & $\begin{array}{l}\text { Hoffman et } \\
\text { al.[34] }\end{array}$ \\
\hline SLM & 50 & $100-160$ & 100 & - & 60 & $52-83$ & $\begin{array}{c}\text { Shishkovsky et } \\
\text { al.[10] }\end{array}$ \\
\hline \multicolumn{8}{|c|}{ Directed energy deposition } \\
\hline DED & 1000 & 10.6 & 1900 & 12 & 300 & 167 & $\begin{array}{l}\text { Hamilton et } \\
\text { al.[20] }\end{array}$ \\
\hline LENS & 300,500 & 10,15 & 762 & 5.5 & $127-254$ & $103-516$ & Krishna et al. \\
\hline
\end{tabular}

Table. 2. AM laser parameters to produce dense NiTi achieved by different groups. 


\begin{tabular}{|c|c|c|c|c|c|c|c|}
\hline \multirow[b]{2}{*}{ LENS } & \multicolumn{7}{|c|}{$\begin{array}{lc} & {[46]} \\
\end{array}$} \\
\hline & 250 & 12.5 & 500 & 5.6 & 254 & 157.5 & $\begin{array}{l}\text { Halani et al. [49, } \\
50]\end{array}$ \\
\hline LRM & $\begin{array}{c}1000- \\
1500\end{array}$ & $3.3-8.3$ & - & $5-8$ & - & - & Shiva et al. [51] \\
\hline DMD & $250-600$ & 10.16 & - & - & 381 & - & $\begin{array}{l}\text { Malukhin et al. } \\
\text { [52] }\end{array}$ \\
\hline LENS & $200-400$ & $10-20$ & - & 4.36 & - & $20-80 *$ & $\begin{array}{l}\text { Marattukalam et } \\
\text { al. [53] }\end{array}$ \\
\hline LSF & $\begin{array}{r}2000- \\
3000\end{array}$ & $3-7$ & - & 10 & - & - & $\mathrm{Xu}$ et al. [54] \\
\hline LENS & 350 & 15 & - & 10 & - & $19.8^{*}$ & Bernard et al. [55] \\
\hline
\end{tabular}

* These data are reported as laser energy per unit area (laser power/scanning velocity. beam diameter) and the unit is $\mathrm{J} / \mathrm{mm}^{2}$.

- These values were not mentioned in the references.

+ These values are reported for the energy density $\left(\mathrm{w}_{\mathrm{v}}\right)$.

\subsection{Fabrication Chamber}

In the AM techniques, non-metallic elements (e.g., O, C) are often concentrated within the NiTi part while the layers are getting deposited and sintered. Such impurity pick-up is unfavorable because all impurity related phases (e.g., Ti4Ni2Ox) strongly affect the microstructural properties of NiTi structures and functional properties. Therefore, it is necessary to maintain a low impurity content within the NiTi products through providing inert atmosphere (e.g., argon, nitrogen) [70, 71].

In addition to the inert atmosphere, pre-heating the substrate is another critical step for NiTi fabrication. Provided the substrate is not pre-heated, high residual stresses appears at the very bottom region of the sample supports due to the high gradient temperature between the first layers and the build platform. It is desirable to minimize the residual stresses because they may directly cause the separation of the sample from the substrate (i.e., warping effect). One solution might be the preheating of substrate, and therefore decreasing the gradient temperature in the interlayer between the first layers of the supports and the substrate [17-19]. It is notable that the effect of preheating the substrate for NiTi production is not understood so far. 


\section{Microstructure Characteristics and Structural Defects}

\subsection{Microstructure of $\mathrm{AM} \mathrm{NiTi}$}

In laser-based AM techniques, complex thermal history (i.e., high laser power and high cooling rate) contributes to a non-equilibrium solidification process which may result in the change of microstructure [72]. For instance, the high cooling rate $\left(10^{3}-10^{8} \mathrm{KS}^{-1}\right)$ associated with the AM techniques results in the formation of finer powders compare to conventional methods for producing metallic parts, and therefore, the mechanical properties as well as the density of the final product improves in some extends $[73,74]$. In this section, the influencing factors on the microstructure including processing parameters, powder properties, and part positioning are explained in details.

\subsubsection{Effect of processing parameters on the microstructure}

\subsubsection{Epitaxial solidification}

In AM techniques, while the laser melts the current powder layer, it also re-melts the previously sintered layer (i.e., sublayer). This phenomenon is known as "epitaxial solidification." The re-melting enhances the bonding and continuity between the layers and results in a stronger structure [36]. However, it is critical to utilize a set of processing parameters that results in fully melting the deposited layer as well as partially melting the sublayer. Otherwise, the bonding in the interlayers is not that strong, and the porosity and intermetallic phases tend to be created in these regions [47].

With the optimum laser parameters, the associated epitaxial solidification causes the growth of the grains located in the sublayer while the grains in the current layer are sintered $[33,72]$. Borman et al. [33], demonstrated that the grains are increased in length and width due to epitaxial growth. In addition, the grains are shown to be elongated with a platelet shape parallel to the direction of the laser path, i.e., side view (See figure 8a). From the top view in figure $8 \mathrm{~b}$, the grains present $S$-shaped configurations which is the indication of the laser movement. The reason is that the grains tend to reorient parallel to the direction of the highest thermal gradient, which is parallel to the scanning direction. 


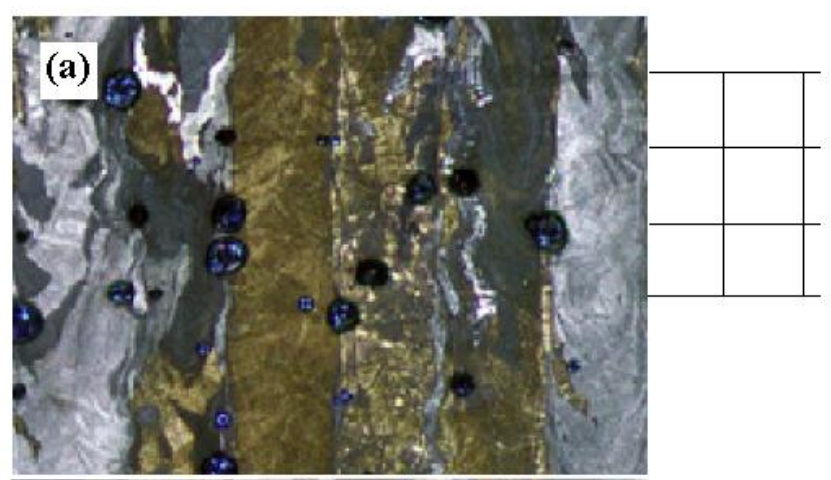

\section{Building direction}

Z-axis
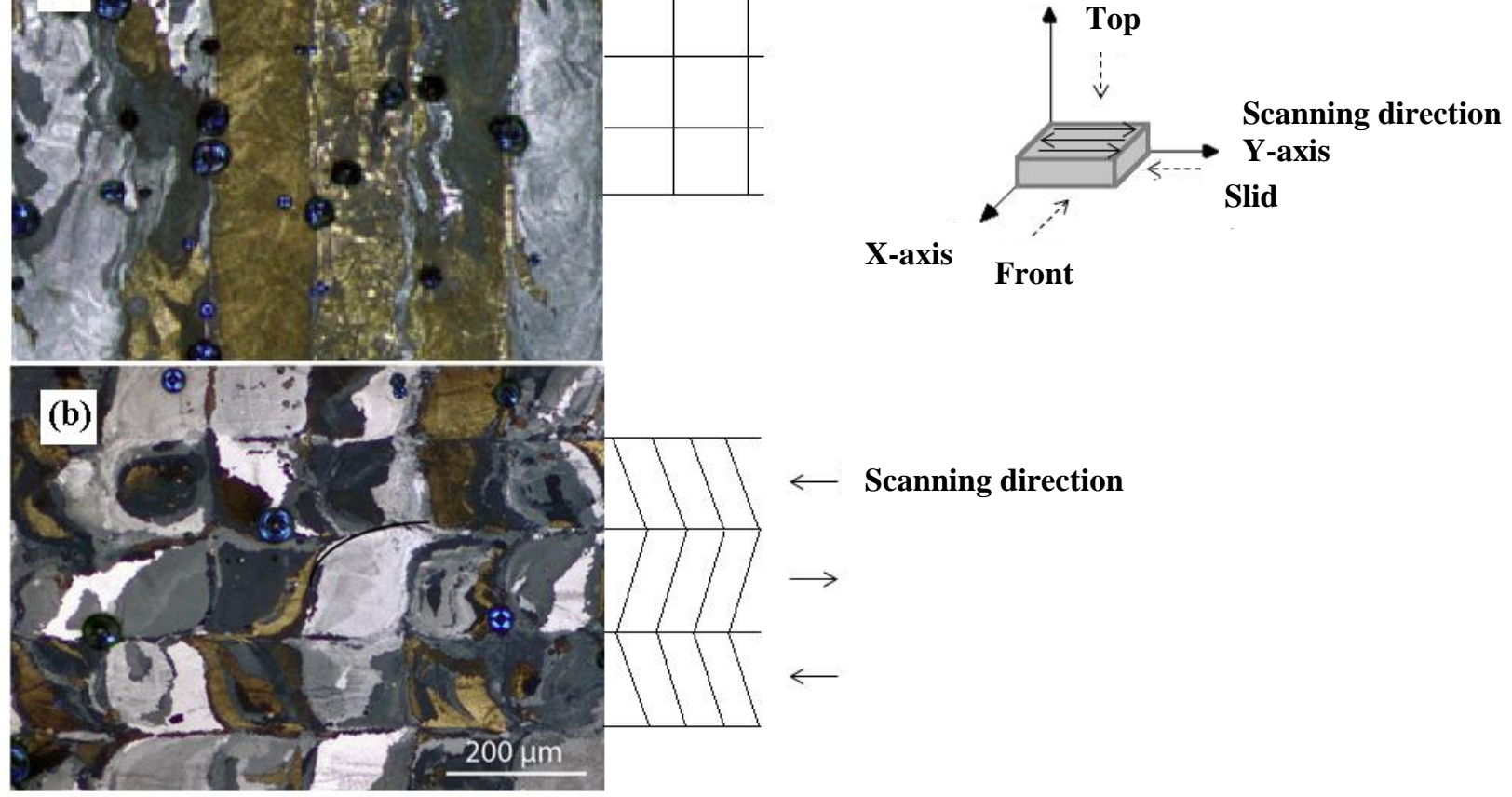

Fig.8. Optical images of SLM NiTi: a) side view explains the elongated grains showing grid-shape columnar configuration, and b) top view, describes the $\mathrm{S}$-shaped grains formation as the result of laser movements [33].

\subsubsection{Effect of parameters with epitaxial solidification}

NiTi microstructural characteristics are highly dependent on the processing parameters (e.g., laser focus, laser power, and scanning speed). The laser focus has to be determined in a way to minimize the adherent particles in the final product and to ensure the appropriate surface quality (e.g., smoothness and precision). It is especially important in biomedical applications since the harmful Ni release increases with higher level of adherent particles [4, 21]. Habijan et al. [21] studied the effect of change in diameter of the laser beam $(61 \mu \mathrm{m}$ and $128 \mu \mathrm{m})$ at the position of focus for two different dense SLM Ni50.2Ti samples. The corresponding SEM (Scanning electron microscope) images demonstrate reduction in the adherent particle via focused laser beam $(61 \mu \mathrm{m})$ (figure 9). Accordingly, the cell culture experiments demonstrated reduction in Ni release for both samples (Dense: 59.3 to $32.5 \mathrm{ng} / \mathrm{ml}$, Dense: 48.8 to 21.7 
$\mathrm{ng} / \mathrm{ml})$. One should consider that the divergent laser beam $(128 \mu \mathrm{m})$ leads to smoother surface for creating dense samples (figure 9).

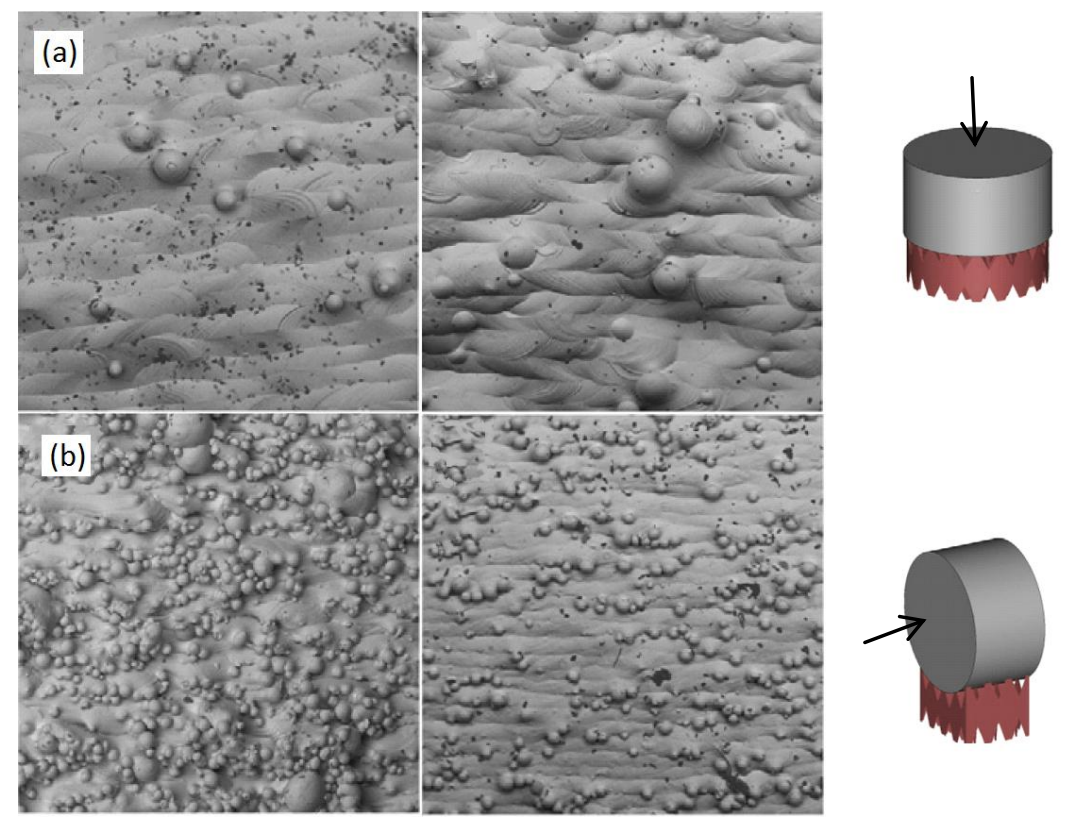

Fig.9. SEM micrographs showing the effect of two different beam diameters of $128 \mu \mathrm{m}$ (left) and $61 \mu \mathrm{m}$ (right) on the level of adherent particles as well as the top surface quality of SLM NiTi: (a) vertically fabricated; (b) horizontally fabricated. Focused laser beam reduce the amount of adherent particles. Divergent laser enhance the top surface of the vertically fabricated while the sharp focused laser result in a more smooth surface for horizontally one [75]. (Arrows show the top surfaces of both samples)

In addition to optimum laser focus, a minimum level of energy input called "critical energy," is required to generate epitaxial solidification. An elevated level of energy input form a superheated melt pool that can liquefy a larger zone of the material, and therefore, it takes longer for the liquid to get solidified. Under these situations, the temperature of the sublayer surface increases which results in the decreased gradient temperature at the interlayer. The associated lower rate of cooling (dT/dt) leads to the formation of coarser grains (See figure 10) $[46,73,76]$. Several groups $[33,46,53]$ studied the effect of laser power and scanning speed on the grain size of $\mathrm{AM} \mathrm{NiTi}$, as presented in table 3 . The results indicate that the grain sizes are increased with higher laser power while scanning speed seems not to have a significant effect on the grains width and length. It should be noted that the grain width cannot be 
increased beyond the hatching space (i.e., the center distance between two adjacent scanning tracks) [33, 36].

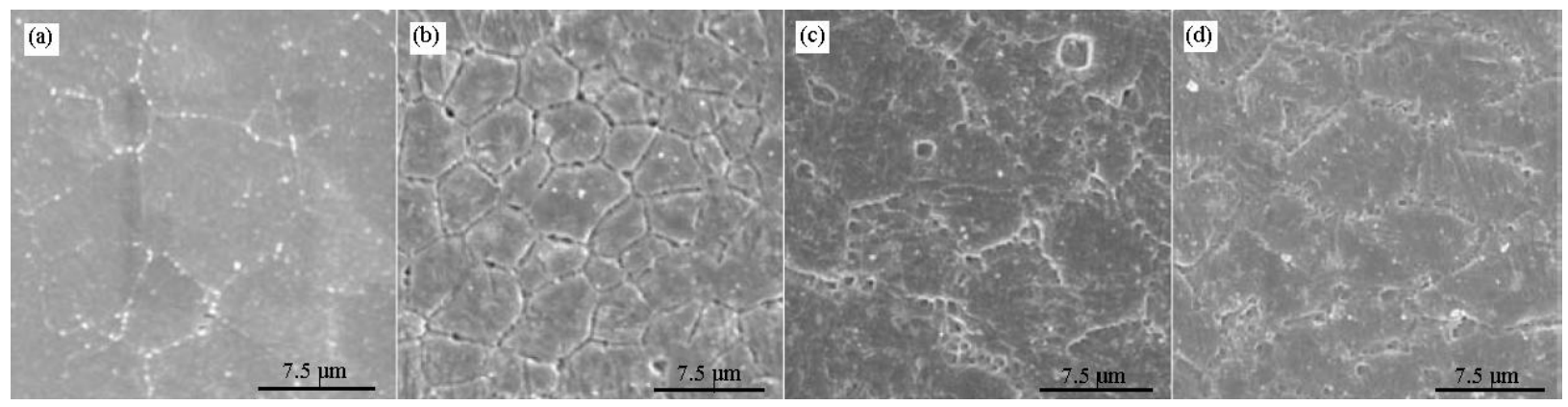

Fig.10. SEM micrographs showing the effect of changing laser parameters on the grain size of dense NiTi samples using LENS technique: (a) as-received powder; (b) $\mathrm{P}=300 \mathrm{~W}, \mathrm{v}=10 \mathrm{~mm} / \mathrm{s}$; (c) $\mathrm{P}=500 \mathrm{~W}, \mathrm{v}=10 \mathrm{~mm} / \mathrm{s}$; (d) $\mathrm{P}=500 \mathrm{~W}$, $\mathrm{v}=15 \mathrm{~mm} / \mathrm{s}$. While the elevated laser power enlarges the grain width and length, the change in scanning speed does not show a significant effect on the grain size [46].

Table. 3. The effect of laser parameters on the grain size.

\begin{tabular}{|c|c|c|c|c|c|c|}
\hline AM Technique & $\begin{array}{l}\text { Particle Size } \\
(\mu \mathrm{m})\end{array}$ & $\begin{array}{l}\text { Laser Power } \\
\text { (W) }\end{array}$ & $\begin{array}{c}\text { Scanning Speed } \\
(\mathrm{mm} / \mathrm{s})\end{array}$ & $\begin{array}{c}\text { Grain Width } \\
(\mu \mathrm{m})\end{array}$ & $\begin{array}{c}\text { Grain Length } \\
(\mu \mathrm{m})\end{array}$ & Groups \\
\hline SLM & $35-180$ & $\begin{array}{c}56 \text { to } 100 \\
80\end{array}$ & $\begin{array}{c}133 \\
107 \text { to } 190\end{array}$ & $\begin{array}{c}33 \text { to } 90 \\
185 \text { to } 190\end{array}$ & $\begin{array}{c}61 \text { to } 655 \\
145 \text { to } 172\end{array}$ & $\begin{array}{c}\text { Bormann et al. } \\
{[33]}\end{array}$ \\
\hline LENS & $50-150$ & $\begin{array}{l}200 \text { to } 400 \\
200 \\
400\end{array}$ & $\begin{array}{c}20 \\
10 \text { to } 20 \\
10 \text { to } 20\end{array}$ & $\begin{array}{c}8.5 \text { to } 15.2 \\
8.5 \text { to } 9.5 \\
11.5 \text { to } 15.2\end{array}$ & - & $\begin{array}{c}\text { Marattukalam et } \\
\text { al. }[53]\end{array}$ \\
\hline LENS & $50-150$ & $\begin{array}{l}300 \text { to } 500 \\
300 \\
500\end{array}$ & $\begin{array}{c}15 \\
10 \text { to } 15 \\
10 \text { to } 15\end{array}$ & $\begin{array}{l}3.7 \text { to } 6.7 \\
3.2 \text { to } 3.7 \\
6.3 \text { to } 6.7\end{array}$ & - & $\begin{array}{c}\text { Krishna et al. } \\
{[46]}\end{array}$ \\
\hline
\end{tabular}

The level of imposed energy input also affects the crystallographic texture of NiTi products. Electron backscatter diffraction (EBSD) is a common technique to convey visually the crystallographic features (e.g., orientation, shape, and etc.) of the grains. On the EBSD colored maps, each color is attributed to a specific orientation. Using this technique, Bormann et al. [33] demonstrated that the higher laser power (56 W to $100 \mathrm{~W})$ results in more crystallographic texture structure such that the grain shapes are transited from s-shaped to rectangular. Moreover, the higher number of oriented grains along the heat flow direction $(<111\rangle$ ) colored by blue can be seen as the result of such increase in laser power (See figure 11). Although the grains are shown to obtain more crystallographic features, figure 11 
demonstrated that the porosity is increased as the result of the higher laser power. According to Haberland et al. [8], the increased energy input beyond a high level (e.g., $74 \mathrm{~J} / \mathrm{mm}^{3}$ ) increases surface roughness and reduces the density of SLM NiTi due to pore formation between the adjacent tracks. The reason is that the molten pool is kept melted for a longer period that leads to instability of the expanded molten pool that can result in irregular tracks as well as the vaporization of elements (See figure 11b) [14, 27, 28]. It worth noting that the scanning speed is showing a negligible effect on these features [33].
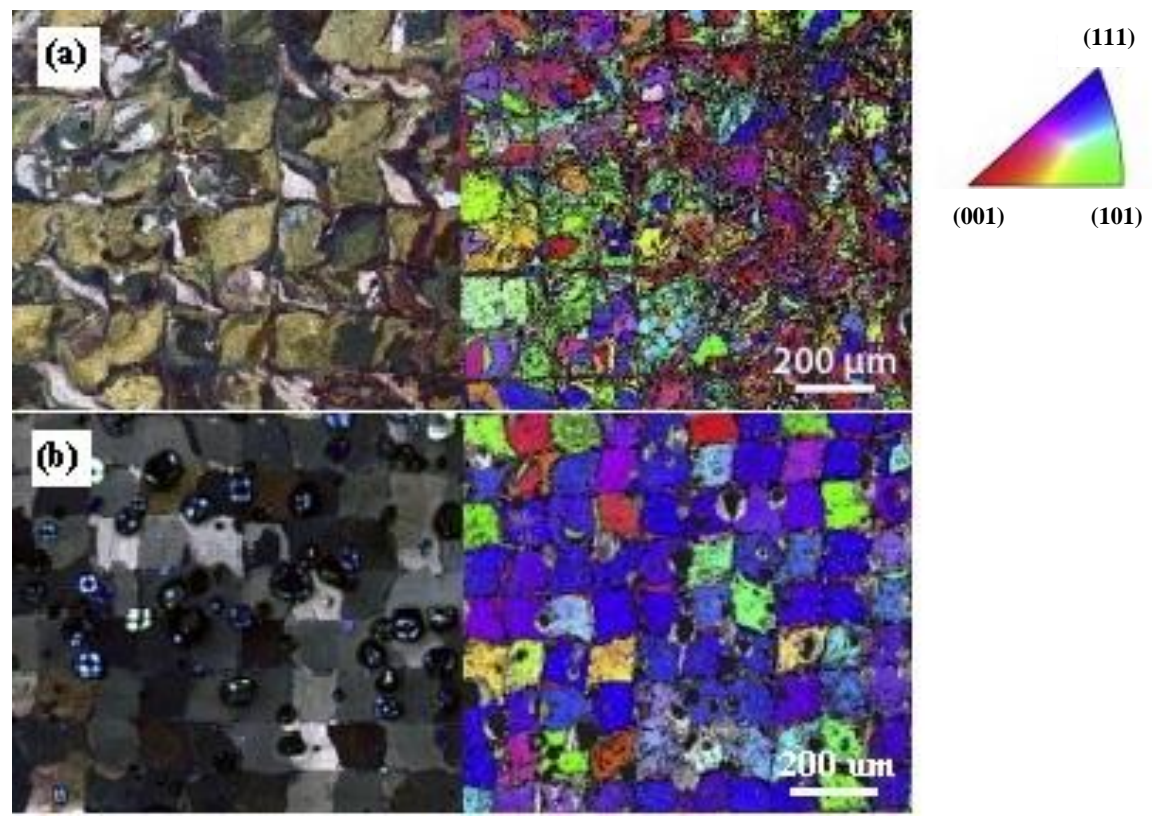

Fig.11. Optical micrographs (left) and EBSD color maps (right) showing the effect of laser power on the grain shape and orientation: a) $\mathrm{P}=56 \mathrm{~W}, \mathrm{v}=133 \mathrm{~mm} / \mathrm{s}$; b) $\mathrm{P}=92 \mathrm{~W}, \mathrm{v}=133 \mathrm{~mm} / \mathrm{s}$ ). Color map shows different orientations of the grains. The elevated laser power enhances the crystallographic features, however, the resultant product includes higher numbers of pores between the adjacent layers [33].

\subsubsection{Effect of parameters in absence of epitaxial solidification}

When the energy input is less a critical level, the melt pool does not sufficiently penetrate the sublayer, and therefore, it tends to have a cylindrical shape due to the surface tension. The resultant reduced contact area between the layers results in the formation of porosity, weak interlayer bonding, poor heat conduction, and a low cooling rate. Such lower level of cooling rate leads to the enlargement and re-orientation of the resultant grains [73]. Krishna et al. [47] showed that the reduced energy (from 
103 to $38 \mathrm{~J} / \mathrm{mm}^{3}$ ) increases the porosity (from 8 to $28 \%$ ) and also enlarges the average grain size (from 2.9 to $9.5 \mu \mathrm{m})$ in the fully melted regions of LENS NiTi. However, the grain size continuity is observed to be more uniform for the parts with higher porosity (See figure 12).

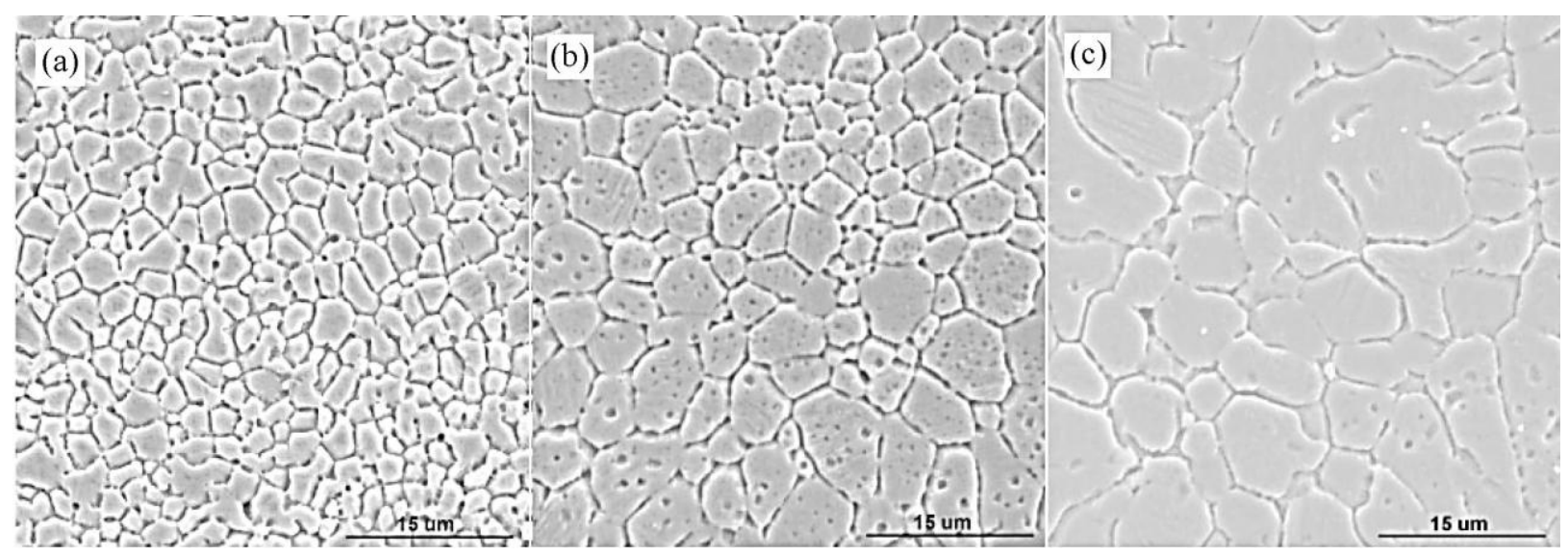

Fig.12. SEM micrographs showing the effect of changing laser parameters on the grain size (a) $P=200 \mathrm{~W}, \mathrm{v}=10$ $\mathrm{mm} / \mathrm{s}, \mathrm{t}=0.127 \mathrm{~mm}$, porosity=92\%; (b) $\mathrm{P}=200 \mathrm{~W}, \mathrm{v}=10 \mathrm{~mm} / \mathrm{s}, \mathrm{t}=0.254 \mathrm{~mm}$, porosity $=85 \%$; and (c) $\mathrm{P}=150 \mathrm{~W}, \mathrm{v}=20$ $\mathrm{mm} / \mathrm{s}, \mathrm{t}=0.254 \mathrm{~mm}, 30$ porosity $=72 \%$. The reduced energy input in absence of epitaxial grow results in enlargement of grains [47].

\subsubsection{Effect of powder properties on the microstructure}

Another important factor that affects the microstructure of AM NiTi is the powder characteristics including powder composition, size, and distribution. Shiva et al. [51] studied the microstructure of three different material compositions (Elementally blended; Ni55Ti, Ni50Ti, and Ni45Ti) that had been fabricated with LRM technique. As it is evident in figure 13, equiatomic NiTi presents the most uniform, finest, and highest packed grains compare to the other two compositions. Ni45Ti demonstrates uniformly distributed grains that are irregular and large. Although the grains size of Ni55Ti are smaller than Ni45Ti, they are still greater than the grains of Ni50Ti. 

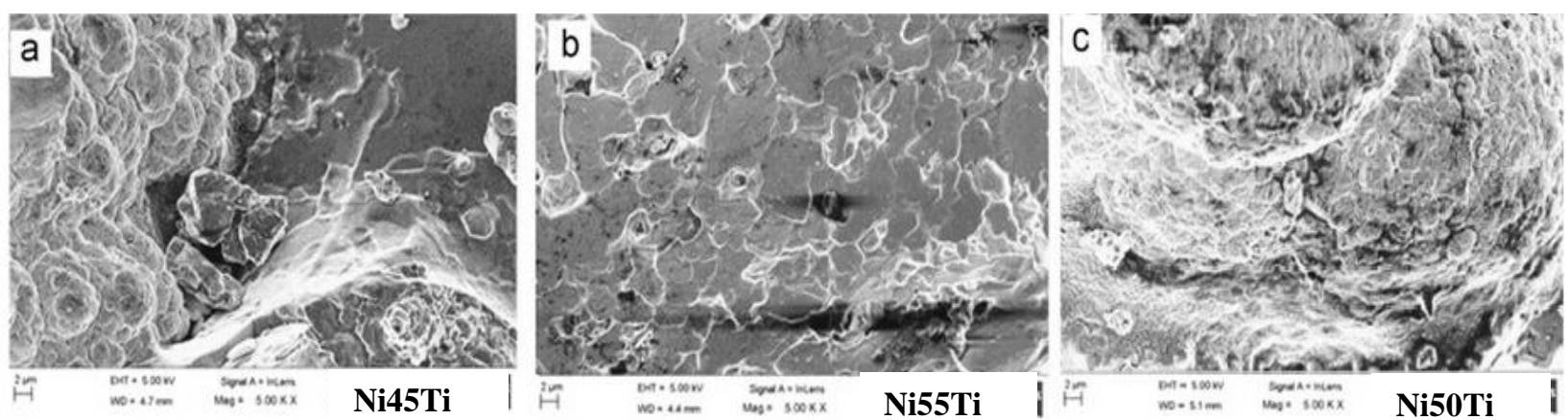

Fig.13. SEM images showing the effect of material composition on the microstructure (a) Ni45Ti, (b) Ni55Ti, and (c) Ni50Ti. Equiatomic NiTi presents the most uniform, finest, and highest packed grains compare to the other two compositions [51].

In addition to material composition, powder size is another important influencing factor. Generally, finer particle sizes are more favorable because the final part tends to be denser as the result of smaller initial particles. Moreover, the finer particles require a lower level of energy in order to satisfy epitaxial solidification [73]. However, different factors simultaneously need to be considered to find the best particle size range including flowability, impurity content, and transformation ability. Haberland et al. $[13,29]$ reported the best range of particle size for using in SLM as summarized in Table 4. Mediumsized fractions between $25-75 \mu \mathrm{m}$ are suitable with acceptable particle size, spherical shape, good flowability and packing density, low impurity content, and excellent transformation ability.

Table. 4. Qualitative classification of different particle sizes for AM [8].

\begin{tabular}{lllll}
\hline & $<\mathbf{2 5} \mu \mathbf{m}$ & $<\mathbf{4 5} \mu \mathbf{m}$ & $\mathbf{2 5 - 7 5} \mu \mathbf{m}$ & $\mathbf{4 5 - 1 0 0 \mu \mathbf { m }}$ \\
\hline Particle Size & Excellent & Very Good & Good & Fair \\
\hline Spherical Shape & Excellent & Excellent & Excellent & Excellent \\
\hline Flowability & Very Poor & Very Poor & Very Good & Very Good \\
\hline Packing Density & Poor & Good & Very Good & Very Good \\
\hline Impurity Content & Poor & Fair & Good & Very Good \\
\hline Transformation Ability & Excellent & Excellent & Excellent & Excellent \\
\hline
\end{tabular}

\subsubsection{Variation in the microstructure}

The microstructure of AM NiTi is expected to vary constantly within the part. However, the grains tend to get finer in the regions far away from the base of the sample while coarser grains can be observed 
in the very bottom region of the sample $[28,73,76]$. This might be attributet to the lower level of heat flux associated with the regions near the supports. Generally, the main heat transfer mechanism in AM is heat conduction through solid bodies while the effect of convection and radiation is negligible. The already solidified body beneath the scanning layer in the upper regions is responsible for the high flux capacity. On the other hand, it is unfortunate for the bottom region to transfer heat because they are mostly on a powder bed and they only have a few contacts with solid supports $[77,78]$. As the result of reduced heat flux, the melt pool tends to enlarges and leads to a longer period of powder exposure time to high temperature. Therefore, it results in the enlargement of grain sizes (See section 4.1.1.2), as well as the evaporation of $\mathrm{Ni}$ elements in the NiTi matrix which causes an increase in transformation temperatures (See section 5.1 ) [73]. Meier et al. [28] showed that the regions near the base of SLM Ni49.7Ti include larger grains as well as dendrites with Ti-rich phases (e.g., $\mathrm{Ti}_{2} \mathrm{Ni}$ ) (See figure 14). These Ti-rich phases are clear indication for lower heat flux near the substrate. (versus upper regions). The increased transformation temperatures in the bottom region of the sample was also reported by Hamilton et al. [20] using DED NiTi. The results showed equivalent transformation temperatures (Mp: $57 \pm 4{ }^{\circ} \mathrm{C}$, $\mathrm{Ap}=98 \pm 3^{\circ} \mathrm{C}$ ) starting from the height of $3.4 \mathrm{~mm}$.
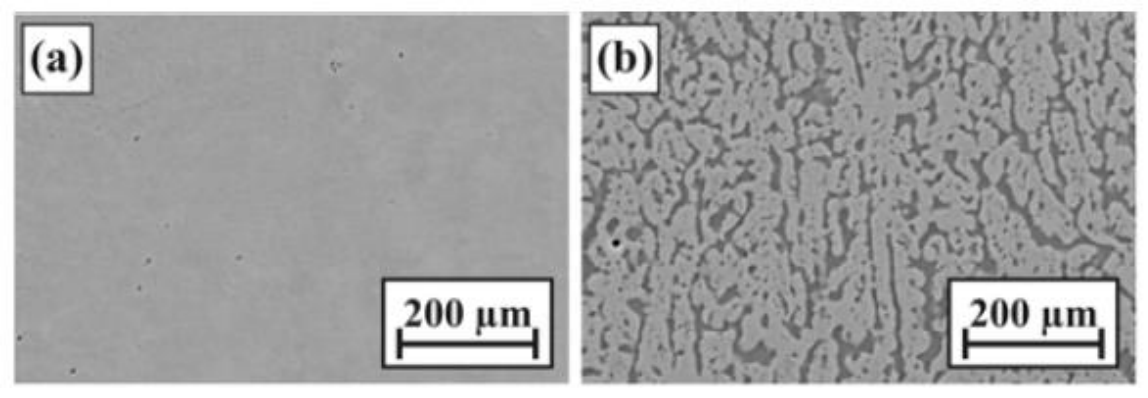

Fig.14. The microstructure of SLM NiTi: a) at the center, b) at the edge near the supports. Dark gray particles indicate $\mathrm{Ti}_{2} \mathrm{Ni}$ formation. The regions near the supports demonstrate enlarged grains as well as Ti-rich phases due to lower capacity for heat flux [28].

The position of the sample through processing is also another critical issue that needs to be considered. Habijan et al. [21] demonstrated that the surface of the cylinder which is fabricated 
horizontally is rougher compared to the one built vertically (See figure 15). The reason is that the face of the horizontally fabricated part is formed by the sidewalls of the laser scanning tracks. To be able to produce a smoother surface at the top of the cylinders, one should note that the horizontally fabricated NiTi requires a sharp focused laser (beam diameter $61 \mu \mathrm{m}$ ) while the vertically one needs a divergent laser focus (beam diameter $61 \mu \mathrm{m}$ ).

(a)

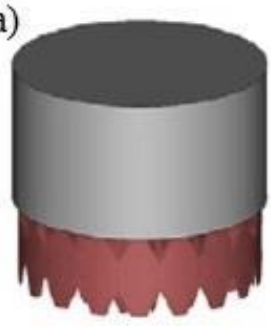

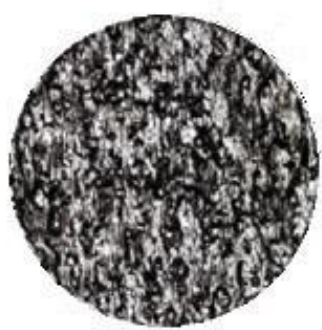

(b)

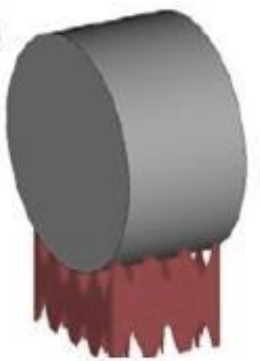

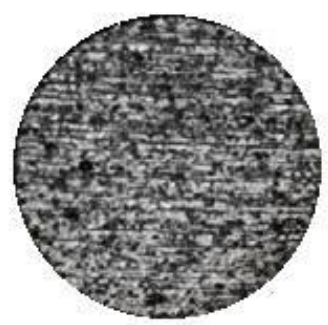

Fig.15. Fully dense NiTi rods: a) fabricated vertically presents a smooth surface, b) fabricated horizontally results in a rougher surface [21].

\subsection{Structural defects}

Common structural defects in AM fabricated NiTi are porosity and crack formation. The factors responsible for the creation of these defects as well as remedies to minimize their effects are discussed in this section.

Two type of porosities could be observed inside the AM NiTi parts, spherical and irregular [72]. Spherical pores are created due to the mixture of the ambient gas with the NiTi powder. During the process the trapped gas does not have enough time to escape from the melt pool. On the other hand, the unfavorable balling effect is responsible for the formation of irregular pores. One way to alleviate the creation of such porosities is to choose the processing parameters in a way to assure that epitaxial solidification takes place (See section 4.1) [79]. Yang et al. [44] demonstrated that stronger bonding between the layers can be achieved as the result of elevated energy input through increasing the laser power and decreasing the scanning speed. Li et al. [79], showed that a change in hatch space does not 
significantly affect the pore formation (Note: the hatch distances are selected in a way to ensure the overlapping of the subsequent tracks). One should not that increasing the energy input beyond a high level (this value is reported by Haberland et al. [8] to be more than $74 \mathrm{~J} / \mathrm{mm}^{3}$ for SLM NiTi) may result in pore formation (more details in section). Another technique to minimize the balling effect and therefore reduce the possibility of pore formation is to decrease the oxygen content in the manufacturing chamber via purging the inert atmosphere (e.g., argon) inside the manufacturing chamber. Oxygen could be trapped between the new and previously deposited layers during the fabrication of the new layer. The formed cavities tends to expand and create large pores due to the laser heat as it scans the new layer [80]. Li et al. [79] compared the microstructure of the SLM NiTi that has been fabricated under three different oxygen levels (i.e., $0.1,2$, and $10 \%$ ). As reported in figure 16, a level of oxygen below $0.1 \%$ is required to reduce balling phenomena (See figure 16).

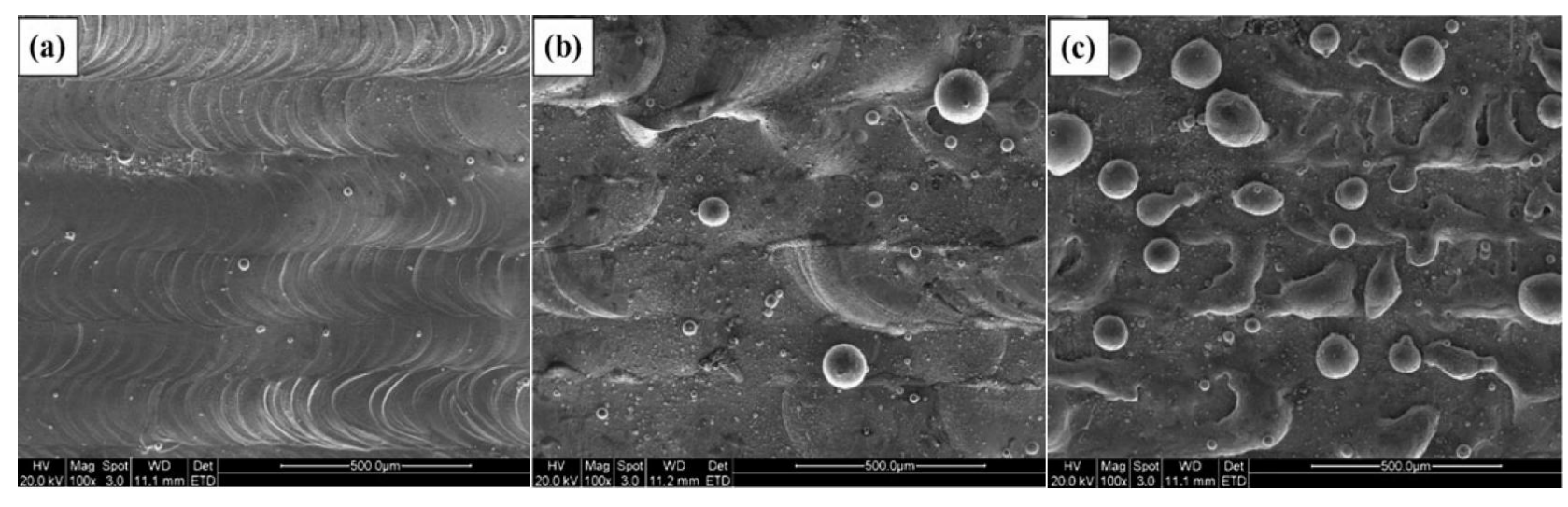

Fig.16. SEM images of SLM NiTi processed under different oxygen contents in the fabrication chamber: a) $0.1 \%$, b) $2 \%$, and c) $10 \%$. The low level of oxygen during fabrication decreases the balling effect and therefore microstructural defects within the final product [79].

There are several reasons that might contribute to the crack formation in a fabricated NiTi part $[20,44]$. Residual stresses are one of the major reasons for crack initiation throughout NiTi samples which are often caused by high thermal gradients associated with AM techniques [20]. Balling effect between layers is another reason for crack formation, which effect can be minimized via selecting an optimum set of parameters to assure epitaxial solidification as well as providing inert atmosphere during 
the fabrication $[44,79,80]$. It is worth noting that vaporization also can cause crack initiation via forming excessive pores through the structure. Although cracks form during the AM, these cracks do not propagate due to the rapid cooling which prevents the propagation [20,44].

Li et al. [81] investigated the effect of processing parameters on the crack formation within the dense SLM Ni44.3Ti. Although it was expected to see reduction in numbers of produced cracks with energy until a threshold point (where fully consolidation occurs), not a trend was observed in this study. Figure 17 demonstrates that. In this study, the energy inputs higher than $300 \mathrm{~J} / \mathrm{mm} 3$ with laser power more than $70 \mathrm{~J} / \mathrm{mm} 3$ are suggested to result in acceptable cracks.
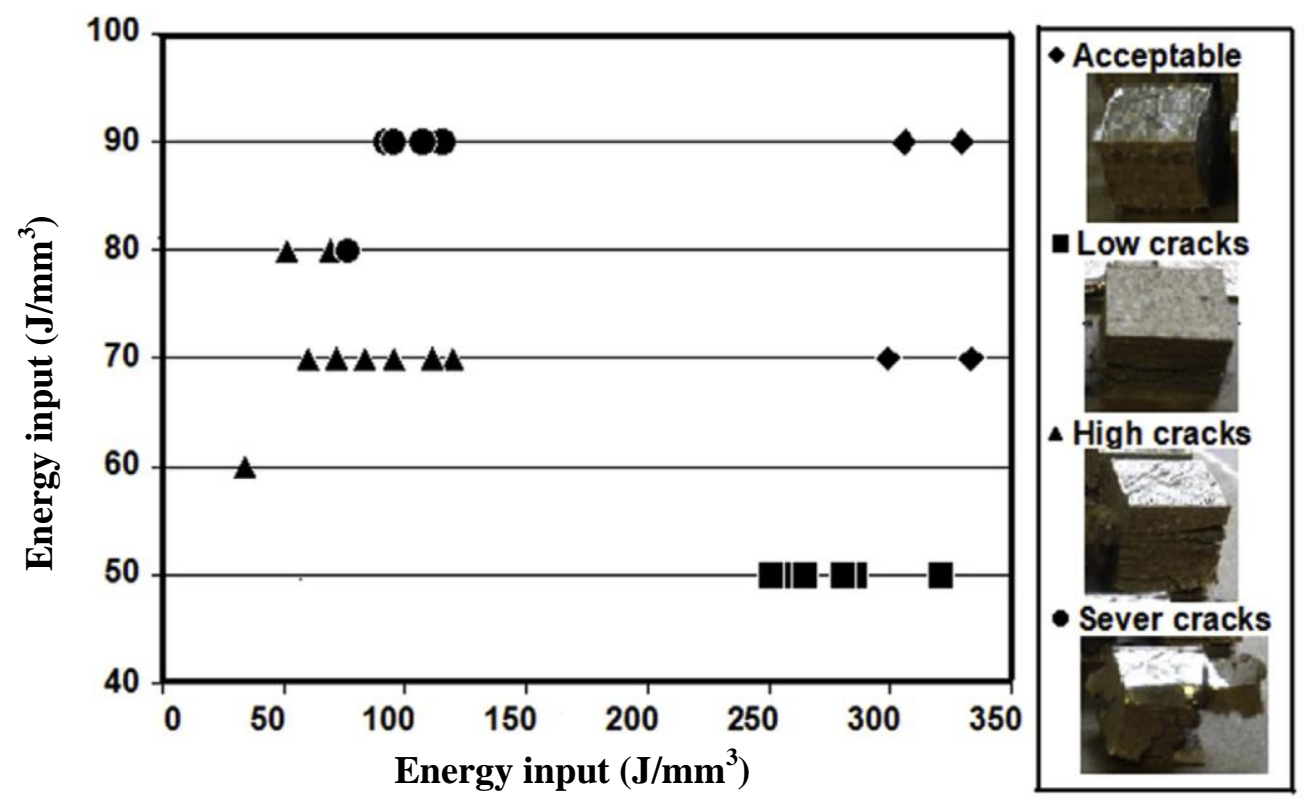

Fig.17. The crack formation resulted from different energy input for SLM Ni44.3Ti. The acceptable cracks are observed for energy inputs higher than $300 \mathrm{~J} / \mathrm{mm}^{3}$ with laser power more than $70 \mathrm{~J} / \mathrm{mm}^{3}[81]$.

\section{Transformation Temperatures}

Four transformation temperatures define the boundaries of the solid-state phase transformation in NiTi. At these temperatures the martensite and austenite phases start and finish (i.e., martensite start Ms, martensite finish Mf, austenite start As, and austenite finish Af). These four temperatures result in a hysteresis in the transformation process [82]. In addition to these boundary temperatures, it is also 
common to define the austenitic (Ap) and martensitic (Mp) peak transformation temperatures, that are representative for highest transformation temperatures during heating and cooling, respectively [83].

\subsection{The effect of material composition and processing parameters on the transformation temperatures}

It is crucial to understand how the powder compositions and laser parameters would affect the transformation temperature. This way one can tailor the transformation temperatures for a particular application. In general the transformation temperatures raise by approximately $83^{\circ} \mathrm{C}$ at $1 \%$ decrease in $\mathrm{Ni}$ (i.e., Ni depletion) [8, 84]. Haberland et al. [8] compared the transformation temperatures of three different material composition (Ni-rich: Ni50.7T, Equi-atomic: Ni50.2Ti, and Ti-rich: Ni49.7Ti) of NiTi. Using optimized energy density $\left(234 \mathrm{~J} / \mathrm{mm}^{3}\right)$, the results demonstrated higher transformation temperatures for the Ti-rich $\left(A_{s}=335, M_{s}=339\right)$ versus equi-atomic $\left(A_{s}=325, M_{s}=327\right)$, and higher values for equiatomic compared to Ni-rich NiTi $\left(\mathrm{A}_{\mathrm{s}}=288, \mathrm{M}_{\mathrm{s}}=293\right)$ both during cooling and heating.

Haberland et al. [8] also showed that the transformation temperatures shift to higher values as the result of an increased energy density from 45 to $545 \mathrm{~J} / \mathrm{mm}^{3}$ for SLM NiTi. This trend was observed in all three different compositions (i.e., Ti-rich, near equiatomic, and Ni-rich) (See figure 18). The reason is that the higher level of energy input results in a larger melt pool that exposes the material to high temperature for a longer period of time, and therefore nickel evaporates at a higher rate (Note that Ni has lower melting point compare to $\mathrm{Ti}$ ). The matrix composition, therefore, shifts to a higher titanium content (i.e., $\mathrm{Ni}$ depletion) that typically leads to an increase in the transformation temperatures [13, 49]. One should consider that the higher level of impurity pickup resulted from elevated energy input could cause a reduction in transformation temperature values through the formation of Ti-rich precipitates. However, the results indicate that the effect of $\mathrm{Ni}$ evaporation compensate or even overcome the effect of impurity pickup and the transformation temperature increases with energy input [8].

As depicted in figures $18 \mathrm{~d}$-e, the Ni-rich transformation temperatures are more dependent on the 
energy input than the Ti-rich and equiatomic samples. This may be attributed to the fact that the transformation temperature of a Ni-rich alloy is also influenced by the formation of Ni-rich precipitates. Generally, an Ni-rich alloy exceeds the limit of Ni solubility, and, therefore, the extra Ni tends to form Ni-rich precipitates such as $\mathrm{Ni}_{4} \mathrm{Ti}_{3}, \mathrm{Ni}_{3} \mathrm{Ti}_{2}$, and $\mathrm{Ni}_{3} \mathrm{Ti}$ which results in the depletion of $\mathrm{Ni}$ from the NiTi matrix. Ni-rich precipitates formation together with Ni evaporation leads to a high Ti contents within NiTi matrix, and therefore the transformation temperatures increase significantly by increasing energy input [68].

It is important to know that the transformation profile (i.e., peak width and height) of Ni-rich samples are influenced by the level of energy input while this effect cannot be seen for the other two compositions (i.e., Ti-rich and equi-atomic). For Ni-rich samples, the sharpest peak is attributed to the optimum laser energy density $\left(234 \mathrm{~J} / \mathrm{mm}^{3}\right)$. The lowest energy density results in a broad flatten profile which is the indication for un-fully melting of the material as well as the inhomogeneity caused by $\mathrm{Ni}$ rich precipitates. Under high energy density (e.g., $545 \mathrm{~J} / \mathrm{mm}^{3}$ ), the formation of two or more peaks are observed during heating and cooling in DSC tests. The first peak is often attributed to the existence of Nirich precipitates, and the second or last one indicates the transformation into martensite (See figure 18a-c) [8].
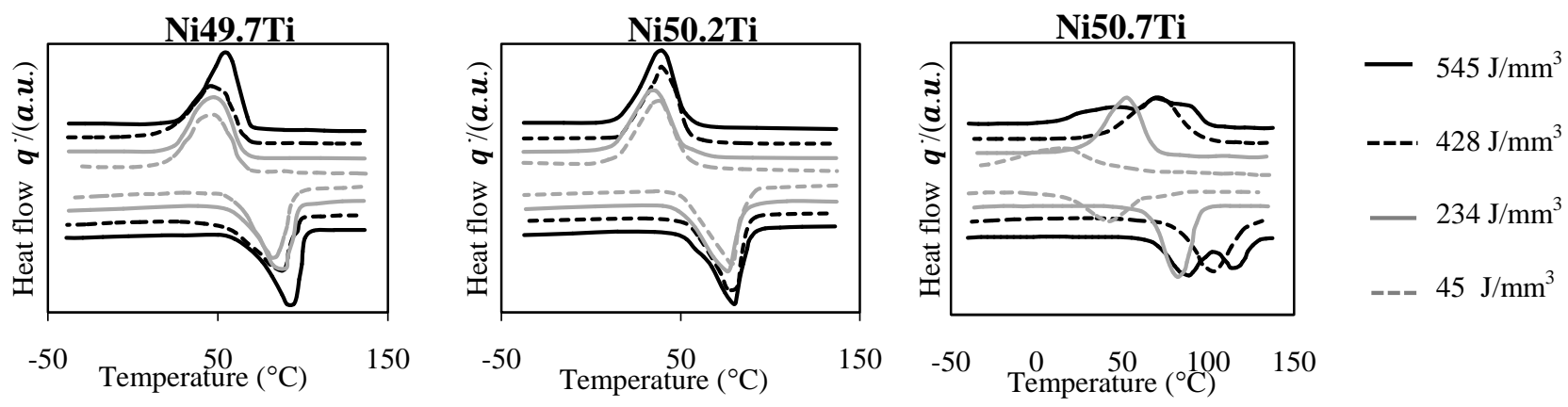

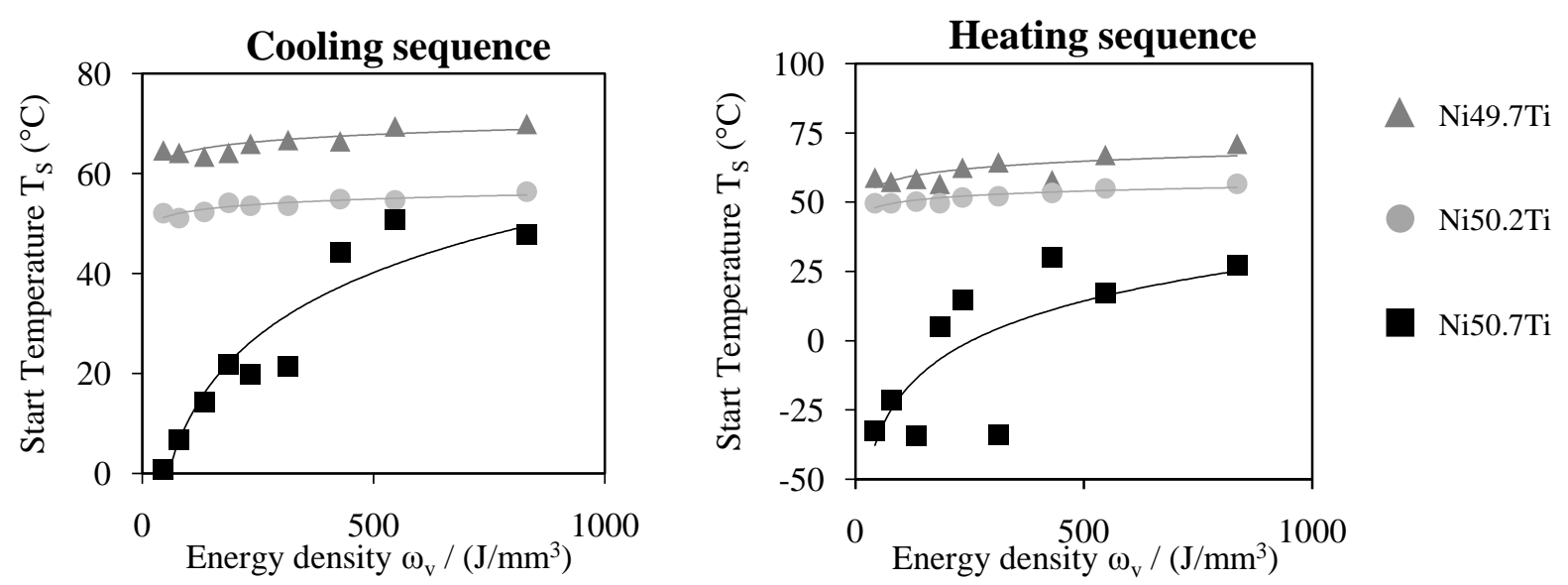

Fig.18. The effect of energy density on the martensitic and austenitic transformation start temperatures of NiTi with different compositions including a) Ti-rich, b) near equiatomic, and c) Ni-rich. The start transformation temperatures are compared during d) cooling and e) heating. The dashed lines show transformation temperature for related powders. (Note: Energy density term is explained in section 3 of this paper) [8].

Taheri Andani et al. [40] and Bormann et al. [31] also presented evidence that the higher level of energy input increases the phase transformation temperatures up to 8 degrees as the result of $15 \mathrm{~J} / \mathrm{mm}^{3}$ increase in energy input, and up to 75 degrees resulted by $40 \mathrm{~J} / \mathrm{mm}^{3}$, respectively.

It is also important to know that the transformation temperatures vary throughout the build height. As reported by Hamilton et al., [20] the transformation temperatures are higher in the bottom region of the DED NiTi sample, while equivalent temperature values are seen starting from the height of $3.4 \mathrm{~mm}$ (more details in section 4.1.3).

\subsection{The effect of post-heat treatment on the transformation temperatures and behavior}

Ni-rich NiTi have higher intrinsic strength in comparison with equi-atomic and Ti-rich NiTi, and therefore, they are better candidate for the applications where high superelasticity is needed [35]. It is notable that as-fabricated Ni-rich NiTi cannot fully recover the strength of the NiTi due to the nucleation of martensite in an austenite region [85]. In order to create superelasticity in parts fabricated from Ni-rich alloys there is a need to post-process heat treatments (i.e., solution annealing and aging) [86]. The purpose 
of solution annealing is to provide an equilibrium state for the material through reducing the microstructural defects as well as residual stresses. Subsequent aging treatments are necessary to fully recover the initial strength via formation of Ni-rich precipitates (Ni4Ti3, Ni3Ti2, and Ni3Ti) within NiTi matrix (See also section 5.1) which act as barriers to dislocation slip and can therefore improve the strength of the material and suppress the nucleation of martensite. However, the strength level is highly dependent to the precipitation properties (i.e., size and distance between precipitates), where nano-size precipitates with small relative distance result in perfect superelasticity properties. These precipitates are not only tunable by heat treatment conditions, they are also influenced by the cooling procedures (e.g., water quenching, oil quenching). (In this section, the effect of aging conditions on the transformation temperatures are fully discusses while their effect on superelasticity behavior will be explained in section $6.2)$.

Haberland et al. [8] showed that solution annealing $\left(950{ }^{\circ} \mathrm{C}, 5.5 \mathrm{~h}, \mathrm{H}_{2} \mathrm{O}\right)$ and subsequent water quenching has a significant effect on the transformation temperature of Ni-rich, while it has no influence on the Ti-rich alloy. For Ni-rich samples, the transformation temperatures are shifted slightly to lower values as the result of solution annealing, particularly during martensitic transformation (Figure 19). This phenomenon occurs due to the solving of metastable precipitates such as $\mathrm{Ni}_{3} \mathrm{Ti}_{2}$ during solution annealing as well as the suppression of renewed precipitation by subsequent water quenching. These together result in Ti depletion within the NiTi matrix, and, therefore, a reduction in transformation temperatures. The reason that solution annealing has more effect on Ni-rich alloys is the existence of Ni-rich precipitates such as $\mathrm{Ni}_{4} \mathrm{Ti}_{3}, \mathrm{Ni}_{3} \mathrm{Ti}_{2}$, and $\mathrm{Ni}_{3} \mathrm{Ti}$ (more details in section 5.1). In addition to decreased transformation temperatures, after solution annealing, the peak width (in DSC results) also is decreased for Ni-rich material (Figure 19). The reason is that the solution annealed material has a more homogenous equilibrium state, and, therefore, the material tends to have fewer obstacles for transformations in the absence of microscale heterogeneities that are associated with as-fabricated SLM Ni-rich material. In addition to these observations, the solution annealed material demonstrate single step transformation both 
during cooling and heating [86, 87]. Taheri Andani et al. [68] and Saedi et al. [35] also confirmed these observations, with showing lower transformation temperatures (approximately $20^{\circ} \mathrm{C}$ ) and single phase transformation as the result of solution annealing.
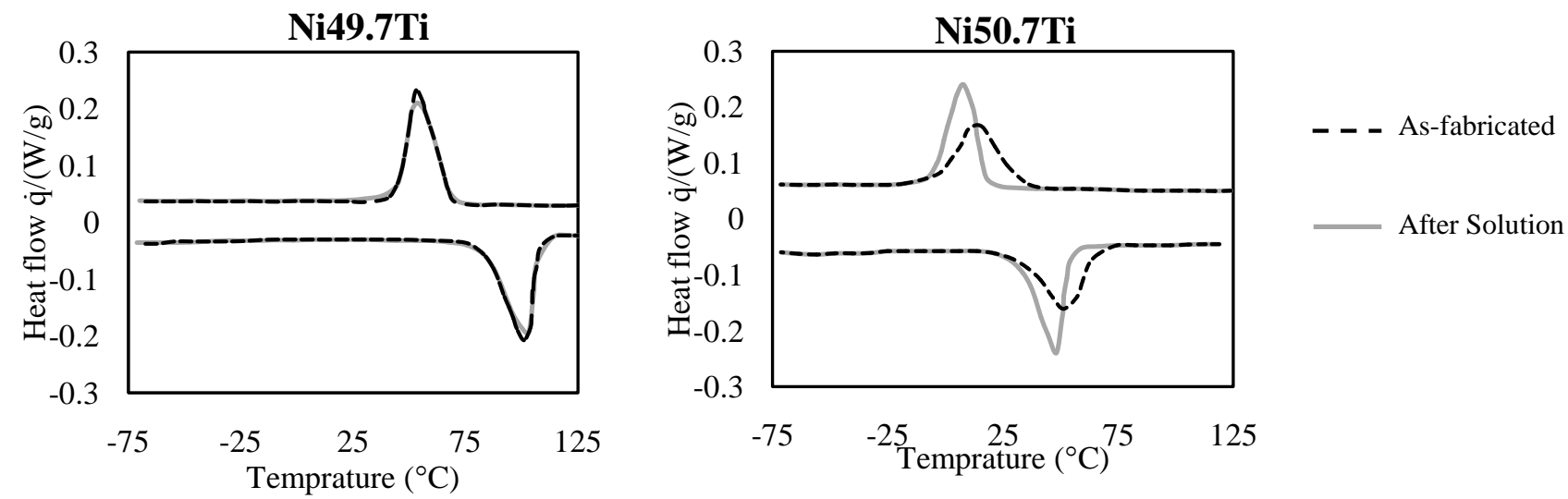

Fig.19. The effect of solution annealing $\left(950^{\circ} \mathrm{C}, 5.5 \mathrm{~h}, \mathrm{H} 2 \mathrm{O}\right)$ on a: Ti-rich NiTi, and b: Ni-rich SLM NiTi. The DSC plots depicts a reduction in the transformation temperatures of $\mathrm{Ni}$-rich[8].

Saedi et al. [87] investigated the effect of subsequent aging at two different temperatures $\left(350^{\circ} \mathrm{C}\right.$ and $\left.450^{\circ} \mathrm{C}\right)$ under varying aging time (5 min-18 hr) using SLM Ni50.8Ti. As it is depicted in figure 20, a longer period for aging elevates the transformation temperatures. Two reasons might be attributed to this phenomenon: First, the level of Ni evaporation increases as the sample undergoes high temperature for a longer period of time. Second, the Ni solubility increase with temperature, and, therefore, Ni-rich precipitates forms that leads to Ni depletion within NiTi matrix. The resultant Ni depletion leads to an increase in the transformation temperatures (See section 5.1). While the solution annealed NiTi demonstrates a single step phase transformation, a two-step phase transformation with two distinct peaks can be observed for aged parts with increasing temperature and time. According to DSC plots in figure 20, the two-step transformation occurs after 30 minutes for aging at $350^{\circ} \mathrm{C}$, and after 15 minutes at $450^{\circ} \mathrm{C}$. The first peak shows the transformation from austenite to R-phase and the second represents the R-phase trasnformation to B19' martensite. R-phase generally appears during cooling because the kinetic barrier to form R-phase is lower than that to form martensitic phase. Three reasons might contribute to the multi- 
step transformation: a) the precipitates formation and the associated inhomogeneity throughout the composition, b) the difference in the nucleation barriers for R-phase and B19' martensite, and c) Ni concentration between the particles as the result of super saturation of Ni. It is notable that the aged NiTi show a single-step transformation during heating [35]. Hamilton et al. [20] also showed the higher transformation temperatures due to a longer period of aging.
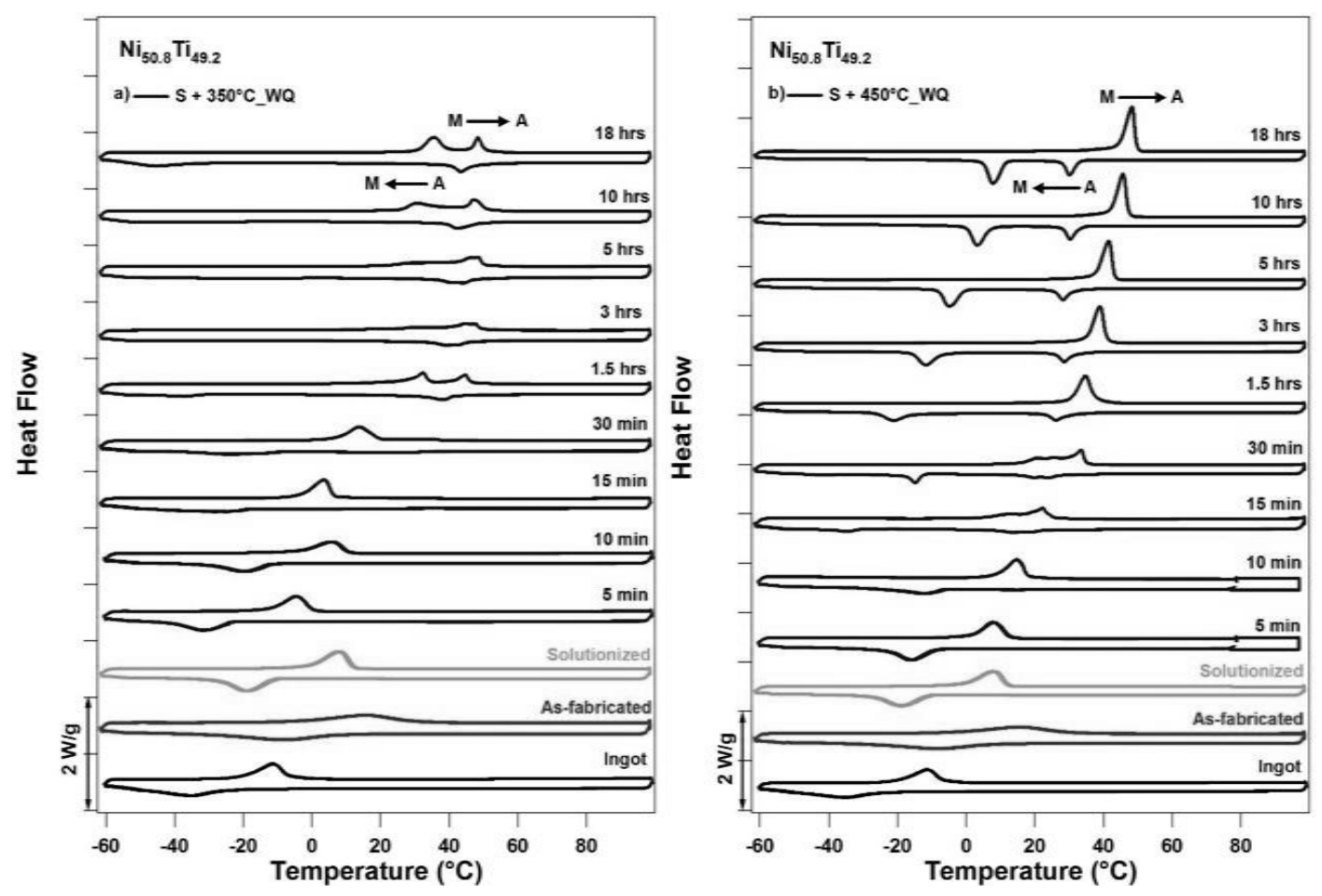

Fig.20. Transformation temperatures of As-received SLM, solution annealed, and solution annealed with subsequent aging at temperatures of $350^{\circ} \mathrm{C}$ and $450^{\circ} \mathrm{C}$ for different periods $(5 \mathrm{~min}-18 \mathrm{hr})$. The DSC plots demonstrate higher values for transformation temperatures with aging time. Two-step transformations are observed after 30 minutes at $350^{\circ} \mathrm{C}$ and after 15 minutes at $450^{\circ} \mathrm{C}[35]$.

Hamilton et al. [20] also studied the effect of aging conditions $\left(400{ }^{\circ} \mathrm{C}\right.$ and $\left.500{ }^{\circ} \mathrm{C}, 1-5 \mathrm{~h}\right)$ on the elementally blended Ni57Ti using LENS technique. Similar trends are observed here, i.e., the transformation temperatures are increased with aging time and multi-phase transformations are observed during cooling after $5 \mathrm{~h}$ aging time at $500^{\circ} \mathrm{C}$. 
In addition to the period of aging, aging temperature might be another important factor. Hamilton et al. [20] and Halani et al. [49] showed that increased temperature of the aging treatment decreases the transformation temperatures. However, the results observed by Saedi et al. [35] do not support this claim with showing unclear relation between the aging temperature and transformation temperatures.

\subsection{The effect of thermal cycling on the transformation temperatures and behavior}

Meier et al. [28] compared the transformation temperatures of SLM Ti-rich NiTi (Ni49.7Ti) and the conventionally processed Ti-rich NiTi (Ni50Ti) under thermal cycling (i.e., 20 heating and cooling cycles). As shown in figure 21, both alloys follow similar stabilization trends under thermal cycling. The slight temperature discrepancy (Approximately $8^{\circ} \mathrm{C}$ ) observed might be attributed to the level of impurity content (i.e., Carbon, Oxygen) of the implemented NiTi. The Arc melted conventional NiTi (Oxygen: 0.006 wt.\%, Carbon 0.006 wt.\%) in their work was purer in comparison with the SLM NiTi (Oxygen: 0.038 wt.\%, Carbon 0.028 wt.\%). .

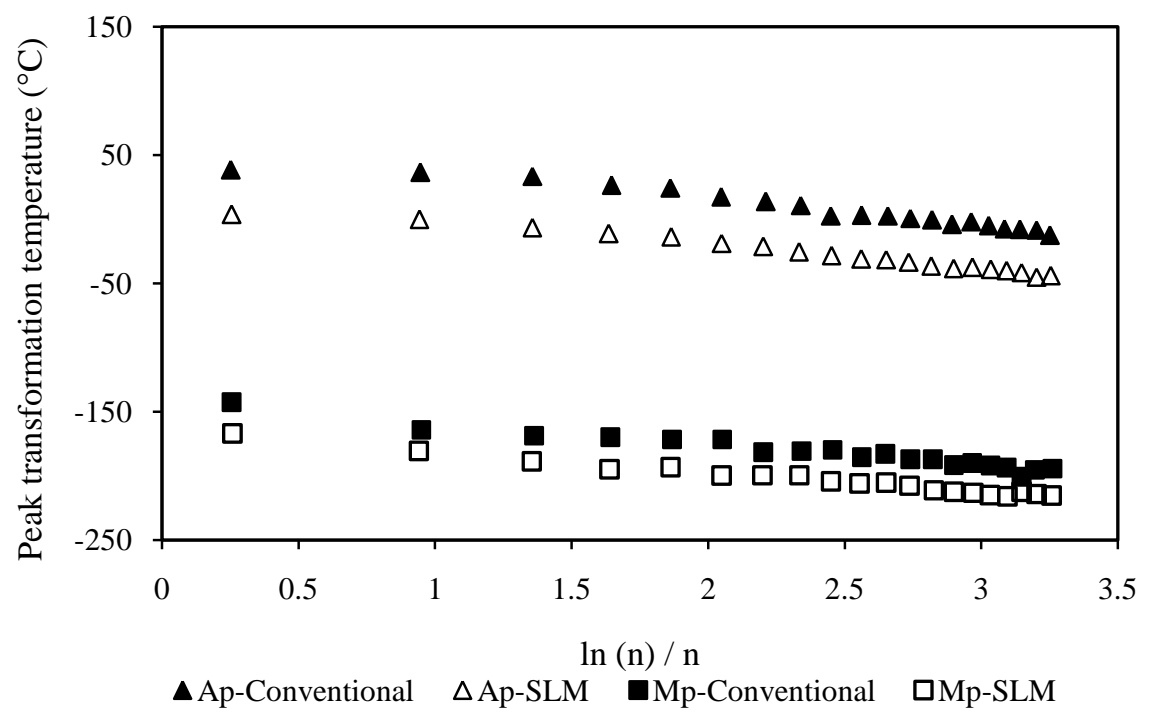

Fig.21. Peak transformation temperatures under thermal cycling for SLM versus conventional NiTi [28]. ( $\mathrm{Ap}=$ austenitic peak transformation temperature, $\mathrm{Mp}=$ martensitic peak transformation temperature, $\mathrm{n}=\mathrm{cycle}$ number). 
Saedi et al. [87] studied the effect of a single thermal cycling under different level of constant loading (50-500 MPa) for solution annealed $\left(950^{\circ} \mathrm{C}, 5.5 \mathrm{~h}, \mathrm{H}_{2} \mathrm{O}\right)$, as well as solution annealed plus aged $\operatorname{NiTi}\left(950{ }^{\circ} \mathrm{C}, 5.5 \mathrm{~h}, \mathrm{H}_{2} \mathrm{O}\right.$; aging at $350{ }^{\circ} \mathrm{C}$ and $18 \mathrm{~h}$ ). The strain-temperature curves of solution annealed NiTi shows symmetric transformation, while the associated curves with aged samples demonstrate a triangle shape under low stress level $(50 \mathrm{MPa})$. This observation is due to the associated two-step transformation during cooling $\left(\mathrm{B} 2 \rightarrow \mathrm{R}\right.$-phase $\left.\rightarrow \mathrm{B} 19^{\prime}\right)$ and the different temperature hysteresis between $\mathrm{R}$ phase and martensitic B19'. However, the triangle shape tends to evolve into symmetric shape with increasing the applied constant load, where the fully symmetric shape for transformation can be observed under high stress level of $500 \mathrm{MPa}$. This can be attributed to the single-phase transformation associated with higher stress levels. As the level of applied stress increase (500 MPa versus $50 \mathrm{MPa}$ ), $\mathrm{M}_{\mathrm{s}}$ tends to increases $\left(-40{ }^{\circ} \mathrm{C}\right.$ versus $\left.62{ }^{\circ} \mathrm{C}\right)$ until it becomes greater than $\mathrm{R}_{\mathrm{s}}\left(42^{\circ} \mathrm{C}\right)$, and therefore a single-phase transformation can be assured. It should be noted that $R_{s}$ has a constant value since $R$-phase is stable [87, 88]. (Figure 22) 


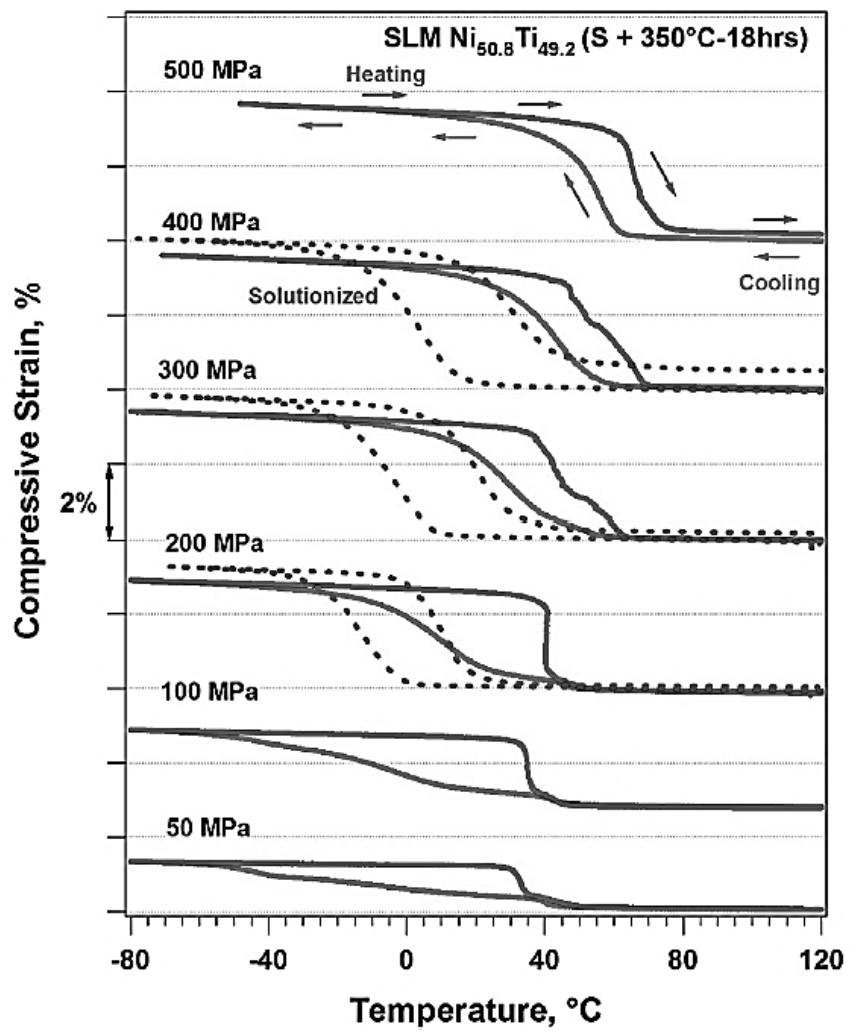

Fig.22. The train-temperature curves for solution annealed $\left(950^{\circ} \mathrm{C}, 5.5 \mathrm{~h}, \mathrm{H}_{2} \mathrm{O}\right)$, as well as solution annealed plus aged NiTi $\left(950{ }^{\circ} \mathrm{C}, 5.5 \mathrm{~h}, \mathrm{H}_{2} \mathrm{O}\right.$; aging at $350{ }^{\circ} \mathrm{C}$ and $18 \mathrm{~h}$ ). The results show triangle transformation under low stress level and it evolves into symmetric with increasing applied stress.

\section{Functional Properties}

The functional properties of NiTi are mainly related to the phase transition and are categorized into two distinct behaviors: I) shape memory effects (thermomechanical memory) which are based on temperature-induced transformation and II) superelasticity behavior (mechanical memory) which are associated with stress-induced transformation [13]. Degradation of shape memory and superelasticity effects can be defined as the accumulation of irreversible strain inside the NiTi part during each transformation. This unwated phenomenon is due to microstructural defects, particularly dislocations. It is desired to minimize such degradation during phase transformations [89]. 


\subsection{Shape memory effect (Ti-rich)}

Haberland et al. $[8,13]$ and Meier et al. [14] compared the shape memory effect of SLM NiTi with hot worked conventional NiTi with similar composition (Ni50.2Ti). Using an instrument of type Zwick/Roell Z100, compression rods were tested at $20^{\circ} \mathrm{C}\left(30^{\circ} \mathrm{C}\right.$ below the As temperature $)$ under a maximum stress level of $400 \mathrm{MPa}$, where detwinning is completed but the plastic deformation is not that significant. Then, the samples where unloaded and subsequent heated to $120^{\circ} \mathrm{C}\left(33^{\circ} \mathrm{C}\right.$ above the Af temperature-initiation of austenitic elastic deformation) to ensure the complete shape recovery. These cycles were repeated to investigate the evolution of the shape memory behavior. As it is shown in figure 23, the stress-strain curves, as well as the amount of irreversible strain, show minor change for SLM fabricated parts as the number of cycles are increasing, while significant changes can be seen for conventional materials. It can be inferred that SLM shows a more stable recovery for the first five cycles, but the amount of reversible strain are similar after cycle number 6 . It should be noted that the irreversible strain after 15 cycles is more promising for the SLM (2.5\%) compared to the conventional material (3.9\%) (See figure 23c).

(a)

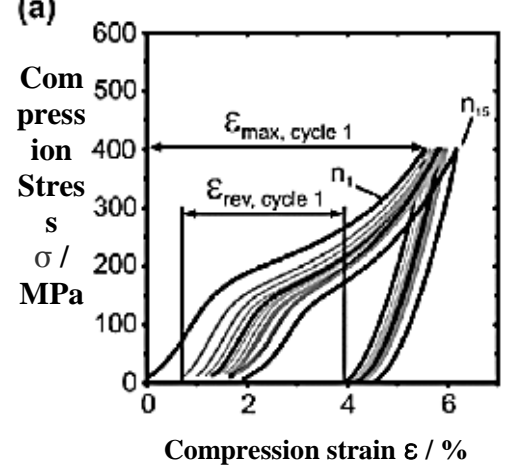

(b)

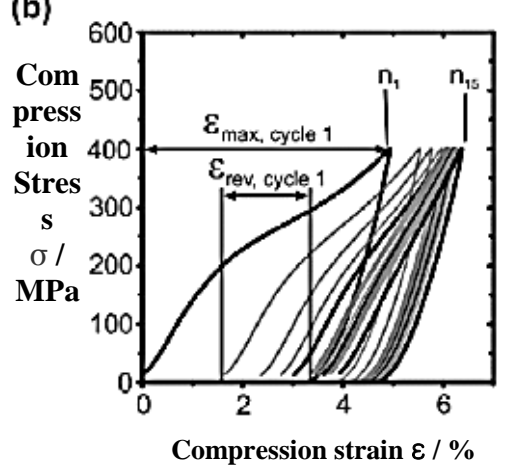

(c)

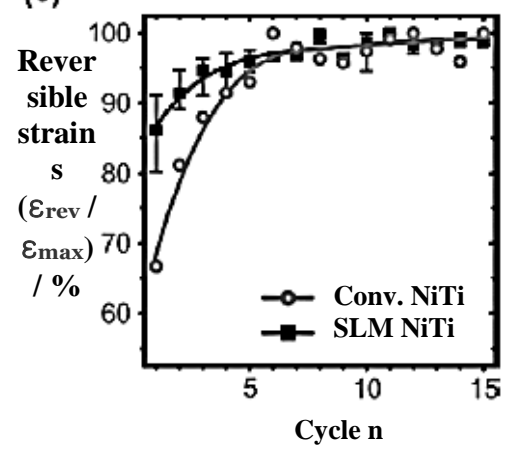

Fig.23. Shape memory behavior: stress-strain curves for a) SLM, and b) conventionally fabricated NiTi; c) the ratio between reversible and maximum strain [13]. 
Meier et al. [14] also investigated the effect of higher level of loading up to $1200 \mathrm{MPa}$, where elastically loading of detwinned martensite is approximately exhausted. The irreversible strain is seen to be higher for the conventional (8.2\%) than the SLM NiTi (5.2\%) under this level of axial loading.

\subsection{Superelasticity Effect (Ni-rich)}

In order for Ni-rich materials to have superelastic behavior, post fabrication heat treatments (i.e., solution annealing and aging) are necessary to tailor transformation temperature and cause superelasticity behavior at the desired temperature (see section 5.2) [91, 92]. This section reviews the effect of postprocess heat treatment conditions on the superelastic behavior of Ni-rich NiTi. Table 5 shows the heat treatment parameters that have been used for Ni-rich AM NiTi so far.

Table.5. Heat treatment parameters achieved by different groups.

\begin{tabular}{|c|c|c|c|c|c|c|}
\hline $\begin{array}{l}\text { Solution Annealing } \\
\text { Temperature }\left({ }^{\circ} \mathrm{C}\right.\end{array}$ & $\begin{array}{l}\text { Solution Annealing } \\
\text { Duration (h) }\end{array}$ & Quenching & $\begin{array}{c}\text { Aging } \\
\text { temperature } \\
\left({ }^{\circ} \mathrm{C}\right)\end{array}$ & $\begin{array}{c}\text { Aging } \\
\text { duration (h) }\end{array}$ & $\operatorname{Af}\left({ }^{\circ} \mathbf{C}\right)$ & Group \\
\hline 950 & 5.5 & $\mathrm{H}_{2} \mathrm{O}$ & 350 & 24 & 58 & $\begin{array}{c}\text { Haberland } \\
\text { et al. [9] }\end{array}$ \\
\hline 950 & 5.5 & $\mathrm{H}_{2} \mathrm{O}$ & 350,450 & 18,10 & 48 & $\begin{array}{c}\text { Saedi } \text { et } \\
\text { al. }[35]\end{array}$ \\
\hline 775 & 10 & Oil & 400,500 & 1 & $46.6,16.5$ & $\begin{array}{c}\text { Halani } \text { et } \\
\text { al. }[49]\end{array}$ \\
\hline
\end{tabular}

It is necessary first to evaluate the superelasticity behavior of additively manufactured versus conventionally fabricated NiTi. Haberland et al. [9, 90] performed studies on SLM Ni-rich samples (Ni50.7Ti). The samples were solution annealed at $950^{\circ} \mathrm{C}$ for $5.5 \mathrm{~h}$ and subsequently water quenched. Then aging treatments were performed at $350^{\circ} \mathrm{C}$ for the duration of $24 \mathrm{~h}$ using a test instrument of type Zwick/Roell Z100. Both heat treated SLM fabricated and conventional samples were tested under cyclic compressive loading-unloading (up to $600 \mathrm{MPa}$ ) at a temperature $10^{\circ} \mathrm{C}$ above the austenite temperature $\left(\mathrm{Af}=87^{\circ} \mathrm{C}\right)$. It is notable that stress-induced phase transformation is completed at $600 \mathrm{MPa}$. As shown in figure 24 the conventional material shows $2.5 \%$ residual strain and $2.8 \%$ reversible strain after the 15 th 
cycle while these values are about $3.3 \%$ and $3.4 \%$ for SLM NiTi, respectively. For both cases, a broad hysteresis with distinct plateaus can be seen in the first cycle while the hysteresis width decreases by increasing the number of cycles as an indication of the degradation of superelastic behavior during cycles. It should be noted that the irreversible strain is highest after the first cycle while this value is decreased for the other cycles. As it can be inferred from figure $24 \mathrm{c}$, the ratio of reversible strain to total strain $\left(\epsilon_{\mathrm{rev}} / \epsilon_{\max }\right)$ of the conventional is marginally higher than SLM NiTi. However, the differences are negligible, and both samples demonstrate the ratio of reversible strain $\left(\epsilon_{\mathrm{rev}} / \epsilon_{\max }\right)$ of $95 \%$ after 15 cycles (See figure 24c).

(a)

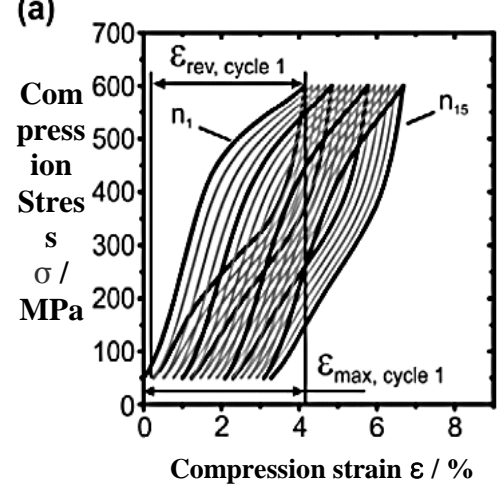

(b)

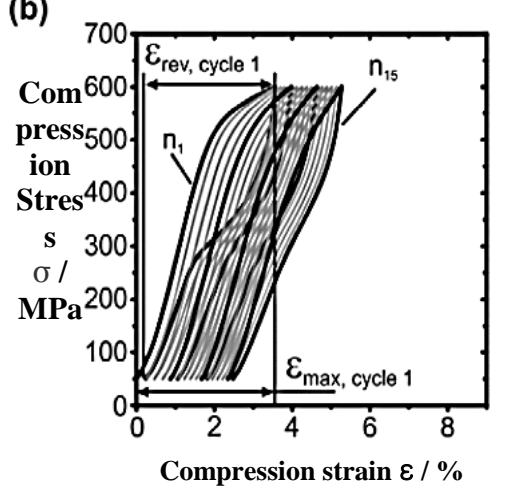

(c)

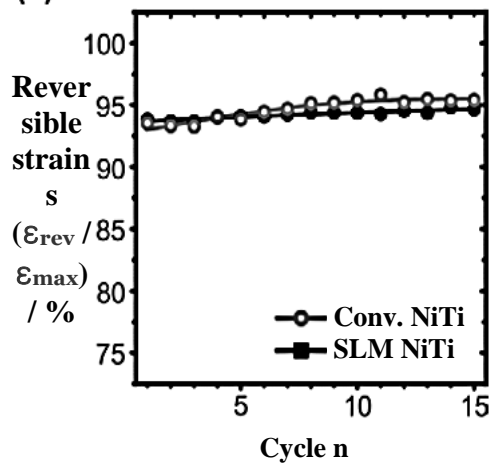

Fig.24. superelasticity behavior: cyclic compressive loading-unloading stress-strain curves for a) heat treated SLM and b) conventionally fabricated $\mathrm{NiTi}$; c) the ratio between reversible and maximum strain. Both samples demonstrate similar reversible strain $\left(\boldsymbol{\varepsilon}_{\text {rev }} / \boldsymbol{\varepsilon}_{\text {max }}\right)$ after 15 cycle [13].

Saedi et al. [87] studied the effect of solution annealing $\left(950^{\circ} \mathrm{C}, 5.5 \mathrm{~h}, \mathrm{H}_{2} \mathrm{O}\right)$ as well as solution annealing plus aging at two different aging conditions $\left(350^{\circ} \mathrm{C}, 18 \mathrm{~h} ; 450^{\circ} \mathrm{C}, 10 \mathrm{~h}\right)$ on the superelasticity behavior of Ni-rich NiTi (Ni50.8Ti). As depicted in figure 25, all four samples demonstrate broad hysteresis with noticeable plateaus in the first cycle. Although the response becomes stable with cycling, the hysteresis decreases and the plateau become indistinguishable. In addition, the residual strain increases with cycling due to the existence of microstructural/textural defects, retained martensitic phase, and resultant plastic deformation. The lowest total residual strain of $2.5 \%$ is observed for the case of solution annealed plus aging at $350^{\circ} \mathrm{C}$ for $18 \mathrm{~h}$ while this value is $7.62 \%, 5.62 \%$, and $4.5 \%$ for as- 
fabricated, solution annealed, and solution annealed plus aging at $450{ }^{\circ} \mathrm{C}$ for $10 \mathrm{~h}$. The reversible strain after $10^{\text {th }}$ cycle is $2.64 \%, 3.42 \%, 4.2 \%$, and $3.8 \%$ for as-fabricated, solution annealed, and solution annealed plus aging at $350^{\circ} \mathrm{C}$ for $18 \mathrm{~h}$, and solution annealed plus aging at $450^{\circ} \mathrm{C}$ for $10 \mathrm{~h}$, respectively.
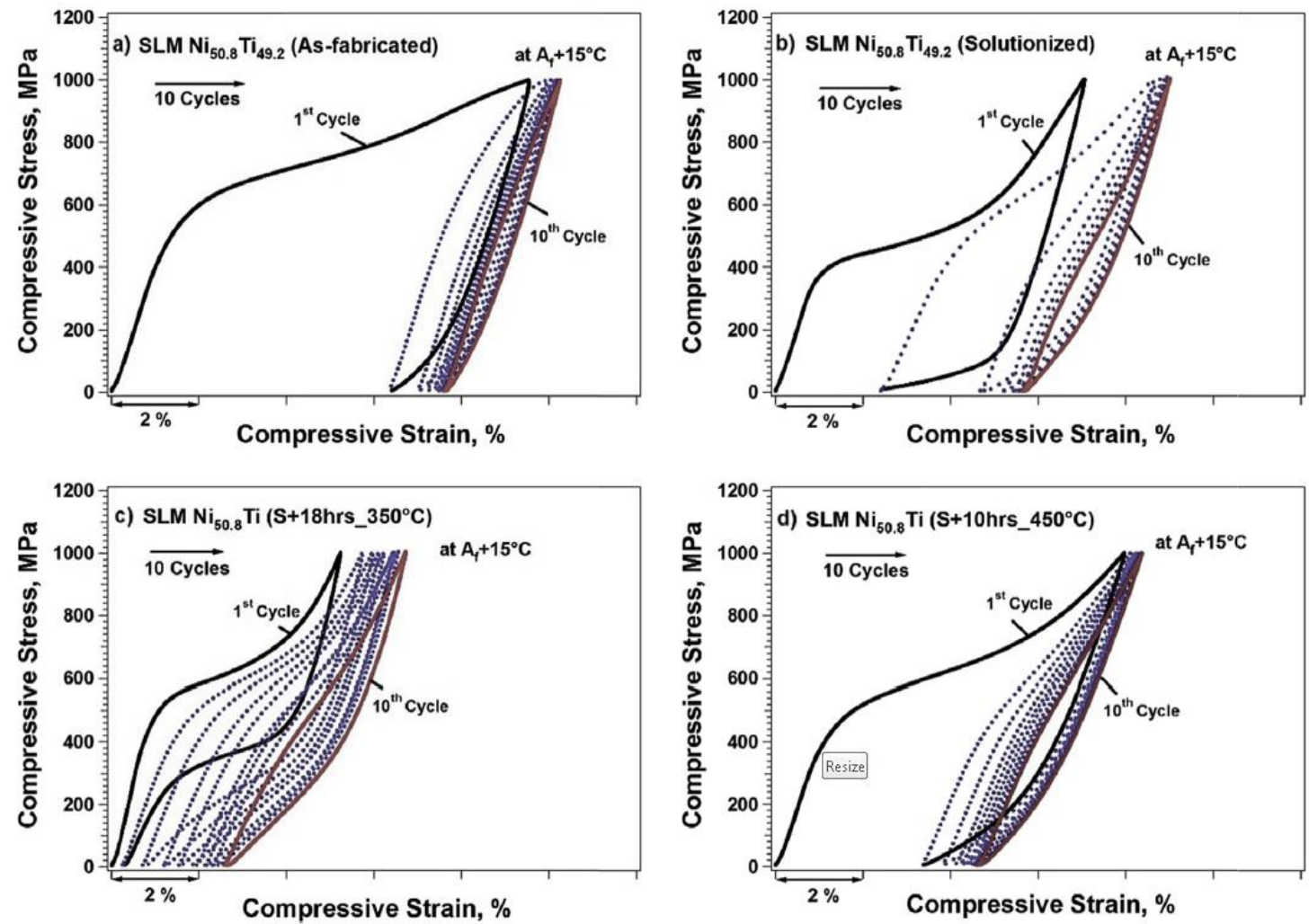

Fig.25. The superelasticity behavior of SLM Ni50.8Ti with cycling for, a) as-fabricated, b) solution annealed, solution annealed and aged at c) $350^{\circ} \mathrm{C}$ for $18 \mathrm{~h}$, and d) $450^{\circ} \mathrm{C}$ for $10 \mathrm{~h}$. the lowest reversible strain is observed after $10^{\text {th }}$ cycle for the sample aged at $350^{\circ} \mathrm{C}$ for $18 \mathrm{~h}[87]$.

Halani et al. [49] studied the effect of aging temperature on the superelasticity behavior of LENS NiTi rods (Elementally blended; Ni55Ti). The rods were first solution annealed at $1050^{\circ} \mathrm{C}$ for $10 \mathrm{~h}$ in an argon atmosphere, and then oil quenched. Subsequent age treatments were performed at two different temperatures of $400^{\circ} \mathrm{C}$ and $500^{\circ} \mathrm{C}$ for one $\mathrm{h}$. The compressive tests up to $1200 \mathrm{MPa}$ were subsequently performed at a temperature above their Af using a MTS Landmark servo hydraulic instrument. According to DSC plots, the associated Af with the aged samples at $400^{\circ} \mathrm{C}$ and $500^{\circ} \mathrm{C}$ are $46.6^{\circ} \mathrm{C}$ and $16.5^{\circ} \mathrm{C}$, 
respectively. The recoverable strain for aging at $400^{\circ} \mathrm{C}$ showed to be $2 \%$ while this amount is increased to $3 \%$ for the aging at $500^{\circ} \mathrm{C}$.

\section{Mechanical Properties}

\subsection{Hardness and corrosion resistance}

Due to the rapid cooling associated with AM techniques, the resulting parts have increased residual stress, the formation of martensitic $\alpha^{\prime}$ grains, grain refinement and consequently the additional hardening of the NiTi matrix. If the optimum set of parameters is used to produce a crack and pore free structure, the high residual streeses can enhance the microhardness significantly $[10,74,91]$. As reported by Shishkovsky et al. [10], the microhardness of SLM processed NiTi is 1.5-2 times greater than the conventional casting NiTi. It is worth noting that less ductility is expected due to the increasing microhardness [51].

Different factors might contribute to the microhardness level of AM NiTi, including manufacturing type (e.g., SLM, LENS), material composition, post heat treatments and laser parameters. For the same material composition (Elementally blended; Ni55Ti), SLM processed NiTi demonstrates a higher level of microhardness versus LENS processed. These values are approximately 540-735 HV versus $380 \mathrm{HV}$, as reported by Shishkovsky et al. [10] and Shiva et al. [51].

The average microhardness is more for NiTi samples with a higher level of Ti content, and it is due to the formation of $\mathrm{NiTi}_{2}$ that results in the increased hardness $[51,92]$. These values are reported by Shiva et al. [51] to be 380, 440 and $525 \mathrm{HV}$ for elementally blended Ni55Ti, Ni50Ti, and Ni45Ti, respectively.

Saedi et al. [35] used SLM Ni-rich NiTi samples to investigate the effect of post heat treatments, i.e., solution annealing $\left(950{ }^{\circ} \mathrm{C}, 5.5 \mathrm{~h}, \mathrm{H}_{2} \mathrm{O}\right)$ and subsequent aging $\left(350^{\circ} \mathrm{C}\right.$ and $18 \mathrm{~h}$, and $450{ }^{\circ} \mathrm{C}$ for $\left.10 \mathrm{~h}\right)$. The Vicker's hardness tests were performed at room temperature, therefore, one should note that the samples do not have similar phases. As depicted in figure 26, the hardness of SLM fabricated NiTi (224 
$\mathrm{HV})$ is dramatically lower than the original ingot (278 HV), however solution annealing compensates this dramatic decrease of hardness to a level even more than that of initial ingot $(278 \mathrm{HV} \rightarrow 288 \mathrm{HV})$. This is attributed to the fact that solution annealing solve the brittle $\mathrm{Ni}_{4} \mathrm{Ti}_{3}$ precipitates that results in reduction of brittlity. Subsequent aging is also shown to gradually increase the hardness from $288 \mathrm{HV}$ into $345 \mathrm{HV}$ with aging for $18 \mathrm{~h}$ at $350^{\circ} \mathrm{C}$ and into $330 \mathrm{HV}$ at $450^{\circ} \mathrm{C}$. It is notable that the hardness of aged NiTi at $350^{\circ} \mathrm{C}$ are higher (up to $54 \mathrm{HV}$ ) than those aged at $450^{\circ} \mathrm{C}$.

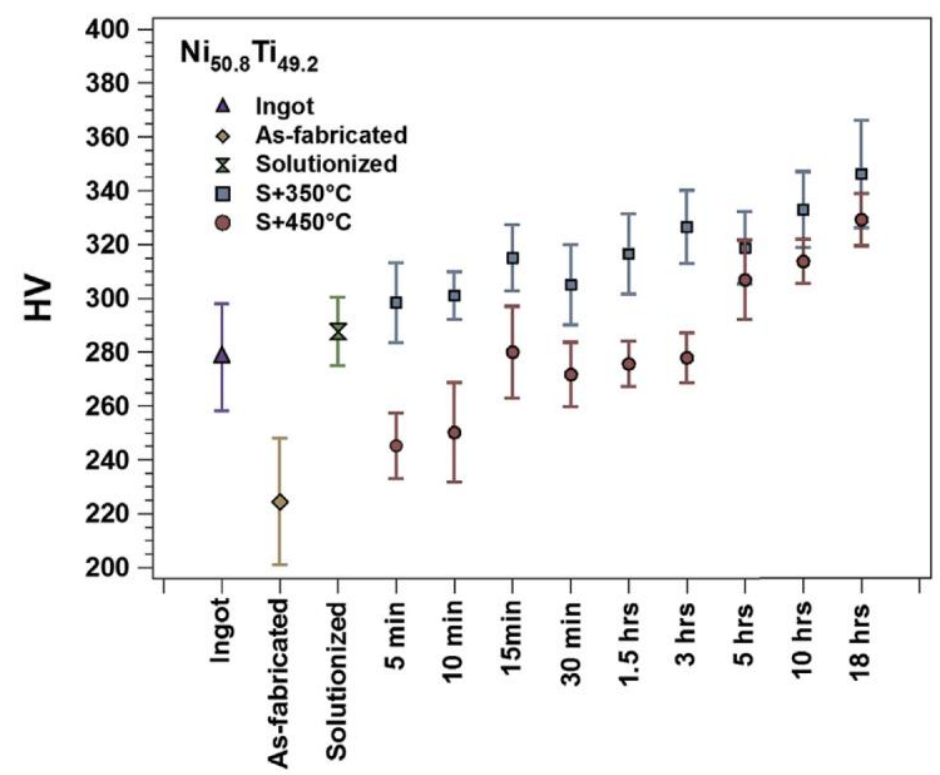

Fig.26. The effect of post heat treatments on the Vicker's hardness of SLM Ni-rich NiTi (Ni50.2Ti). The results show elevated hardness as the result of solution annealing as well as aging time. Aging at $350^{\circ} \mathrm{C}$ shows higher hardness versus $450^{\circ} \mathrm{C}[35]$.

According to Marattukalam et al. [53], the hardness of LENS processed NiTi (Ni50.05Ti) is increased by the adoption of higher laser powers. However, it can be observed that the resulting hardness of NiTi parts is decreased marginally by increasing scanning velocity (See figure 27a).

The increased microhardness of NiTi resulted from increased energy input (i.e., higher laser power and lower scanning speed) also enhances the corrosion resistance [53]. The reason is that the increased energy input results in the reduction of grain boundaries (i.e., discontinuities in the regular atomic structure of a crystal). Grain boundaries are the most favorite place for the precipitates and 
impurities nucleation, and the reduction of grain boundaries obviously decrease the corrosion rate [53, 93, 94].

The corrosion rate (C.R.) of metals can be obtained directly from the following equation [95]:

$$
\text { C. R. }=\frac{0.13 \mathrm{I}_{\text {corr }}(E . W .)}{d}
$$

Where

C.R.= corrosion rate, mpy (milli-inches per year)

Icorr $=$ corrosion current density, $\mu \mathrm{A} / \mathrm{cm}^{2}$

E.W.= equivalent weight of the corresponding species, $g$

$\mathrm{d}=$ density, $\mathrm{g} / \mathrm{cm}^{3}$

Marattukalam et al. [53] investigated the effect of changing laser power ( $\mathrm{P}=200-400$ Watt) as well as scanning speed $(\mathrm{v}=10-20 \mathrm{~mm} / \mathrm{s})$ on the corrosion current density (Icorr) and the corrosion rate (C.R.) of LENS NiTi samples. Icorr values were first estimated using a three-electrode electrochemical system, and subsequently, and the corrosion rate values were then calculated using the equation above. The results depicted in figure 27b-c demonstrate a reduction in corrosion rate as the energy input increases (i.e., increase in laser power and/or decrease in scanning velocity).
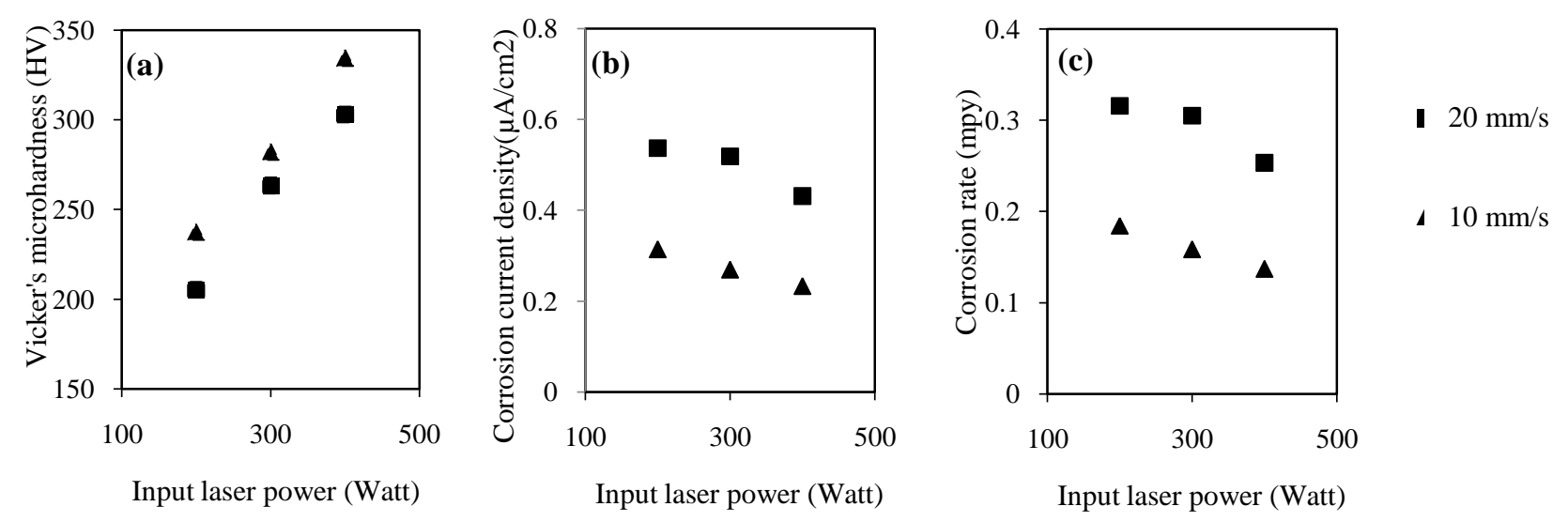

Fig. 27. The effect of LENS processing parameters on (a): Vicker's microhardness, (b) corrosion current density (Icorr), and (c) corrosion rate (C.R.) of NiTi parts fabricated [53]. 


\subsection{Compressive strength}

To compare the mechanical properties of AM NiTi and conventional NiTi, different groups have performed compressive testing on the Ti-rich as well as Ni-rich samples fabricated by various orientations (See Tables 7 and 8). Meier et al. [14] used Ti-rich (Ni50.2Ti) with different orientations as well as conventional NiTi to evaluate the compressive behavior of SLM fabricated NiTi. All the samples were loaded at $\mathrm{T}=20^{\circ} \mathrm{C}\left(\mathrm{T}<\mathrm{A}_{\mathrm{s}}=50^{\circ} \mathrm{C}\right)$ until failure using a compression test instrument of type Zwick/Roell Z100. It is notable that the samples were inserted into ice water to ensure they are fully martensite state $\left(\mathrm{Mf}=12^{\circ} \mathrm{C}<\mathrm{T}\right)$. The results showed that the fabrication orientation does not have a significant effect on the compressive behavior of these samples (Table 7 and figure 28). The reason is that the localized defects (e.g., small pores and particles) in the sensitive regions (i.e., the interface between the layers) are collapsed during the compression and they do not play a critical role on the failure (It should be noted that these regions could be of great importance for failure under tensile loading [27]). The results also demonstrated that the compressive behavior of Ti-rich SLM is comparable to conventional NiTi; however, the failure of SLM occurs at lower stress levels (up to $750 \mathrm{MPa}$ ) compare to the initial crack formation of conventional one [14].

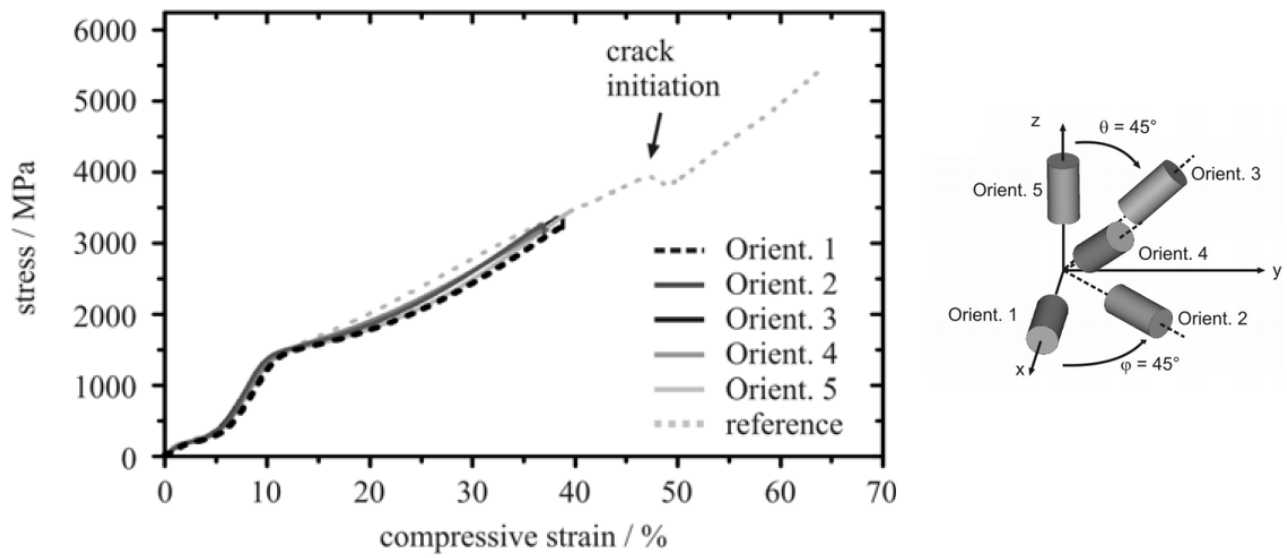

Fig.28. Stress-strain curves of SLM Ti-rich NiTi until failure for different directions (right) as well as the conventional NiTi until crack initiation. The fabrication orientation does not show significant effect on the compressive behavior. The failure of SLM occurs sooner than the crack initiation in conventional [14]. 
Table. 7. Mechanical behavior of SLM and conventional Ti rich (Ni50.2Ti)for compressive loading up to failure [14].

\begin{tabular}{|c|c|c|c|c|c|}
\hline & & $\begin{array}{c}\text { Plateau start } \\
(\mathrm{MPa})\end{array}$ & $\begin{array}{c}\text { Yield stress } \\
(\mathrm{MPa})\end{array}$ & $\begin{array}{c}\text { Fracture } \\
\text { stress (MPa) }\end{array}$ & $\begin{array}{r}\text { Fracture } \\
\text { strain }(\%)\end{array}$ \\
\hline \multirow{6}{*}{$\begin{array}{c}\text { orient. } 1 \\
\text { orient. } 2 \\
\text { orient. } 3 \\
\text { orient. } 4 \\
\text { orient. } 5 \\
\text { reference }\end{array}$} & SLM & $155-168$ & $1400-1420$ & $3245-3343$ & $39-40$ \\
\hline & SLM & $165-166$ & $1400-1420$ & 3256-3349 & $37-39$ \\
\hline & SLM & $157-160$ & $1400-1420$ & $3231-3403$ & $39-40$ \\
\hline & SLM & $148-160$ & $1400-1420$ & $3209-3366$ & $37-39$ \\
\hline & SLM & $159-167$ & $1400-1420$ & $3458-3469$ & $40-42$ \\
\hline & Conventional & 191-210 & $1400-1420$ & $3942-3975 *$ & $47 *$ \\
\hline
\end{tabular}

* The initiation of the first crack

In another study, Haberland et al. [9] used Ni-rich (Ni55.88Ti) specimens with different orientations to explore the effect of orientation on the compressive properties of superelastic NiTi. Using a compression instrument of type Zwick/Roell Z100, the SLM and conventional samples were tested until failure at $\mathrm{T}=72^{\circ} \mathrm{C}\left(\mathrm{SLM}\right.$ : $\left.\mathrm{T}>\mathrm{A}_{\mathrm{f}}=62^{\circ} \mathrm{C}\right)$ and $\mathrm{T}=17^{\circ} \mathrm{C}\left(\right.$ Conventional: $\left.\mathrm{T}>\mathrm{A}_{\mathrm{f}}=7^{\circ} \mathrm{C}\right)$, respectively. Again, for Nirich specimens all the SLM samples disregard of the orientation show similar behavior to each other (Table 8 and figure 29). However, these as-fabricated materials need to undergo further post-process heat treatments (i.e., solution annealing and aging) in order to acquire superelasticity behavior similar to conventional NiTi, otherwise, they exhibit slightly different behaviors such as a longer plateau region, a flatter curve, and a lower failure stress (Figure 29).

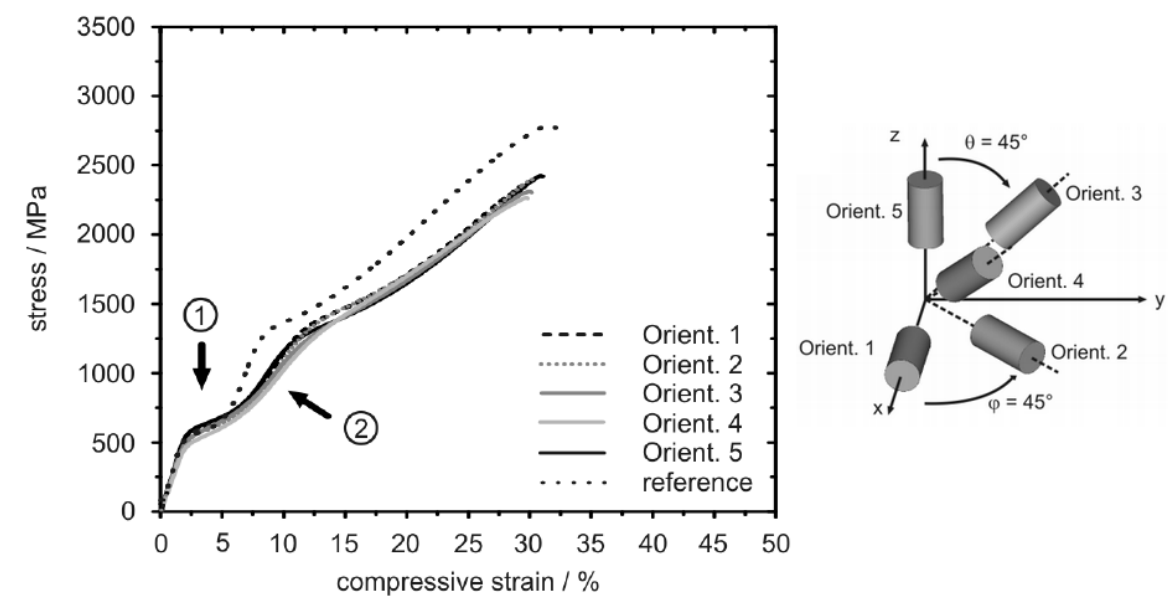


Fig.29. Stress-strain curves of SLM Ni-rich NiTi until failure for different directions (right) as well as the conventional NiTi. The samples fabricated with different orientations show similar behavior, but different from conventional NiTi [9].

In their study, the as-fabricated samples were first solution annealed at $950^{\circ} \mathrm{C}$ for $5.5 \mathrm{~h}$ and then water quenched. As it is shown in figure 30, solution annealing changes the behavior of the untreated SLM samples towards showing a more flat loading curve (versus steep curve), and greater stress and strain at failure. In addition, the resultant plateau region is hardly visible. These observations are attributed to the fact that solution annealing dissolves the nucleated brittle $\mathrm{Ni}_{4} \mathrm{Ti}_{3}$ precipitates previously formed in the SLM processed parts. Generally, the precipitates acts as osbtacles for plasticity deformation within the crystal, and therefore, the lack of precipitate hardening allows for more stress and strain at fracture (See more details in section 5.2).

It can be infered from the figure 30 that all aged samples demonstrate plateu regions which are the indication for stress induced martensite. Generally, subsequent aging is associated with the formation of a large number of Ni-rich precipitates (e.g., Ni4Ti3) that hinder the plasticity deformation and results in the reduction in fracture strain and stress. As it was fully explained in section 5.2, aging condition influence the resultant size and distribution of Ni-rich precipitates, where finely dispersed precipitates ensure fully recovery of the material after unloading. The lowest values for fracture stress and strain are observed as the result of the subsequent mild aging $\left(350^{\circ} \mathrm{C}, 24 \mathrm{~h}\right)$. It is interesting that the increased aging conditions (i.e., aging temperature and period) enhances the material behavior towards a more ductile curve as well as higher values for fracture stress and strain. The reason is that increased aging conditions cause a reduced amount of dispersed precipitates in broader areas which do not act as obstacles in dislocation plasticity (See more details in section 5.2) [9]. 


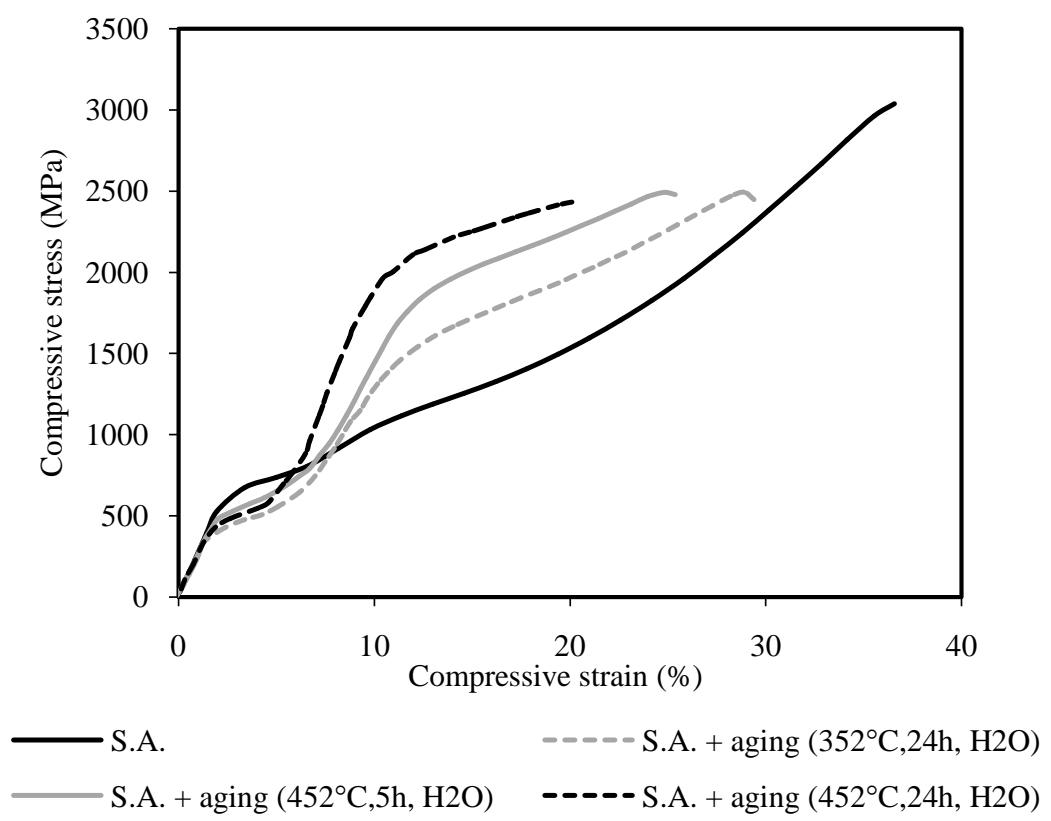

Fig.30. Stress-strain curves of SLM Ni-rich NiTi until failure for solution annealed as well as aged NiTi. Solution annealing increase stress and strain at failure while degrading the plateau. Subsequent aging visibly shows plateau, but smaller stress and strain at failure [9]

Table. 8. Mechanical behavior of SLM and conventional Ni-rich NiTi (Ni50.7Ti) for compressive loading up to failure.

\begin{tabular}{|c|c|c|c|c|c|c|}
\hline & & & $\begin{array}{l}\text { Plateau start } \\
\text { (MPa) }\end{array}$ & $\begin{array}{c}\text { Yield stress } \\
(\mathrm{MPa})\end{array}$ & $\begin{array}{c}\text { Fracture } \\
\text { stress (MPa) }\end{array}$ & $\begin{array}{c}\text { Fracture } \\
\text { strain }(\%)\end{array}$ \\
\hline \multirow{5}{*}{ As-received } & \multirow{5}{*}{$\begin{array}{c}\text { orient.1 } \\
\text { orient.2 } \\
\text { orient.3 } \\
\text { orient.4 } \\
\text { orient.5 }\end{array}$} & SLM & $478-550$ & 1246-1338 & 2291-2363 & $30.0-30.4$ \\
\hline & & SLM & $524-578$ & $1246-1338$ & 2193-2402 & $27.7-30.4$ \\
\hline & & SLM & $471-514$ & $1246-1338$ & $2309-2362$ & $30.1-30.6$ \\
\hline & & SLM & $472-588$ & $1246-1338$ & $2257-2720$ & 29.9-32.7 \\
\hline & & SLM & $466-576$ & $1246-1338$ & $2422-2631$ & $31.1-32.3$ \\
\hline \multicolumn{2}{|c|}{$\mathbf{S A}$} & SLM & 589-738 & $1060-1100$ & 2994-3037 & $36.7-37.2$ \\
\hline \multirow{2}{*}{\multicolumn{2}{|c|}{$\begin{array}{c}\mathrm{SA}+\mathrm{A}\left(350^{\circ} \mathrm{C}, 24 \mathrm{~h}, \mathrm{H} 2 \mathrm{O}\right) \\
\mathrm{SA}+\mathrm{A}\left(450^{\circ} \mathrm{C}, 5 \mathrm{~h}, \mathrm{H} 2 \mathrm{O}\right)\end{array}$}} & SLM & $441-444$ & $2030-2100$ & $2447-2449$ & $18.5-21.1$ \\
\hline & & SLM & $472-486$ & $1800-1880$ & $2365-2494$ & $25.4-25.6$ \\
\hline \multirow{2}{*}{\multicolumn{2}{|c|}{$\begin{array}{c}\mathrm{SA}+\mathrm{A}\left(450^{\circ} \mathrm{C}, 24 \mathrm{~h}, \mathrm{H} 2 \mathrm{O}\right) \\
\text { reference }\end{array}$}} & SLM & 411 & $1416-1500$ & 2496 & 29.1 \\
\hline & & Conventional & 523 & $1312-1350$ & 2793 & 32.1 \\
\hline
\end{tabular}

$\mathrm{SA}=$ Solution annealed; $\mathrm{A}=$ Aged.

Saedi et al. [35] also studied the effect of solution annealing $\left(950^{\circ} \mathrm{C}, 5.5 \mathrm{~h}, \mathrm{H}_{2} \mathrm{O}\right)$, and subsequent aging $\left(350^{\circ} \mathrm{C}\right.$ and $450^{\circ} \mathrm{C} ; 5,10$, and $\left.18 \mathrm{~h}\right)$ on the mechanical behavior of SLM Ni-rich NiTi (Ni50.8Ti) in terms of critical stresses at plateau start (i.e., the indication for stress induced martensitic transformation) and yield stress (i.e., the indication for initiation of plastic deformation). The compression tests were performed at $15^{\circ} \mathrm{C}$ higher than the samples $\mathrm{A}_{\mathrm{f}}$ temperatures using $100 \mathrm{kN}$ MTS Landmark servo-hydraulic 
test platform under $2000 \mathrm{MPa}$ loading. As it is shown in figure 31, the subsequent aging increases the yield stress of solution treated samples by approximately $700 \mathrm{MPa}$, but the aging condition does not show significant effect. These observations are due to the precipitate hardening (Aging hardening) effect (See more details in section 5.2). In addition, aging at $350^{\circ} \mathrm{C}$ offers marginally higher values (about $100 \mathrm{MPa}$ ) for stress induced martensitic transformation, in comparison with the aging at $450^{\circ} \mathrm{C}$.

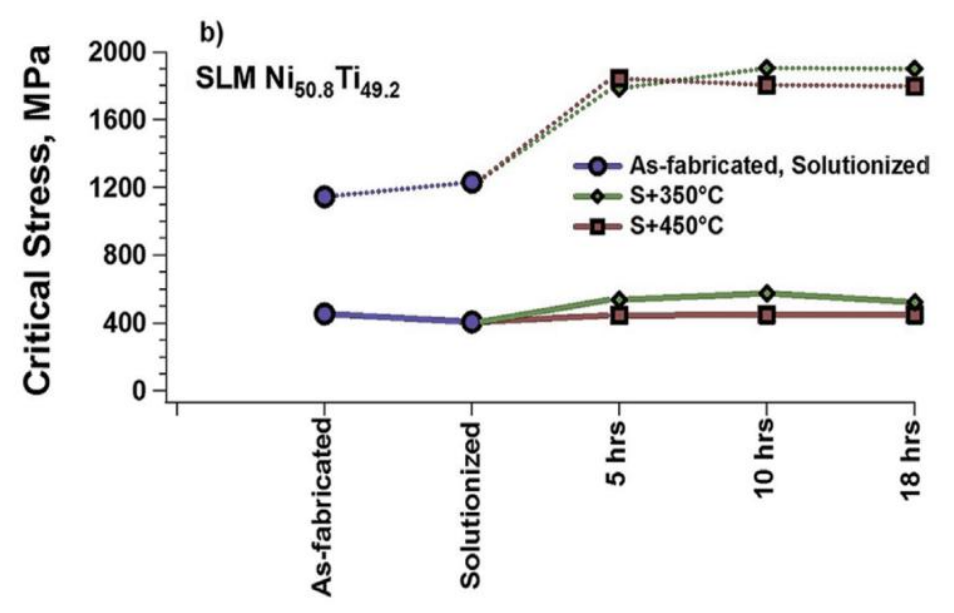

Fig.31. Critical stress values at plateau start (solid line) and yield stress (dashed line). Aging significantly increase the yield stress while aging condition is not that important [35].

In addition to fabrication orientation and post-process heat treatment, additively manufactured parts are also sensitive to laser power and scan speed due to the complicated melting process and subsequent rapid solidification. Haberland et al. [13] showed that the increased energy density from 92 to $195 \mathrm{~J} / \mathrm{mm}^{3}$ increases the failure stress and strains of SLM Ni50.2Ti from 1700 to $3200 \mathrm{MPa}$ and from 27 to $38 \%$, respectively. Using same material composition but LENS technique, Krishna et al. [46] observed a lower level of fracture stress in the range of 890-1050 MPa. Therefore, it can be inferred that SLM technique produce stronger NiTi structure with higher values for fracture stress.

\subsection{Fatigue Behavior}


Fatigue failure is one of the principal modes of failure of dense and especially porous NiTi. Transformation temperature, microstructure defects, loading type, austenitic and martensitic strength, volume fraction and the existence of unwanted secondary phases are a few factors that affect the fatigue behavior of NiTi [96].

Bernard et al. [55] studied the high cyclic compression fatigue behavior of LENS fabricated dense Ni50Ti parts using a servohydraulic materials test system machine with $250-\mathrm{kN}$ capacity. Fatigue tests were conducted on NiTi samples at $15 \mathrm{~Hz}$ with a stress ratio $(\mathrm{R})$ of 0.1 up to $10^{6}$ cycles unless the samples undergo failure sooner. The samples with having different porosities were stressed under cyclic loading at several values of their corresponding maximum compressive yield stress (i.e., $\mathrm{S}_{\mathrm{y}}, 1.2 \mathrm{~S}_{\mathrm{y}}, 1.4 \mathrm{~S}_{\mathrm{y}}$, and $\left.1.5 \mathrm{~S}_{\mathrm{y}}\right)$. The results showed that none of the samples were fractured, which means that these samples can sustain at least 1.5 times of their yield strength up to $10^{6}$ cycles without failure. Additionally, all the samples undergo an initial permanent strain until it reaches a constant value after a certain number of cycles. The increased applied stress causes the samples to undergo increased permanent deformation. However, it should be noted that these accumulated strains are considered small. Figure 32 compares the permanent deformation of the three samples with different porosities when they undergo $100 \%, 120 \%$, $140 \%$, and $150 \%$ of their respective yield strength. The results show that the permanent deformation decrease as the porosity increase (It should be noted that the comparison is not based on a similarly applied stress, but it is based on the same ratio of each sample's maximum yield strength). 


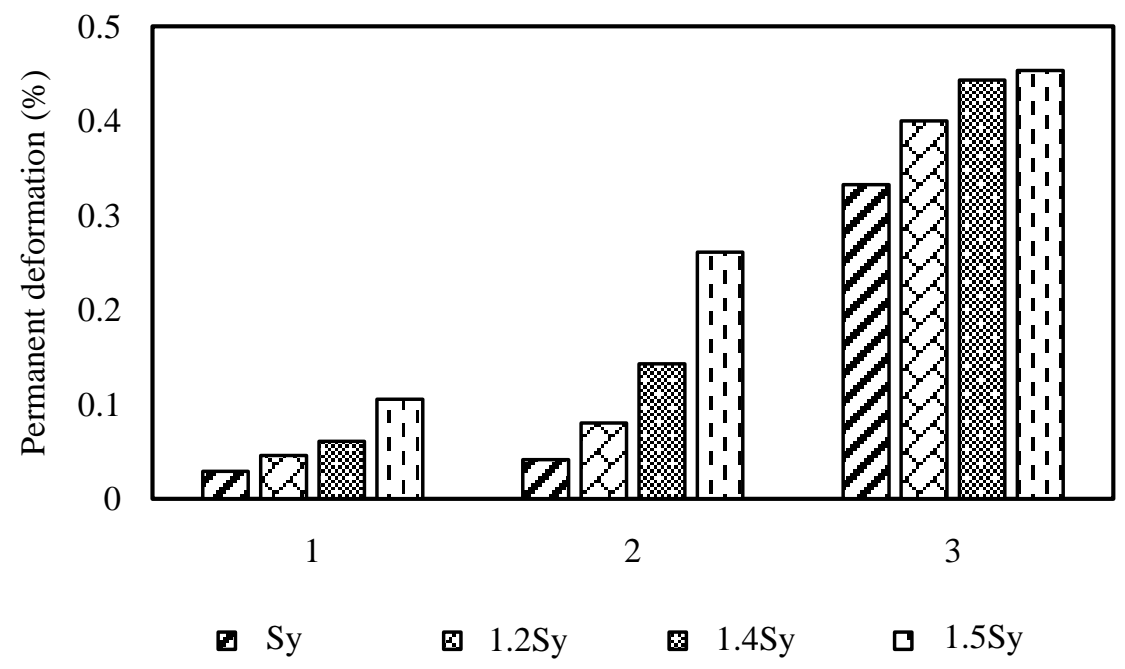

Fig.32. The effect of stress amplitude on maximum strain accumulation at $10^{6}$ cycles of NiTi samples with different porosities (The values of Sy are 368 $\pm 60,656 \pm 84$, and $971 \pm 20$ for $80 \%, 90 \%$ and fully dense, respectively.) [55].

\subsection{Damping properties}

Damping capacity is the material capability to dissipate the sudden shocks and oscilations. It is a crucial factor in different applications including medical devices (e.g., dental and spinal implants) and automative industry (e.g., damper) [97]. De Wild et al. [30] studied the damping properties of SLM and conventional NiTi with similar material composition (Ni50.2Ti). The vibration technique used in this study to measure damping ratios is the using of a cantilever beam and it is based on the exciting of beam into its fundamental mode of flexural vibration $(1.5-3 \mathrm{~mm})$. In this way, the damping ratio, $\xi$, can be calculated through measuring and analyzing the decay of the amplitude while tracking a sinusoidal motion during a certain period of time $(0.4 \mathrm{~s})$. Since it is hypothesized that the damping of NiTi is phase dependent, the tests were carried out inside a temperature-controllable chamber and the damping ratios were measured at 16 various temperatures, while changing the temperature of the chamber continuously from $-20^{\circ} \mathrm{C}$ to $50^{\circ} \mathrm{C}$ (This temperature range include the phase transformation during heating). As shown in figure 33, the temperature range is divided into three different zones that approximately demonstrate 
regions of fully Martensite ( $\mathrm{Mf}<\mathrm{T}<\mathrm{As}$ ), Martensite to austenite (As $<\mathrm{T}<\mathrm{Af}$ ), and Austenite (Af $<\mathrm{T})$. The maximum damping ratio up to 0.04 is seen for both conventional and SLM NiTi. It can also be inferred that damping properties are dependant to the Ni-Ti phases, and it is significantly higher for the martensite phase $(\mathrm{SLM}$ NiTi= $0.041 \pm 0.004$, conventional NiTi: $0.038 \pm 0.004)$ compared to austenite $(\mathrm{SLM}$ NiTi= $0.003 \pm 0.004$, conventional $\mathrm{NiTi}=0.002 \pm 0.004)$.

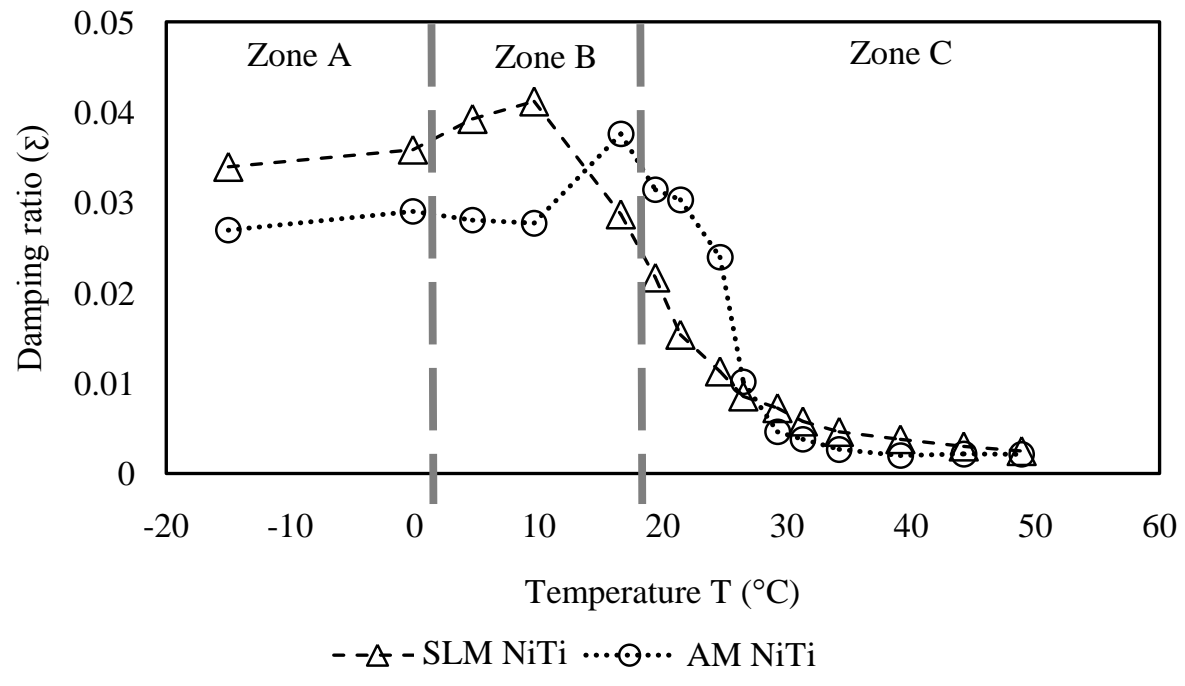

Fig.33. The damping properties comparison between SLM and conventionally fabricated NiTi [30]. Zone A: Martensite; Zone B: Martensite to austenite; Zone C: Austenite.

\section{AM enables the production of porous NiTi}

Additive manufacturing (AM) has recently been of great interest for producing complicated porous NiTi structures. Porosity within the scaffold can be achieved either through decreasing the energy input (i.e., decreasing laser power, increasing scanning speed, and increasing hatch distance) or via imposing engineered porosity via CAD file. Table 8 summarizes the work of different groups on fabricating porous NiTi.

Table.8. List of current publications on laser-based AM techniques to produce porous NiTi either by changing lase parameters (LP) or be designed porosity (CAD) 


\begin{tabular}{|c|c|c|c|c|c|c|c|c|c|c|}
\hline $\mathbf{A M}$ & $\begin{array}{c}\text { Effective } \\
\text { laser } \\
\text { power }(W \\
\end{array}$ & $\begin{array}{c}\text { Scanning } \\
\text { velocity } \\
(\mathbf{m m} / \mathbf{s}) \\
\end{array}$ & $\begin{array}{c}\text { Hatch } \\
\text { distance } \\
(\mu \mathrm{m}) \\
\end{array}$ & $\begin{array}{c}\text { Layer } \\
\text { thickness } \\
(\mu \mathrm{m}) \\
\end{array}$ & $\begin{array}{c}\text { Energy } \\
\text { input } \\
\left(\mathrm{J} / \mathbf{m m}^{3}\right) \\
\end{array}$ & $\begin{array}{l}\text { Pore } \\
\text { shape }\end{array}$ & $\begin{array}{c}\text { Percentage } \\
\text { porosity } \\
(\%) \\
\end{array}$ & $\begin{array}{l}\text { Pore } \\
\text { size } \\
(\mu \mathrm{m}) \\
\end{array}$ & $\begin{array}{l}\text { Powder } \\
\text { size } \\
(\mu \mathrm{m}) \\
\end{array}$ & Author \\
\hline \multicolumn{11}{|c|}{ Porosity via energy } \\
\hline SLM & 77 & 200 & $120-400$ & 50 & 70.2 & Lattice & 12.5 & - & $45-110$ & $\begin{array}{l}\text { Habijan } e t \\
\text { al. [21] }\end{array}$ \\
\hline SLM & $30-90$ & $40-640$ & - & 75 & & $\begin{array}{l}\text { Lattice/ } \\
\text { Irregular }\end{array}$ & Up to 38 & 500 & $45-110$ & $\begin{array}{c}\text { Meier } \\
\text { et al. } \\
{[27,28]}\end{array}$ \\
\hline LENS & $150-200$ & $10-20$ & 762 & 50 & - & Irregular & $12-36$ & 500 & $50-150$ & $\begin{array}{l}\text { Krishna et } \\
\text { al. [47] }\end{array}$ \\
\hline \multicolumn{11}{|c|}{ Porosity via CAD } \\
\hline SLM & 40,250 & $0.160,1.1$ & 75,60 & 30 & 111,126 & $\mathrm{BCC}$ & - & 1000 & $24-45$ & $\begin{array}{l}\text { Speirs et } \\
\text { al. }[43]\end{array}$ \\
\hline SLM & 77 & 200 & 120 & 50 & 70.2 & Lattice & 34.5 & 500 & $45-110$ & $\begin{array}{l}\text { Habijan et } \\
\text { al. [21] }\end{array}$ \\
\hline SLM & 56 & 133 & 120 & - & 50 & $\mathrm{BCC}$ & 84 & - & $35-75$ & $\begin{array}{l}\text { Hoffmann } \\
\text { et al. }[34]\end{array}$ \\
\hline SLM & 250 & 1250 & 120 & - & 30 & $\begin{array}{l}\text { Three } \\
\text { bars }\end{array}$ & Up to 58 & - & $25-75$ & $\begin{array}{c}\text { Taheri } \\
\text { Andani et al. } \\
{[68]}\end{array}$ \\
\hline SLM & 250 & 1250 & 120 & - & 30 & $\begin{array}{c}\text { BCC/ } \\
\text { BCC-Z }\end{array}$ & 69 & - & $25-75$ & $\begin{array}{c}\text { Karamooz } \\
\text { Ravari et al. } \\
{[98]}\end{array}$ \\
\hline SLM & 90 & 115 & 67.5 & 20 & 580 & NPR & - & - & $\sim 22$ & $\begin{array}{l}\text { LI et al. } \\
\text { [81] }\end{array}$ \\
\hline
\end{tabular}

According to Meier et al. [27, 28], the introducing porosity via varying the laser power and scanning speed results in the formation of irregular pores while increasing the hatch distance creates lattice-like pores. It should, however, be noted that there is a limitation on the possible resultant pore shapes and levels of the porosity. On the other hand, the pore size, shape and distribution can be controlled via imposing engineered porosity. Moreover, higher level of porosity can be achieved within the structure [38]. Figure 34 present a few NiTi structures that have been fabricated via AM. 


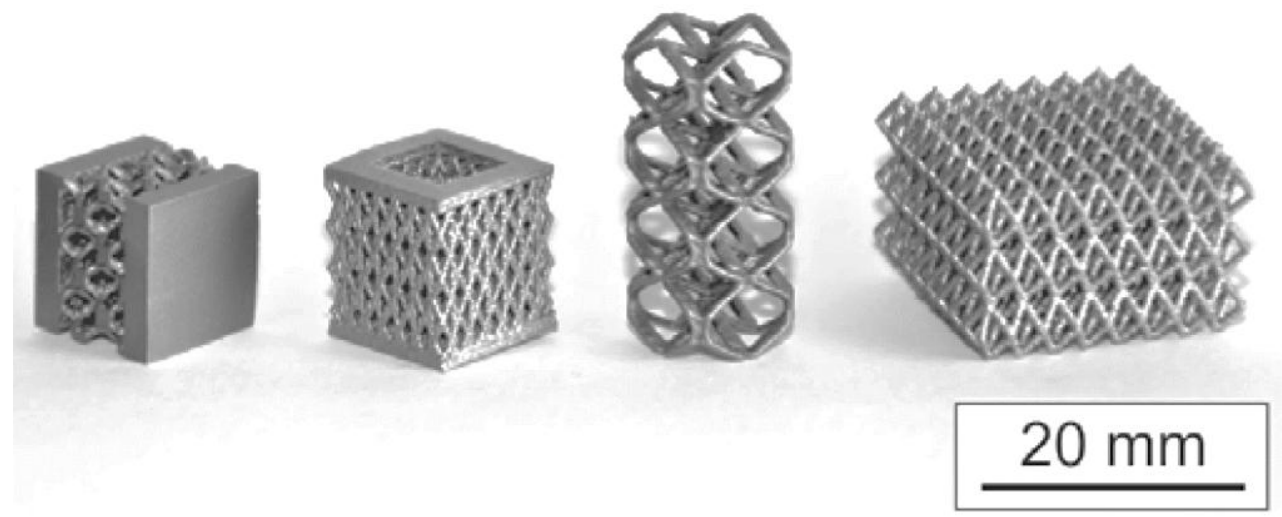

Fig.34. Complex NiTi structures produced by AM technique [16].

\subsection{Biomedical considerations}

Porous NiTi are being studied to be used in biomedical applications because they present superelasticity behavior similar to bone, high bone growth through the interconnecting pores, low tunable stiffness (i.e., modulus of elasticity), and capillary properties [4, 95]. Although the biomedical considerations are well understood on porous NiTi fabricated with conventional NiTi $[4,6,99,100]$, a few studies have been conducted on AM NiTi.

Ni-release has been introduced as one of the critical issues for the scaffolds targeted to be used inside the body, and, therefore, it is preferable to minimize the level of Ni release. According to Habijan et al. [21], porous NiTi fabricated by large hatch distance are associated with high number of adherent particles and also high level of $\mathrm{Ni}$ release when compared to porous NiTi via CAD file. In their experiment, two types of porous NiTi via SLM technique were fabricated, one with increasing the hatch distance from $120 \mu \mathrm{m}$ to $400 \mu \mathrm{m}$ (12.5\% porosity), and one with introducing an engineered porosity with the lattice pore width of $500 \mu \mathrm{m}$ within the CAD file (34.5\% porosity). Although it was expected to see higher Ni release for the more porous sample regardless of the technique of creating pores, the cell culture experiments show significantly higher level of Ni release for the porous NiTi with large hatch distance ( $12.5 \%$ porosity via hatch: $775.2 \mathrm{ng} / \mathrm{ml}$, and 34.5 porosity via CAD: $257.2 \mathrm{ng} / \mathrm{ml}$ ). It is notable that both 
porous samples demonstrate nickel ion release significantly lower than cytotoxic concentrations (25e6 $\mathrm{ng} / \mathrm{ml})$.

Habijan et al. [21] also cultivated the implant by hMSC (i.e., human mesenchymal stem cells) cells for 8 days to study the viability and adherence of the cells into the implant. Using a fluorescence microscopy as well as a live/dead staining, a lot of viable cells were detected both on the surface of the porous implants as well as inside the pores. To study the adherence of the hMSC into the implant, the level of cytokine (i.e., IL-6, IL-8, and VEGF) released by hMSC were measured. The results showed the allowable level of cytokine release below the control values which ensure the adherence of hMSC into the implant overtime.

\subsection{Optimum laser parameters to produce engineered porous AM NiTi}

Ideally, the struts within the porous structure should have the characteristics of a dense NiTi with minimal structural defects [101]. Therefore, to fabricate engineered porosity, it is important that the laser parameters (e.g., laser power-P, scanning speed-v, hatch distance-h, layer thickness-t) that are chosen to fabricate engineered porous parts should be able to process dense parts as well, such that the pore walls will be fully dense [43].

Laser focus is an influencing factor in fabrication of porous samples in terms of resultant adherent particles and quality of the final surface. As reported by Habijan et al. [21], a sharp focused laser beam (beam diameter at laser focus is $61 \mu \mathrm{m}$ ) is more preferable compared to a divergent focus (beam diameter at laser focus is $128 \mu \mathrm{m}$ ) for the porous NiTi samples either fabricated by large hatch distance or engineered porosity. The SEM images in figure 35 state that the level of adherent particles, especially within the pores, significantly decreases via the focused laser. Accordingly, the cell culture experiments demonstrate reduction in Ni release for both types of porous samples when the sharp focused laser is used ( $12.5 \%$ porosity via hatch: 775.2 to $657.1 \mathrm{ng} / \mathrm{ml}$, and 34.5 porosity via CAD: 257.2 to $99.3 \mathrm{ng} / \mathrm{ml}$ ). 


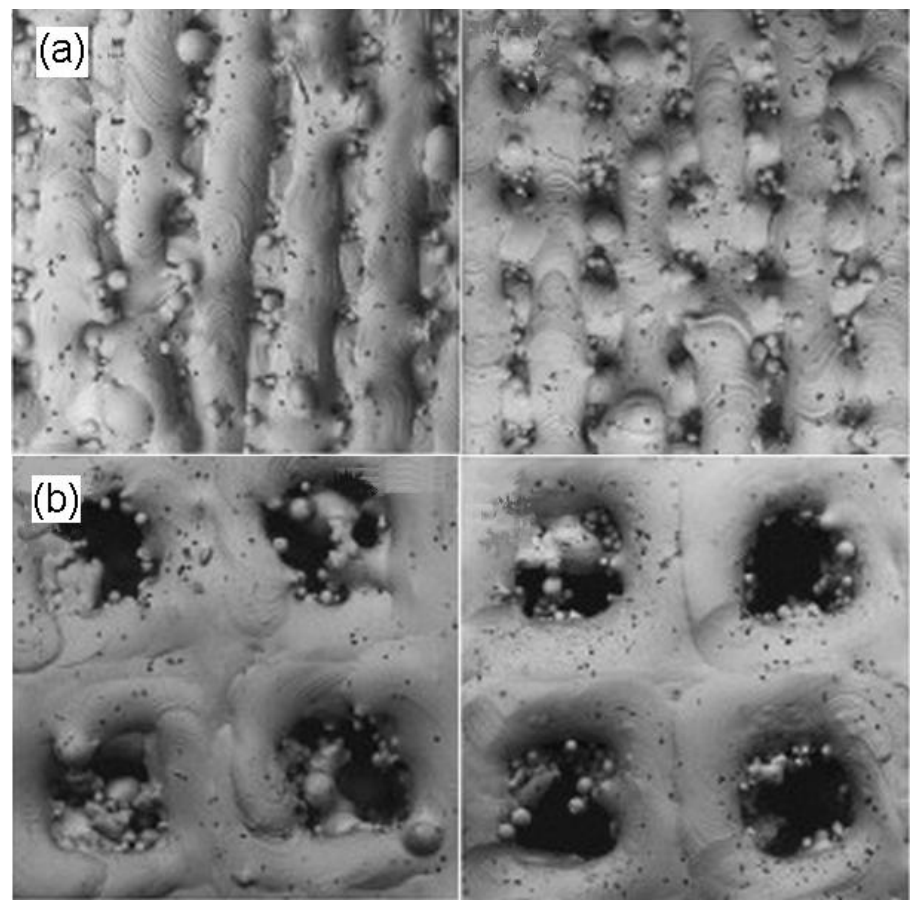

Fig.35. SEM images of SLM Ni50.2Ti: (a) porous (12.5\%) via choosing large hatch distance, and (b) porous $(34.5 \%)$ via engineered porosity fabricated by a divergent focus laser with beam diameter of $128 \boldsymbol{\mu m}$ (left) versus a sharp focus laser with $61 \mu \mathrm{m}$ (right). The sharp focused for both types of porous samples demonstrate a significant reduction in number of adherent particles as well as Ni release [27].

One critical reported issue with AM has been the geometrical variation between the Cad file and the fabricated AM structure, and it is believed that optimum processing parameters can minimize such variation. As an example, Hoffman et al. [34] used SLM Ni50.82Ti scaffolds to study the level of geometrical variation between the CAD file and the fabricated scaffold. The CAD design exhibits $84 \%$ porosity while the SLM-fabricated parts show lower porosity of $76 \%$ determined by micro-computed tomography (i.e., a new technique to measure local strain through combining the 3D CAD file with real data of produced part [102]) and $77.5 \% \pm 0.4 \%$ determined by a gravimetrically (i.e., through the measurement of mass).

Speirs et al. [43] investigated the effect of two different sets of laser parameters, one with energy input of $111 \mathrm{~J} / \mathrm{mm}^{3}(\mathrm{P}=40$ Watt, $\mathrm{v}=160 \mathrm{~mm} / \mathrm{s}, \mathrm{h}=75 \mu \mathrm{m})$ and another with $126 \mathrm{~J} / \mathrm{mm}^{3}(\mathrm{P}=250$ Watt, $\mathrm{v}=1100 \mathrm{~mm} / \mathrm{s}, \mathrm{h}=60 \mu \mathrm{m})$, on the level of geometrical variation of SLM Ni55.2Ti scaffolds. It should be 
noted that both sets of parameters were capably of fabricating fully dense parts. The imposed porosity (i.e., BCC) had the pore diameter of $1000 \mu \mathrm{m}$ and strut thickness of $100-300 \mu \mathrm{m}$. As shown in figure 36, the level of geometrical variation, as well as the number of residual harmful particles are higher for the set of parameters with high laser power versus the one with low laser power.
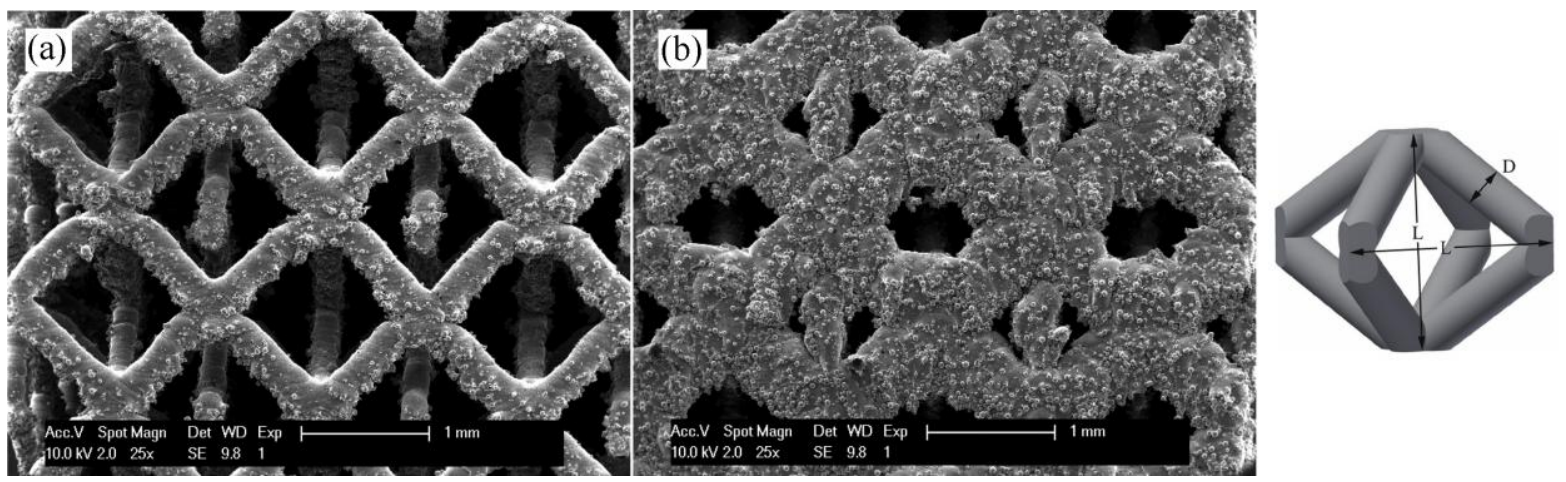

Fig.36. SEM images of SLM Ni55.2Ti: (a) fabricated with low energy input ( $\mathrm{P}=40 \mathrm{Watt}, \mathrm{v}=160 \mathrm{~mm} / \mathrm{s}, \mathrm{h}=75 \mu \mathrm{m})$, and (b) high energy input $(\mathrm{P}=250 \mathrm{Watt}, \mathrm{v}=1100 \mathrm{~mm} / \mathrm{s}, \mathrm{h}=60 \mu \mathrm{m})$. The pore shape (BCC) is shown in the right. The high energy set of laser parameters enhance the geometry variation between the CAD file and SLM fabricated NiTi [27].

The geometrical variation may attribute to a minimum distance that is required for the laser to travel before reaching the assigned scan velocity. Speirs et al. [43] developed a formula that relates the minimum distance required for the laser to reach the desired scanning speed for an in-house developed SLM machine.

\section{Maximum scanning speed $(\mathrm{mm} / \mathrm{s})=1317 \times$ scanning distance $(\mathrm{mm})$}

According to this formula, the laser needs to scan $827 \mu \mathrm{m}$ for the assigned set of laser parameters with high laser power $(\mathrm{P}=250 \mathrm{Watt})$ to reach the assigned scan velocity of $1100 \mathrm{~mm} / \mathrm{s}$, while the designed strut thicknesses in this study are ranged from $100-300 \mu \mathrm{m}$. Therefore, the laser cannot reach the preassigned velocity and the real energy input would be higher than the assigned optimum values. Additionally, the melt pool associated with high laser power is much deeper, which is the main reason for the struts to be fabricated in thicker size [43]. 


\subsection{Mechanical properties of engineered porous NiTi}

Porous NiTi scaffolds are often fabricated with the purpose of altering mechanical properties such as stiffness (i.e., modulus of elasticity) in order to match to the bone stiffness $[6,98,103]$. However, one should note that introducing porosity also affect other mechanical properties.

Taheri Andani et al. [68] assessed the influence of different porosities (i.e., dense, 32\%, 45\%, and $58 \%$ ) on the stiffness of Ti-rich Ni50.09Ti. Each unit cell of the porous NiTi was made out of three perpendicular bars. The level of stiffnesses are shown to be decreased from $69 \mathrm{GPa}$ to $20.5 \mathrm{GPa}$ as the level of porosity increases. It can be also inferred from figure 37 that the level of fracture stresses, fracture strains, critical stresses at plateau and yield stresses are decreased with higher level of porosity.

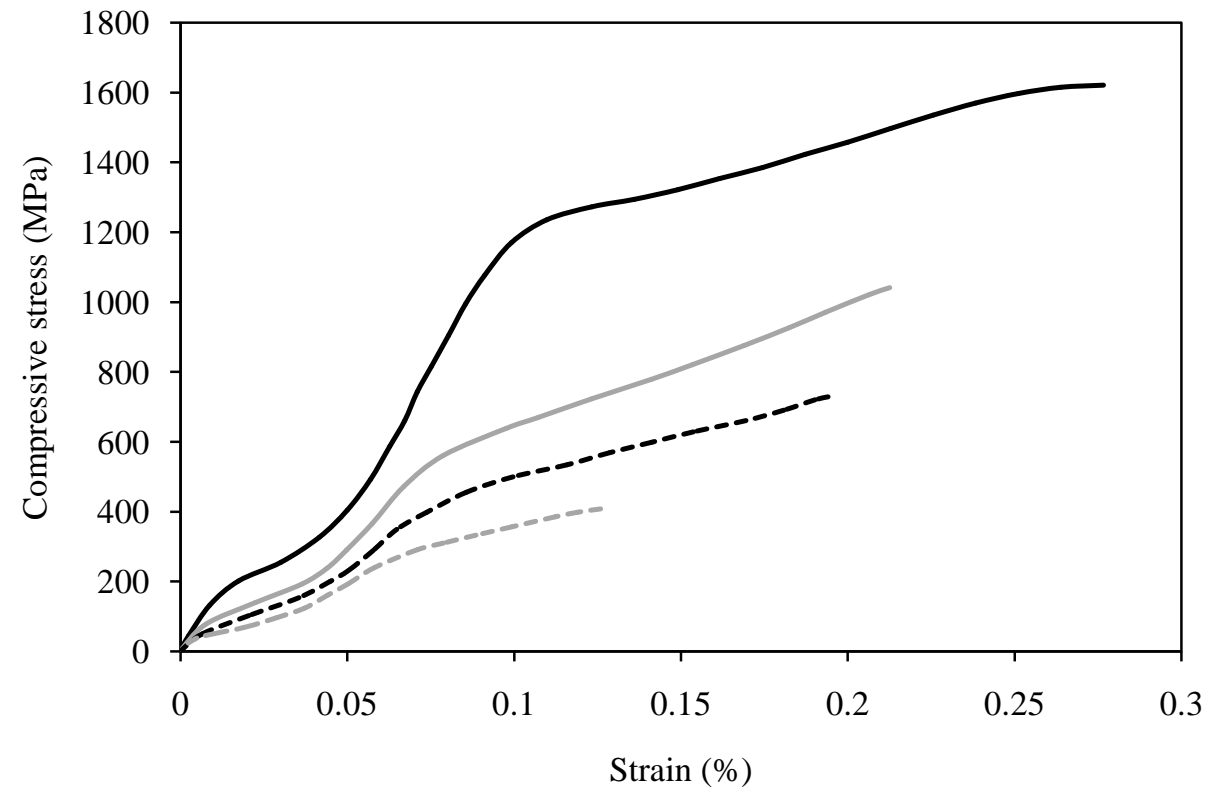

- Dense — Porosity $32 \%$----- Porosity $45 \%$----- Porosity $58 \%$

Fig.37. Compressive stress-strain plot of SLM NiTi samples with three different level of porosities (the pore unit cell is made out of three perpendicular bars). Modulus of elasticity, fracture stress and fracture strain are observed to decrease with higher level of porosities [68]. 
Using same technique and material composition (SLM Ni50.09Ti), Karamooz Ravari et al. [98] studied the fracture stress and strain of two different types of engineered pores (i.e., BCC and BCC-Z) with even higher level of porosity (69\%). As shown in figure 38, the fracture stress and strain of BCC-Z structure (129.7 MPa and 0.15) is higher than those of BCC structure (63.4 and 0.1).

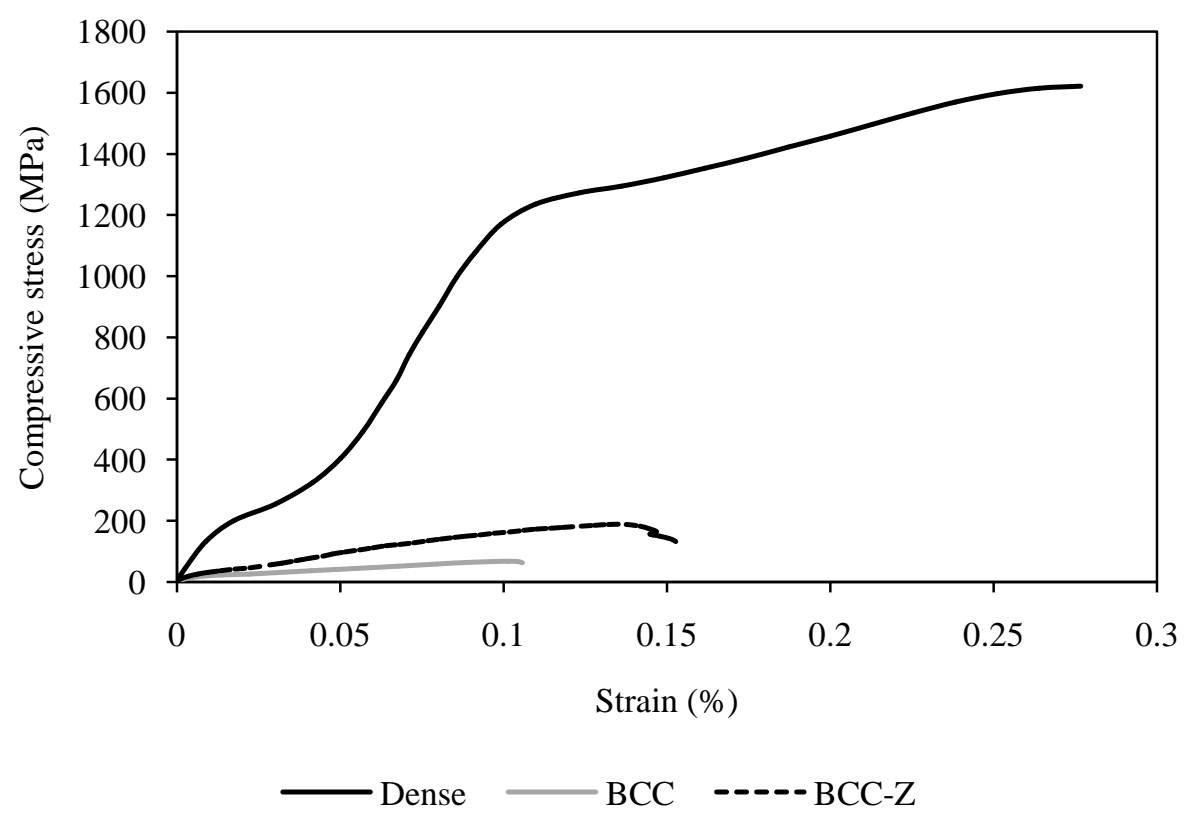

Fig.38. Compressive stress-strain plot of SLM NiTi of dense and two porous samples (BCC and BCC-Z) with 69\% porosity. BCC-Z presents higher modulus of elasticity, fracture stress and fracture strain compared to BCC [98].

\section{Perspectives on AM of NiTi}

NiTi is a high-demanded engineering material which has not been extensively studied by AM technologies. Further studies are needed to be conducted to explore the possibilities of employing AM for producing repeatable, high quality, reliable, and low cost NiTi products in automotive, aerospace, and biomedical industries. To date, the effects of the AM processing parameters, powder composition, and fabrication chamber conditions on the microstructural properties, transformation temperatures, functional and mechanical properties are studied to some extends. 
Several groups have identified optimum laser parameters in a way to satisfy the requirements of high density as well as low impurity content. However, it is expected that other critical factors (e.g., geometry precision, adherent particles, surface quality, functional properties, homogeneity throughout the structure, fatigue behavior, and etc.) also be considered simultaneously as AM techniques continue to improve. It could be great to find a universal algorithm to get the requirements of a specific application as input and present the optimum parameters as the output.

One critical challenge with AM is the high residual stresses that are formed in the first layers of the supports and may result in the warping effect (i.e., separation of the sample from the build platform). These residual stresses are mostly attributed to the high gradient temperatures associated with the fabrication of the first layers, and, therefore, preheating the substrate has been reported for other materials (e.g., titanium, stainless steel) as one solution to minimize the gradient temperature as well as the resultant residual stresses. However, there is a need to investigate the outcome of preheating or present other solutions to address this problem in AM of NiTi.

Another challenge is that the produced samples present higher transformation temperatures as well as different microstructure properties in their very bottom regions. This has been attributed to associate low level of heat flux, which mostly occurs through powder bed as well as the supports with small contact area. There is a lack of study to evaluate the influencing factors to minimize such variation throughout the structure.

One should note that most engineering and medical applications deal with multi-axial loading, however, there has been no reports on the tensile and torsional properties of AM NiTi. Obviously, the defects (e.g., cracks, pores, residual stresses) associated with layer-based feature of AM may lead to serious problems during tensile and torsion testing. However, such detrimental defects may have lower effects during compression loading. On top of these, no studies have been conducted on the fatigue behavior, which is a critical mode of the failure of porous structures because they are extremely prone to the crack formation and propagation. 
Although the literature is rich on reports on AM of dense NiTi, there are a few studies on the optimum processing parameter and the resultant properties of porous products. Moreover, those porous NiTi targeted to be used for biomedical applications need to be further investigated in terms of toxicity and ion release.

It has been reported by a few studies that optimum processing parameters that are used to produce dense samples can be utilized to produce porous structures as well. However, some geometrical deviations are observed between the CAD file and the as-fabricated samples. Initial studies showed that processing parameter sets including focused laser beam, low laser power but high ratio of power to scanning speed can enhance the geometrical deviation, but these studies are limited and need to be further investigated.

Another critical issue is that there has been no report on the post-process heat treatment conditions on porous NiTi Ni-rich. It could be so challenging because of the existence of open pores within the structure. Obviously, the heat treatment parameters used for dense samples cannot be used for porous ones.

It is also a lack of understanding of the effect of different types and level of porosities on the microstructural, functional, and mechanical properties. Again, an algorithm is desired to receive the required factors (e.g., elongation at failure, fracture stress, fracture strain, transformation temperatures, maximum recoverable strain, yield stress, and etc.) as inputs and present an optimum type and level of porosity as output based on a specific application.

\section{Conclusions}

In this paper, the current state of research on the additive manufacturing of NiTi, associated challenges, trends, and opportunities are reviewed. A summary of the conclusions are mentioned as following: 
1. Powder preparation is the first step to additively manufacture NiTi products. Different techniques are implemented for preparing powder including hydriding, mechanical attrition, water atomization, and gas atomization, among which the gas atomization is the most common method. EIGA technique, a gas atomization technique, is proved to be suitable for preparing NiTi powder and it can produce NiTi particles with the limited numbers of inaccurate particles, carbon content, and oxygen content. The resulting powders are shown to be in the wide range and, therefore, sieving and screening procedure is required after atomization. It should be pointed out that suitable range of particle size considering flow ability, impurity content, and transformation ability needs to be considered.

2. AM techniques for NiTi are categorized into two major types, powder-bed based (e.g., SLM) and flow-based (e.g., LENS). The most important step in processing NiTi is to define laser parameters such that the produced NiTi parts will be fully dense.

3. Microstructural characteristics (e.g., intermetallic phases, grain shape, size and orientation) are affected by the complex thermal history associated with AM. For medical applications, it is important to reduce the level of impurity contents (by decreasing the laser power) which are responsible for the formation of intermetallic phases. On the other hand, a minimum laser power is needed in order not to cause porosity within the structure. High laser power causes the grain growth in the orientation $\langle 111\rangle$, increased grain size, and a rectangular shape in the slice plane. Structural defects such as pores, cracks, and residual stresses are several major problems with AM. The balling phenomenon is responsible for pore formation, which can be minimized by increasing the laser power and increasing the scanning speed to provide an appropriate melting depth. Although the possibility of crack formation is high, it is shown that the crack will not be propagated due to rapid cooling.

4. Conventional NiTi shows similar transformation temperature compare to SLM NiTi. The transformation temperature decreases as the number of cycles increase, and it shifts to higher 
values as a result of increased energy input for NiTi with different compositions (i.e., Ti-rich, near equiatomic, and Ni-rich), however, this effect can be seen most for the Ni-rich samples.

5. Series of heat treatments (i.e., solution annealing and aging) need to be performed on NiTi SLM structures after processing to create precipitates in the material to result in superelasticity. Therefore, polishing/machining needs to be done after heat treatment process to remove the oxidation induced layer on the material. Since machining and polishing of complex structures are quite challenging, making complex superelastic structures are not feasible yet. Transformation temperature decreases as a result of solution annealing, and subsequent aging increase it. Aging conditions such as duration and aging temperature affect the size and distribution of precipitates, and it needs to be further studied.

6. Functional properties of NiTi are categorized into shape memory effect and superelasticity behavior. Degradation of shape memory and superelasticity effects can be defined as the accumulation of irreversible strain inside the NiTi part during each transformation. Shape memory NiTi shows comparable behavior to conventional, however AM NiTi shows more stable recovery. The horizontally fabricated NiTi shows more resistance against compressive loading versus vertical ones. Annealing leads to decreasing the strain recovery and increasing the thermal recovery. NiTi parts that are fabricated in $45^{\circ}$ direction shows higher spring back effect. Heat treatment recipes are defined by several groups. The heat treated superelastic AM NiTi behave comparable to conventional; they both show a broad hysteresis with distinct plateaus that is degraded by increasing cycles. The effect of heat treatment conditions needs to be further studied.

7. NiTi performances (e.g., mechanical properties, fatigue behavior, surface characteristics, corrosion resistance, and damping characteristics) are studied here. The fabrication orientation does not have a significant effect on the compressive behavior of $\mathrm{NiTi}$, but the horizontally fabricated show a better tensile performance versus vertical one. The horizontal show even higher tensile strength in comparison with conventional one, but less fracture elongation. The 
compressive behavior of Ti-rich SLM is comparable to conventional NiTi; however, the failure occurs at lower stress levels. For the Ni-rich NiTi, the conventional shows a shorter plateau region, a steeper curve, and a higher failure stress compared to untreated SLM. Solution annealing causes the material not to show plateau region, to have flatter curve, and greater stress and strain at failure. However, the subsequent aging significantly influences the behavior of the solution annealed NiTi. The process parameters have an important influence on the mechanical properties. The increased layer thickness show sooner failure for horizontally produced NiTi and a dramatic failure for vertically produced NiTi. The increased energy increases the failure stress and strains.

8. Regarding fatigue behavior, NiTi sustained at least 1.5 times of their yield strength up to $10^{6}$ cycles without failure. Additionally, all the samples undergo an initial permanent strain until it reaches a plateau value after a certain number of cycles. Further studies needed to be taken to investigate further the fatigue behavior.

9. It is shown that energy input beyond a critical limit causes increased waviness and degradation of the surface. Additionally, the surface of the cylinder that is fabricated horizontally is rougher compared to the one fabricated vertically. The average microhardness is more for Ti-rich samples and, therefore, less ductility can be expected. Microhardness value increases as the laser power is increasing and the scan speed is decreasing. The high laser power provides high corrosion protection versus low laser power. The damping behavior of AM NiTi is comparable to conventional.

10. Additive manufacturing provides the opportunity to fabricate engineered porous NiTi with tunable mechanical properties via changing pore size, shape, and distribution. The porous NiTi has shown to be non-toxic, and the Ni release is below cytotoxic concentrations. A few groups have worked on creating engineered porosity, and further investigations are needed to address current challenges such as producing microporosity, solving geometrical variations. 
Acknowledgements

The authors would like to acknowledge the financial support provided for the project "Nitinol Commercialization Accelerator" by the Ohio Department of Development through Grant WP 10-010. NSF support though award 0731087 Research to Aid Person with Disability is also appreciated.

\section{References:}

1. Elahinia, M., Shape Memory Alloy Actuators: Design, Fabrication, and Experimental Evaluation. 2015, Hoboken, New Jersey: John Wiley and Sons.

2. Taheri Andani, M., et al., Metals for Bone Implants, Part 1: Powder Metallurgy and Implant Rendering Acta Biomaterialia, 2014.

3. Shishkovsky, I., et al., Porous biocompatible implants and tissue scaffolds synthesized by selective laser sintering from Ti and NiTi. Journal of Materials Chemistry, 2008. 18(12): p. 1309-1317.

4. Andani, M.T., et al., Metals for bone implants. Part 1. Powder metallurgy and implant rendering. Acta biomaterialia, 2014. 10(10): p. 4058-4070.

5. Shayesteh Moghaddam, N., et al., Three dimensional printing of stiffness-tuned, nitinol skeletal fixation hardware with an example of mandibular segmental defect repair, in In Procedia CIRP (accepted). 2015.

6. Elahinia, M., et al., Manufacturing and processing of NiTi implants: A review. Progress in Materials Science, 2012. 57(5): p. 911-946.

7. Ravari, M.K., et al., Modeling the Cyclic Shape Memory and Superelasticity of Selective Laser Melting Fabricated NiTi. International Journal of Plasticity, 2016.

8. Haberland, C., et al., On the development of high quality NiTi shape memory and pseudoelastic parts by additive manufacturing. Smart Materials and Structures, 2014. 23(10): p. 104002.

9. Haberland, C., H. Meier, and J. Frenzel. On the Properties of Ni-Rich NiTi Shape Memory Parts Produced by Selective Laser Melting. in ASME 2012 Conference on Smart Materials, Adaptive Structures and Intelligent Systems. 2012. American Society of Mechanical Engineers.

10. Shishkovsky, I., I. Yadroitsev, and I. Smurov, Direct selective laser melting of nitinol powder. Physics Procedia, 2012. 39: p. 447-454.

11. Stobik, M. Nanoval atomizing-capabilities, applications and related processes. in Symposium Spray Forming. 2003. BoD-Books on Demand.

12. Wielage, B., J. Wilden, and T. Schnick. Manufacture of SiC composite coatings by HVOF. in ITSC 2001: International Thermal Spray Conference 2001, Singapore. 2001.

13. Haberland, C., et al., Additive manufacturing of shape memory devices and pesudoelastic components, in ASME 2013 Conference on Smart Materials, Adaptive Structures and Intelligent Systems. 2013, ASM: Snowbird, Utah. p. V001T01A005.

14. Meier, H., C. Haberland, and J. Frenzel, Structural and Functional Properties of NiTi Shape Memory Alloys Produced by Selective Laser Melting. Innovative Developments in Design and Manufacturing: Advanced Research in Virtual and Rapid Prototyping, 2011: p. 291-296.

15. Haberland, C., et al. Additive Manufacturing Of Complex NiTi Shape Memory Devices And Pseudoelastic Components. in ASME Conference on Smart Materials, Adaptive Structures and Intelligent Systems. 2013. Snowbird, Utah.: ASME. 
16. Haberland, C., et al. Visions, concepts and strategies for smart Nitinol actuators and complex Nitinol structures produced by Additive Manufacturing. in ASME 2013 Conference on Smart Materials, Adaptive Structures and Intelligent Systems. 2013. American Society of Mechanical Engineers.

17. Kempen, K., et al. PRODUCING CRACK-FREE, HIGH DENSITY M2 HSS PARTS BY SELECTIVE LASER MELTING: PRE-HEATING THE BASEPLATE. in Solid Freeform Fabrication Symposium. 2013.

18. Vora, P., et al., AlSi12 in-situ alloy formation and residual stress reduction using anchorless selective laser melting. Additive Manufacturing, 2015. 7: p. 12-19.

19. Aggarangsi, P. and J.L. Beuth. Localized preheating approaches for reducing residual stress in additive manufacturing. in Proc. SFF Symp., Austin. 2006.

20. Hamilton, R.F., T.A. Palmer, and B.A. Bimber, Spatial characterization of the thermalinduced phase transformation throughout as-deposited additive manufactured NiTi bulk builds. Scripta Materialia, 2015. 101: p. 56-59.

21. Habijan, T., et al., The biocompatibility of dense and porous nickel-titanium produced by selective laser melting. Materials Science and Engineering: C, 2013. 33(1): p. 419-426.

22. Habijan, T., et al., Rapid manufacturing of porous Nickel-Titanium as a carrier for human mesenchymal stem cells, in Langenbeck's Archives of Surgery 395(6); 14th Annual Meeting on Surgical Research. 2010: Germany.

23. Ravari, M.K., M. Kadkhodaei, and A. Ghaei, A microplane constitutive model for shape memory alloys considering tension-compression asymmetry. Smart Materials and Structures, 2015. 24(7): p. 075016.

24. Gibson, I., D.W. Rosen, and B. Stucker, Additive manufacturing technologies. 2010: Springer.

25. ASTM International, F.-a.-S.T.f.A.M.T., 2013.

26. Hu, D. and R. Kovacevic, Modelling and measuring the thermal behaviour of the molten pool in closed-loop controlled laser-based additive manufacturing. Proceedings of The Institution of Mechanical Engineers, Part B: Journal of Engineering Manufacture, 2003. 217(4): p. 441-452.

27. Meier, H. and C. Haberland, Experimental studies on selective laser melting of metallic parts. Materialwissenschaft und Werkstofftechnik, 2008. 39(9): p. 665-670.

28. Meier, H., et al., Selective Laser Melting of NiTi shape memory components. Innovative Developments in Design and Manufacturing: Advanced Research in Virtual and Rapid Prototyping, 2009: p. 233-238.

29. Haberland, C., Additive Verarbeitung von NiTi-Formgedächtniswerkstoffen mittels SelectiveLaser-Melting. 2012: Shaker.

30. de Wild, M., et al., Damping of selective-laser-melted NiTi for medical implants. Journal of Materials Engineering and Performance, 2014. 23(7): p. 2614-2619.

31. Bormann, T., et al., Tailoring selective laser melting process parameters for NiTi implants. Journal of materials engineering and performance, 2012. 21(12): p. 2519-2524.

32. Bormann, T., et al. Determination of strain fields in porous shape memory alloys using micro computed tomography. in Proc SPIE. 2010.

33. Bormann, T., et al., Microstructure of selective laser melted nickel-titanium. Materials Characterization, 2014. 94: p. 189-202.

34. Hoffmann, W., et al., Rapid prototyped porous nickel-titanium scaffolds as bone substitutes. Journal of tissue engineering, 2014. 5: p. 2041731414540674.

35. Saedi, S., et al., The influence of aging on shape memory response of Ni-rich NiTi alloys manufactured by selective laser melting method. 
36. Walker, J., Additive Manufacturing towards the Realization of Porous and Stiffness-tailored NiTi Implants, in Biomedical Engineering. 2014, University of Toledo.

37. Walker, J., M. Elahinia, and C. Haberland. An investigation of process parameters on selective laser melting of nitinol. in ASME 2013 Conference on Smart Materials, Adaptive Structures and Intelligent Systems. 2013. American Society of Mechanical Engineers.

38. Walker, J., et al., Process Development and Characterization of Additively Manufactured NiTi Shape Memory Parts. Journal of Materials Processing Technology, 2015.

39. Andani, M.T., et al., Achieving biocompatible stiffness in NiTi through additive manufacturing. Journal of Intelligent Material Systems and Structures, 2015.

40. Andani, M.T., et al. An Investigation of Effective Process Parameters on Phase Transformation Temperature of Nitinol Manufactured by Selective Laser Melting. in ASME 2014 Conference on Smart Materials, Adaptive Structures and Intelligent Systems. 2014. American Society of Mechanical Engineers.

41. Dadbakhsh, S., et al., Influence of SLM on shape memory and compression behaviour of NiTi scaffolds. CIRP Annals-Manufacturing Technology, 2015.

42. Dadbakhsh, S., et al., Effect of SLM parameters on transformation temperatures of shape memory nickel titanium parts. Advanced Engineering Materials, 2014. 16(9): p. 1140-1146.

43. Speirs, M., et al. The effect of SLM parameters on geometrical characteristics of open porous NiTi scaffolds. in High Value Manufacturing: Advanced Research in Virtual and Rapid Prototyping: Proceedings of the 6th International Conference on Advanced Research in Virtual and Rapid Prototyping, Leiria, Portugal, 1-5 October, 2013. 2013. CRC Press.

44. Yang, Y., Y. Huang, and W. Wu. One-step shaping of NiTi biomaterial by selective laser melting. in Photonics Asia 2007. 2007. International Society for Optics and Photonics.

45. Clare, A.T., et al., Selective laser melting of high aspect ratio 3D nickel-titanium structures two way trained for MEMS applications. International Journal of Mechanics and Materials in Design, 2008. 4(2): p. 181-187.

46. Krishna, B.V., S. Bose, and A. Bandyopadhyay, Laser processing of net-shape NiTi shape memory alloy. Metallurgical and Materials Transactions A, 2007. 38(5): p. 1096-1103.

47. Krishna, B.V., S. Bose, and A. Bandyopadhyay, Fabrication of porous NiTi shape memory alloy structures using laser engineered net shaping. J Biomed Mater Res B Appl Biomater, 2009. 89(2): p. 481-90.

48. Bandyopadhyay, A., et al., Application of laser engineered net shaping (LENS) to manufacture porous and functionally graded structures for load bearing implants. Journal of Materials Science: Materials in Medicine, 2009. 20(1): p. 29-34.

49. Halani, P.R., et al., Phase transformation characteristics and mechanical characterization of nitinol synthesized by laser direct deposition. Materials Science and Engineering: A, 2012.

50. Halani, P.R. and Y.C. Shin, In Situ Synthesis and Characterization of Shape Memory Alloy Nitinol by Laser Direct Deposition. Metallurgical and Materials Transactions A, 2012. 43(2): p. 650-657.

51. Shiva, S., et al., Investigations on the influence of composition in the development of Ni-Ti shape memory alloy using laser based additive manufacturing. Optics \& Laser Technology, 2015. 69: p. 44-51.

52. Malukhin, K. and K. Ehmann, Material characterization of NiTi based memory alloys fabricated by the laser direct metal deposition process. Journal of manufacturing science and engineering, 2006. 128(3): p. 691-696.

53. Marattukalam, J.J., et al., Microstructure and corrosion behavior of laser processed NiTi alloy. Materials Science and Engineering: C, 2015. 57: p. 309-313.

54. Xu, X., et al., Microstructure evolution in laser solid forming of Ti-50wt\% Ni alloy. Journal of Alloys and Compounds, 2009. 480(2): p. 782-787. 
55. Bernard, S., et al., Compression fatigue behavior of laser processed porous NiTi alloy. Journal of the mechanical behavior of biomedical materials, 2012. 13: p. 62-68.

56. Bernard, S., et al., Rotating bending fatigue response of laser processed porous NiTi alloy. Materials Science and Engineering: C, 2011. 31(4): p. 815-820.

57. Habijan, T., et al., Biocompatibility and particle release of porous nickel-titanium pro-duced by selective laser melting. Biomed Tech, 2011. 56: p. 1.

58. Bidabadi, M., A.H.A. Natanzi, and S.A. Mostafavi, Thermophoresis effect on volatile particle concentration in micro-organic dust flame. Powder Technology, 2012. 217: p. 69-76.

59. Ismail, M.H., et al., Phase transformation temperatures (PPTs) and microstructure of moulded NiTi alloy using a water soluble binder system. Sains Malaysiana, 2013. 42(12): p. 1769-1773.

60. Schulz, G., Method and device for producing fine powder by atomizing molten material with gases. 2002, Google Patents.

61. Bram, M., et al., Reproducibility study of NiTi parts made by metal injection molding. Journal of materials engineering and performance, 2012. 21(12): p. 2701-2712.

62. M, K., Pulvermetallurgie hochporöser NiTi-Legierungen für Implantat- und Dämpfungsanwendungen. 2009.

63. Köhl, M., Pulvermetallurgie hochporöser NiTi-Legierungen für Implantat-und Dämpfungsanwendungen. Vol. 41. 2009: Forschungszentrum Jülich.

64. Srivatsan, T. and T. Sudarshan, Additive Manufacturing: Innovations, Advances, and Applications. 2015: CRC Press.

65. Machado, L. and M. Savi, Medical applications of shape memory alloys. Brazilian Journal of Medical and Biological Research, 2003. 36(6): p. 683-691.

66. Morgan, N., Medical shape memory alloy applications-the market and its products. Materials Science and Engineering: A, 2004. 378(1): p. 16-23.

67. Haberland, C., et al. Visions, Concepts And Strategies For Smart Nitinol Actuators And Complex Nitinol Structures Produced By Additive Manufacturing. in ASME 2013 Conference on Smart Materials, Adaptive Structures and Intelligent Systems. 2013. Snowbird, Utah: ASME.

68. Taheri Andani, M., Modeling, Simulation, Additive Manufacturing, and Experimental Evaluation of Solid and Porous NiTi. 2015, University of Toledo.

69. Saedi, S., et al., Thermomechanical characterization of Ni-rich NiTi fabricated by selective laser melting. Smart Materials and Structures, 2016. 25(3): p. 035005.

70. Johansen, K., H. Voggenreiter, and G. Eggeler, On the effect of TiC particles on the tensile properties and on the intrinsic two way effect of NiTi shape memory alloys produced by powder metallurgy. Materials Science and Engineering: A, 1999. 273: p. 410-414.

71. Mentz, J., et al., Improvement of mechanical properties of powder metallurgical NiTi shape memory alloys. Advanced engineering materials, 2006. 8(4): p. 247-252.

72. Song, B., et al., Differences in microstructure and properties between selective laser melting and traditional manufacturing for fabrication of metal parts: A review. Frontiers of Mechanical Engineering, 2015. 10(2): p. 111-125.

73. Olakanmi, E., R. Cochrane, and K. Dalgarno, A review on selective laser sintering/melting (SLS/SLM) of aluminium alloy powders: Processing, microstructure, and properties. Progress in Materials Science, 2015.

74. Gu, D., Laser Additive Manufacturing of High-Performance Materials. 2015: Springer.

75. Habijan, T., et al., The biocompatibility of dense and porous nickel-titanium produced by selective laser melting. Materials Science and Engineering: C, 2013. 33(1): p. 419-426.

76. Olakanmi, E., R. Cochrane, and K. Dalgarno, Densification mechanism and microstructural evolution in selective laser sintering of Al-12Si powders. Journal of Materials Processing Technology, 2011. 211(1): p. 113-121. 
77. Davis, J.E., N.W. Klingbeil, and S. Bontha. Effect of Free-Edges on Melt Pool Geometry and Solidification Microstructure in Beam-Based Fabrication of Thin-Wall Structures. in Solid Freeform Fabrication Proceedings. 2009.

78. Rangaswamy, P., et al., Residual stresses in components formed by the laserengineered net shaping (LENS®) process. The Journal of strain analysis for engineering design, 2003. 38(6): p. 519-527.

79. Li, R., et al., Balling behavior of stainless steel and nickel powder during selective laser melting process. The International Journal of Advanced Manufacturing Technology, 2012. 59(9-12): p. 1025-1035.

80. Morgan, R., et al., High density net shape components by direct laser re-melting of singlephase powders. Journal of Materials Science, 2002. 37(15): p. 3093-3100.

81. Li, S., et al., The development of TiNi-based negative Poisson's ratio structure using selective laser melting. Acta Materialia, 2016. 105: p. 75-83.

82. Sehitoglu, H., et al. Hysteresis in NiTi alloys. in Journal de Physique IV (Proceedings). 2004. EDP sciences.

83. Manjeri, R.M., Low temperature and reduced length scale behavior of shape memory and superelastic NiTi and NiTiFe alloys. 2009, University of Central Florida Orlando, Florida.

84. Tang, W., et al., Experimental investigation and thermodynamic calculation of the Ti-Ni-Cu shape memory alloys. Metallurgical and materials transactions A, 2000. 31(10): p. 24232430.

85. Turabi, A.S., et al., Experimental Characterization of Shape Memory Alloys. Shape Memory Alloy Actuators: Design, Fabrication, and Experimental Evaluation: p. 239-277.

86. Frenzel, J., et al., Influence of carbon on martensitic phase transformations in NiTi shape memory alloys. Acta Materialia, 2007. 55(4): p. 1331-1341.

87. Haberland, C., et al., On phase transformation behavior, mechanical properties, and pseudoelasticity in Ni-rich shape memory alloys produced by additive manufacturing. Materials Science and Engineering A, 2016.

88. Kaya, I., Shape Memory Behavior of Single and Polycrystalline Nickel Rich Nickel Titanium Alloys. 2014.

89. Großmann, M.C. and M.F.-X. Wagner, A finite element study on localized deformation and functional fatigue in pseudoelastic NiTi strips and plates. 2008.

90. Haberland, C., et al. Additive manufacturing of shape memory devices and pseudoelastic components. in ASME 2013 Conference on Smart Materials, Adaptive Structures and Intelligent Systems. 2013. American Society of Mechanical Engineers.

91. Zhang, L., et al., Manufacture by selective laser melting and mechanical behavior of a biomedical Ti-24Nb-4Zr-8Sn alloy. Scripta Materialia, 2011. 65(1): p. 21-24.

92. Mokgalaka, M.N., et al., NiTi Intermetallic Surface Coatings by Laser Metal Deposition for Improving Wear Properties of Ti-6Al-4V Substrates. Advances in Materials Science and Engineering, 2014. 2014.

93. Landolt, D., Corrosion and surface chemistry of metals. 2007: CRC Press.

94. Hedberg, Y., et al., Correlation between surface physicochemical properties and the release of iron from stainless steel AISI 304 in biological media. Colloids and Surfaces B: Biointerfaces, 2014. 122: p. 216-222.

95. Instruments, G., Getting Started with Electrochemical Corrosion Measurement. 2011.

96. Mahtabi, M., N. Shamsaei, and M. Mitchell, Fatigue of Nitinol: The state-of-the-art and ongoing challenges. Journal of the mechanical behavior of biomedical materials, 2015. 50: p. 228-254.

97. Van Humbeeck, J., Non-medical applications of shape memory alloys. Materials Science and Engineering: A, 1999. 273: p. 134-148. 
98. Ravari, M.K., et al., On the effects of geometry, defects, and material asymmetry on the mechanical response of shape memory alloy cellular lattice structures. Smart Materials and Structures, 2016. 25(2): p. 025008.

99. Bansiddhi, A., et al., Porous NiTi for bone implants: a review. Acta Biomaterialia, 2008. 4(4): p. 773-782.

100. Greiner, C., S.M. Oppenheimer, and D.C. Dunand, High strength, low stiffness, porous NiTi with superelastic properties. Acta Biomaterialia, 2005. 1(6): p. 705-716.

101. Markwardt, J., et al., Experimental findings on customized mandibular implants in Gottingen minipigs - A pilot study. Int J Surg, 2014. 12(1): p. 60-6.

102. Bormann, T., et al., Combining micro computed tomography and three-dimensional registration to evaluate local strains in shape memory scaffolds. Acta biomaterialia, 2014. 10(2): p. 1024-1034.

103. Taheri Andani, M., et al., Achieving biocompatible stiffness in NiTi through porosity optimization and additive manufacturing. Journal of Intelligent Material Systems and Structures, 2016. 